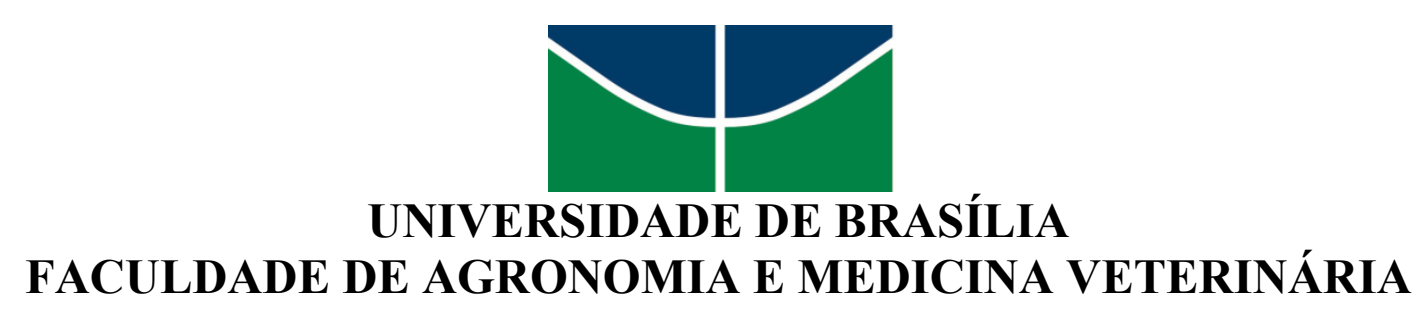

CONTRIBUIÇÃO DO CONDICIONAMENTO PARA O BEM-ESTAR DE ONÇAS- PINTADAS (Panthera onca) EM CATIVEIRO

LIANE CRISTINA FEREZ GARCIA

TESE DE DOUTORADO EM CIÊNCIAS ANIMAIS

BRASÍLIA, DF

DEZEMBRO DE 2015 


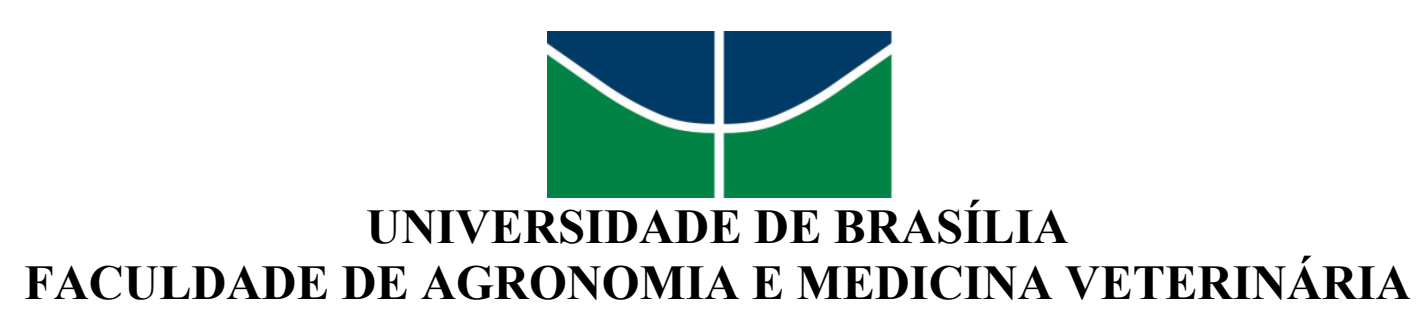

CONTRIBUIÇÃO DO CONDICIONAMENTO PARA O BEM-ESTAR DE ONÇAS-PINTADAS (Panthera onca) EM CATIVEIRO

\section{LIANE CRISTINA FEREZ GARCIA}

ORIENTADOR: DR. FRANCISCO ERNESTO MORENO BERNAL

TESE DE DOUTORADO EM CIÊNCIAS ANIMAIS

PUBLICAÇÃO: 146D/2015

BRASÍLIA, DF

DEZEMBRO DE 2015 


\section{REFERÊNCIA BIBLIOGRÁFICA E CATALOGAÇÃO}

GARCIA, L.C.F. Contribuição do condicionamento para o bem-estar de onças-pintadas (Panthera onca) em cativeiro. Brasília: Faculdade de Agronomia e Medicina Veterinária, Universidade de Brasília, 2015, 104p. Tese de Doutorado.

Documento formal, autorizando reprodução desta tese de doutorado para empréstimo ou comercialização, exclusivamnte para fins acadêmicos, foi passado pelo autor à Universidade de Brasília e acha-se arquivado na Secretaria do Programa. O autor e seu orientador reservam para si os outros direitos autorais, de publicação. Nenhuma parte desta tese de doutorado poderá ser reproduzida sem a autorização por escrito do autor ou do seu orientador. Citações são estimuladas, desde que citada a fonte.

\section{FICHA CATALOGRÁFICA}

GARCIA, L.C.F. Contribuição do condicionamento para o bem-estar de onças-pintadas (Panthera onca) em cativeiro. Brasília: Faculdade de Agronomia e Medicina Veterinária, Universidade de Brasília, 2015, 104p. Tese (Doutorado em Ciências Animais) - Faculdade de Agronomia e Medicina Veterinária da Universidade de Brasília, 2015

1. Bem-estar 2. Onça pintada 3. Condicionamento 
UNIVERSIDADE DE BRASÍLIA

FACULDADE DE AGRONOMIA E MEDICINA VETERINÁRIA

\title{
CONTRIBUIÇÃO DO CONDICIONAMENTO PARA O BEM-ESTAR DE ONÇAS-PINTADAS (Panthera onca) EM CATIVEIRO
}

\author{
LIANE CRISTINA FEREZ GARCIA CARPI
}

TESE DE DOUTORADO SUBMETIDA AO PROGRAMA DE PÓS-GRADUAÇ̃̃̃O EM CIÊNCIAS ANIMAIS, COMO PARTE DOS REQUISITOS NECESSÁRIOS À OBTENÇÃO DO GRAU DE DOUTOR EM CIÊNCIAS ANIMAIS.

\begin{abstract}
APROVADA POR:
\end{abstract}
FRANCISCO ERNESTO MORENO BERNAL, Prof. Dr. (FAV - UnB) (ORIENTADOR)

GIANE REGINA PALUDO, Profa. Dra. (FAV - UnB)

(MEMBRO TITULAR)

ALINE MONDINI CALIL RACANICCI, Profa. Dra. (FAV - UnB)

(MEMBRO TITULAR)

JOSELIO MOURA, Dr. (SBMV)

(MEMBRO TITULAR)

$\overline{\text { FÉLIX HILARIO DIAZ GONZÁLEZ, Prof. Dr. (LACVET/ UFRGS) }}$

(MEMBRO TITULAR)

BRASÍLIA/DF, 11 de dezembro de 2015. 
A todos aqueles que um dia foram roubados de sua natureza e que nunca poderão se embrenhar entre as matas ou escolher o rio por onde nadar...

Às onças cativas, que suprimem parte de seus instintos e, como sábias criaturas, aceitam as limitações impostas pelo cativeiro, como quem nos ensina, serena e constantemente, sobre resignação e resiliência.

Para algumas, no entanto, olhar a vida através das grades parece latejar. A essas dedico toda minha inspiração e sigo sempre em busca de algo que ofereça alento para seus corações selvagens e esperança para esse olhar vazio, que parece buscar um horizonte que lhes foi negado... 


\section{AGRADECIMENTOS}

Ao começar a escrever os agradecimentos foi ficando claro que o fim de um ciclo se aproximava. Enfim, depois de tantos caminhos e descaminhos, existe um trabalho desenvolvido e uma tese prestes a ser apresentada e defendida. É o momento de olhar para esse percurso e agradecer a cada uma das pessoas que esteve presente, em maior ou menor proporção, cada um contribuiu de uma forma para que esse momento se tornasse realidade.

Ao meu orientador e professor Francisco Ernesto Moreno Bernal eu agradeço por cada etapa que foi construída, pela disponibilidade, humanidade e prontidão para auxiliar em cada processo, especialmente nos momentos mais difíceis, em que as circunstâncias nos levaram a buscar outros animais e outro local para a realização do estudo.

À Cleyde Chieregatto, minha primeira orientadora, ainda na graduação, agradeço por ter me apresentado ao fascinante mundo do enriquecimento ambiental, que depois abriria as portas do condicionamento e me conduziria por essa jornada em busca pelo bem-estar animal.

À Cristina Gianni por ter permitido que esse estudo fosse realizado no NEX e por ter possibilitado que as onças fizessem parte da minha vida e que eu faça parte da vida delas.

Ao Bruno Dallago, pela contribuição ao longo de todo o experimento, desde o início das coletas, pelas broncas, por ter me levado a observar rigorosamente onde estava cada objeto do laboratório, a fim de deixá-lo perfeitamente organizado ao encerrar as atividades e pelo inestimável auxílio com as análises laboratoriais e testes estatísticos.

Aos colegas e amigos feitos ao longo desses quatro anos, especialmente à Júlia Eumira Gomes Neves Perini, pelas valiosas trocas durante as disciplinas e pela essencial ajuda com a aquisição dos kits para a conclusão das análises hormonais.

À Angélica Vasconcellos, que me ajudou com as análises estatísticas quando eu realizava meu Trabalho de Conclusão de Curso, ainda na graduação e por toda atenção desde então, até as contribuições na realização desse estudo.

Às minhas alunas Thaís Brasil e Sara Melo pela participação durante a coleta dos dados comportamentais e à Mariana Lessa, que se tornou uma grande amiga, dessas que estão sempre prontas a participar, até mesmo com aquelas tarefas “árduas”, como revisar as 
referências...

À minha amiga Lorrayne Dias, que esteve presente em todas as atividades, observando, coletando saliva e transformando cada dia de trabalho em um dia de histórias a serem contadas, que incluem energético, pneus furados, pegadas de onça, horas de estrada e que vão ficar sempre na lembrança.

À Giovanna Mazotti, uma dessas pessoas que a vida nos traz e que são como irmãs. Pela acolhida em Brasília, por trilharmos juntas parte do mestrado e por essa amizade que é tão valiosa.

De forma geral, mas não menos importante, agradeço a cada um dos professores, por terem sempre instigado em mim o desejo por aprender e buscar sempre mais. Incluem-se aqui o corpo docente do curso de Ciências Biológicas do Centro Universitário Fundação Santo André (SP), dos programas de Pós-Graduação em Biologia Animal e em Ciências Animais da Universidade de Brasília.

Agradeço também aos percalços que, por linhas tortas, me levaram a desenvolver esse estudo com as onças, a espécie com a qual, ainda na graduação, eu sonhava em trabalhar.

Ao Tiago Carpi, pelos anos que passamos juntos, por tantas coisas, pelas aranhas mortas e pelo chá quente nas madrugadas de estudo.

Ao meu filho Rafael, que mesmo sem consciência disso, me "dividiu", durante os últimos quatro anos, com essa minha outra criação, que hoje ganha forma.

Por fim, nada disse teria sido possível sem o apoio incondicional dos meus pais, Neusa Ferez Garcia e Irineu Garcia Fernandes, que sempre estiveram do meu lado, permitindo que buscasse os meus sonhos e auxiliando para que pudesse torná-los realidade.

A participação dessas pessoas, tanto no desenvolvimento do estudo quanto na minha vida, foi tão preciosa, que agradeço imensamente a Deus por ter colocado cada uma delas em meu caminho. 


\section{ÍNDICE}

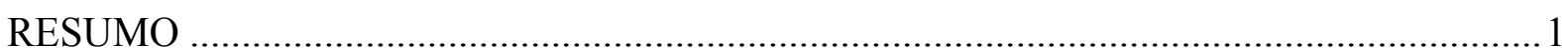

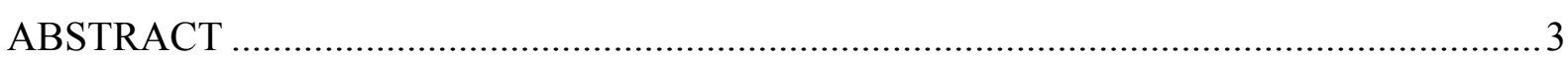

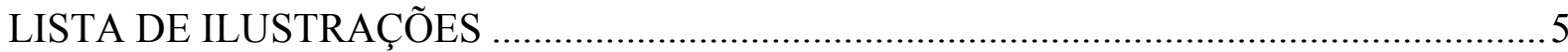

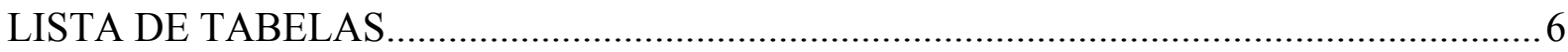

CAPÍTULO 1: INTRODUÇÃO E REVISÃO DE LITERATURA..........................................

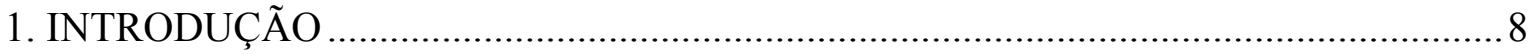

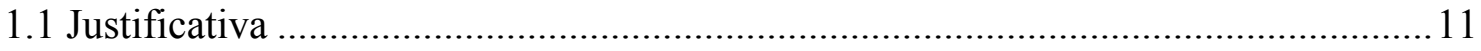

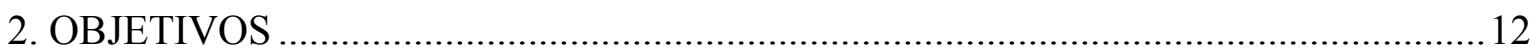

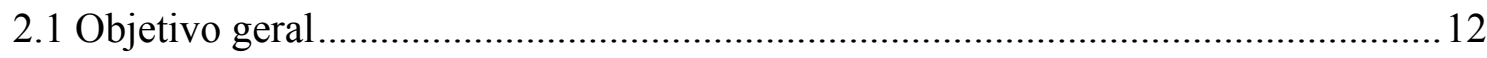

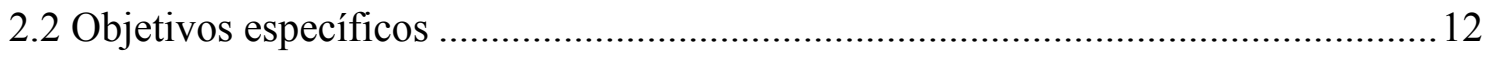

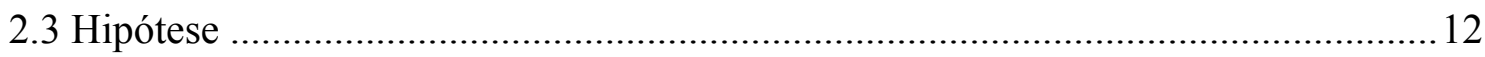

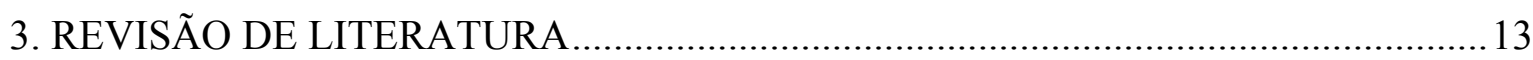

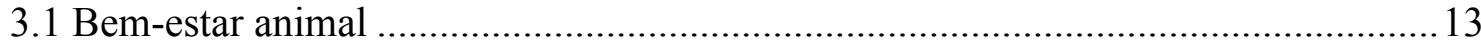

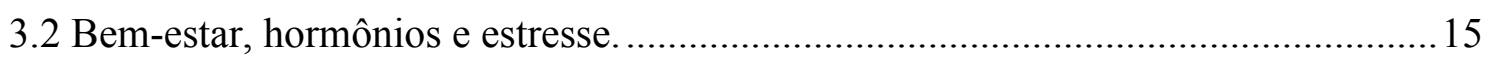

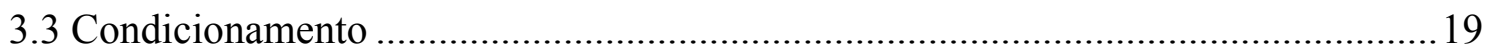

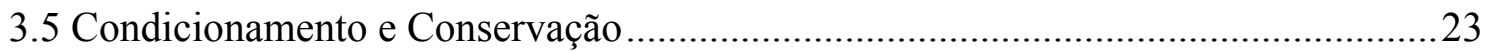

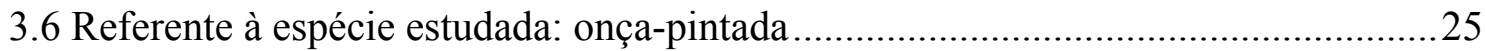

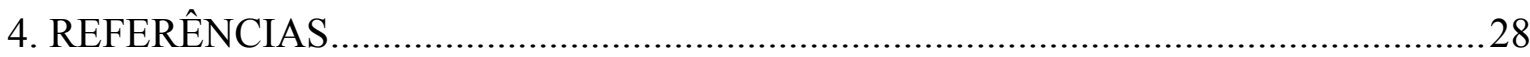

CAPÍTULO 2: EFEITOS DO CONDICIONAMENTO SOBRE O BEM-ESTAR DE ONÇAS

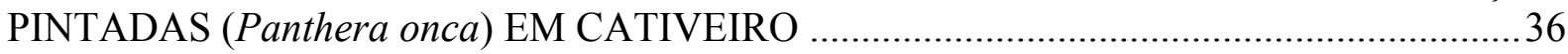

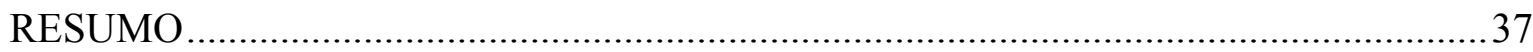

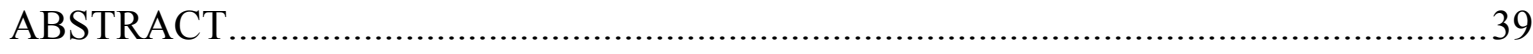

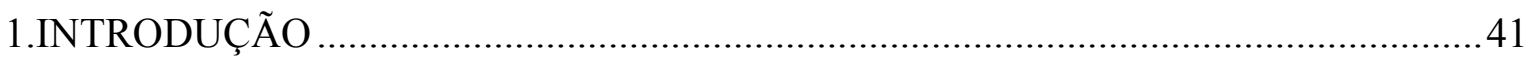

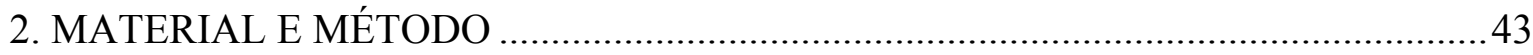

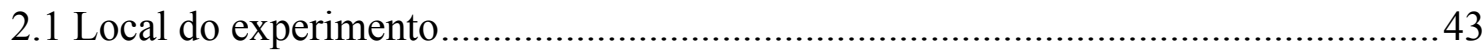

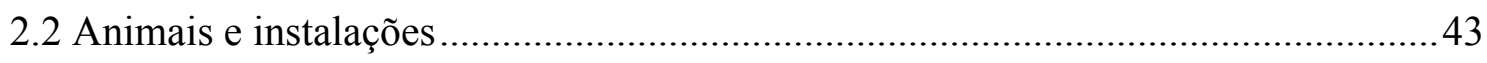

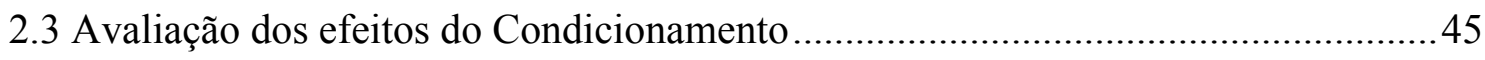

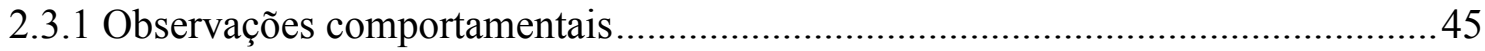

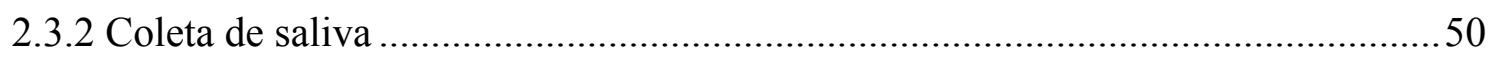

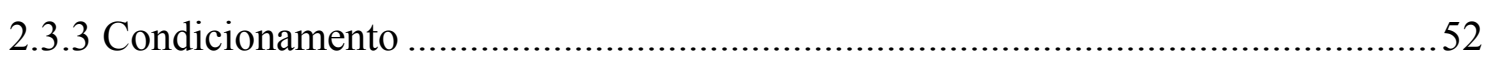

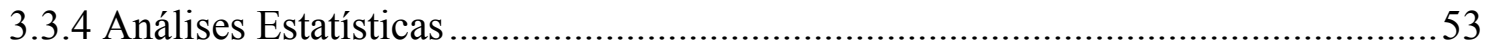

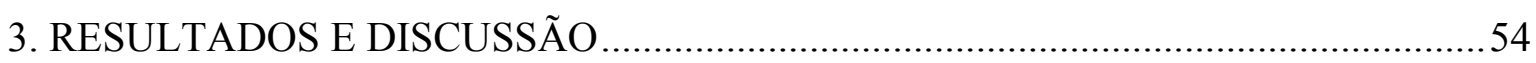

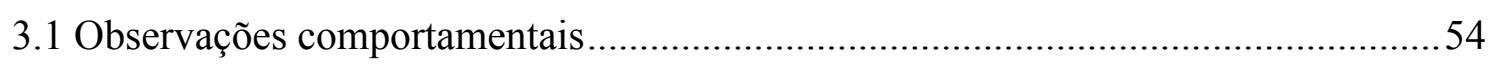

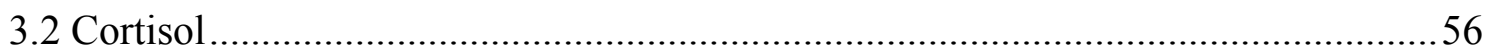

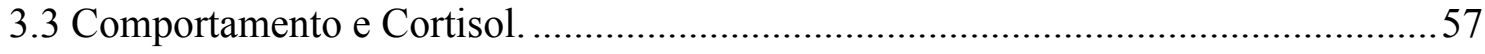

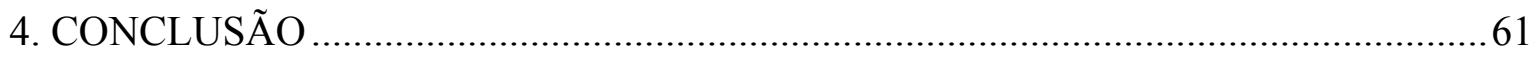

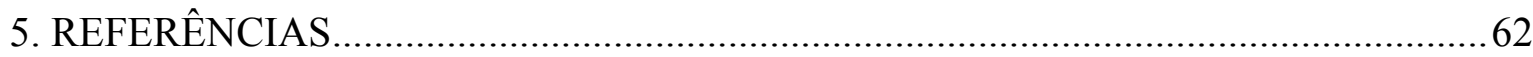


CAPÍTULO 3: CONDICIONAMENTO OPERANTE APLICADO A ONÇAS PINTADAS

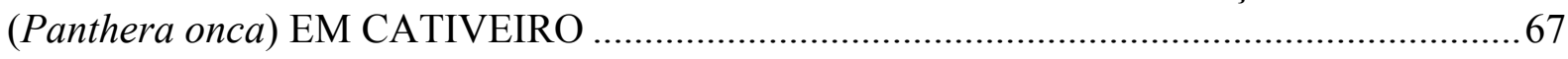

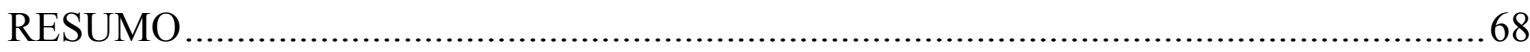

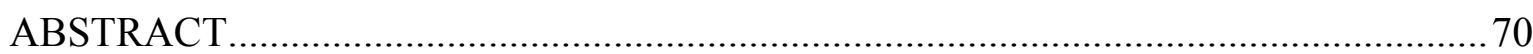

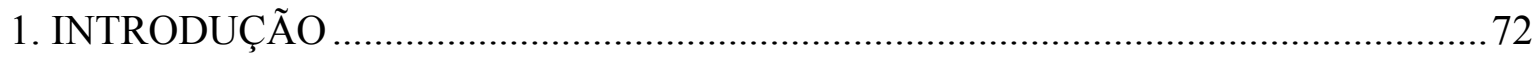

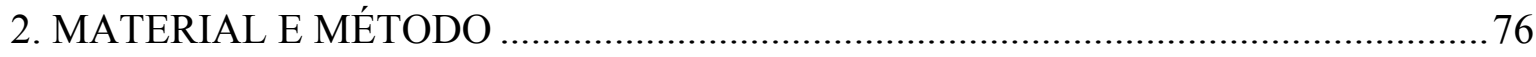

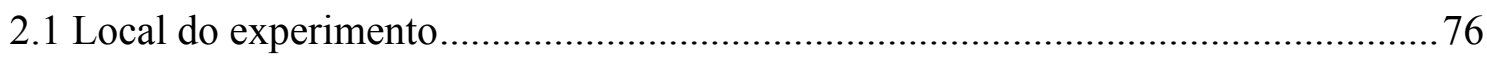

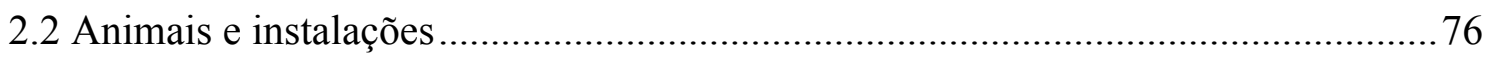

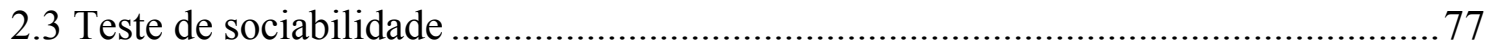

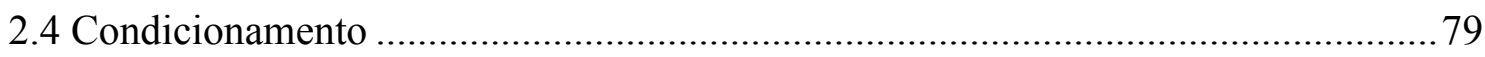

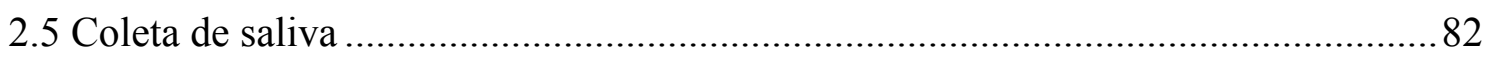

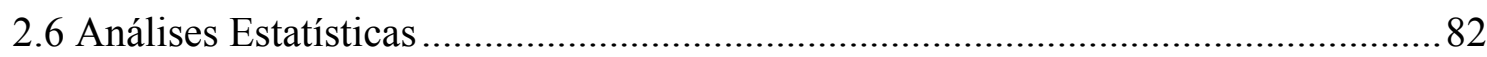

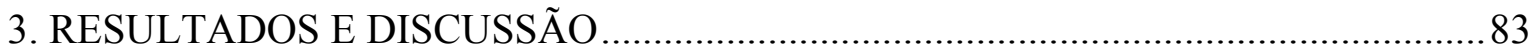

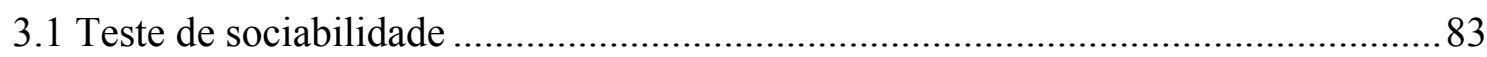

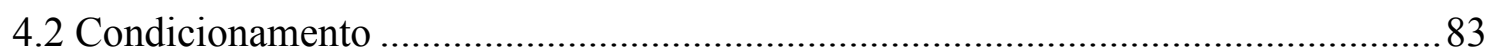

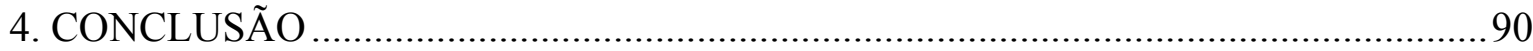

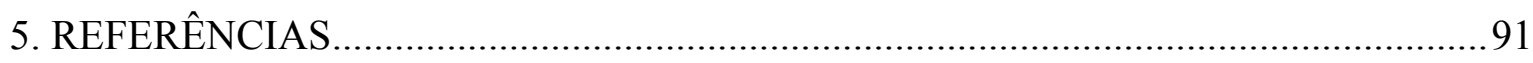

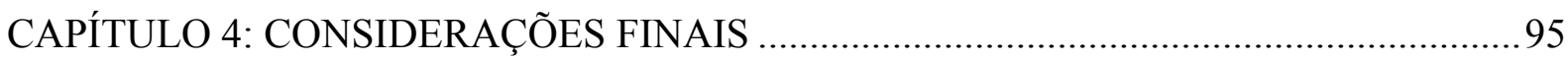

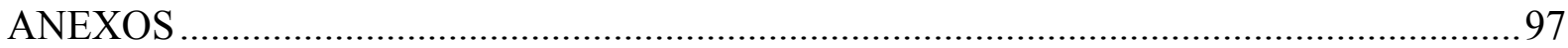

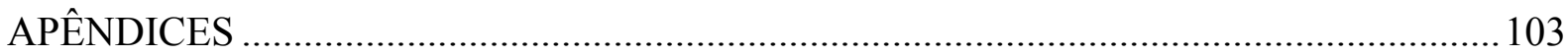




\title{
RESUMO
}

\section{CONTRIBUIÇÃO DO CONDICIONAMENTO PARA O BEM-ESTAR DE ONÇAS-PINTADAS (Panthera onca) EM CATIVEIRO}

\author{
Liane Cristina Ferez Garcia, Msc. \\ Franscisco Ernesto Moreno Bernal, Prof. Dr. \\ Brasília, DF.
}

A manutenção de animais em cativeiro ocorre desde a antiguidade, sustentada por diversas razões, entre as quais está, atualmente, a conservação de espécies ameaçadas, como a onçapintada, maior felino das Américas. Sabe-se que essa condição pode ter como consequência a redução no bem-estar desses animais, especialmente devido à limitação espacial e carência de estímulos ambientais. Nesse sentido, nas últimas décadas têm sido buscadas técnicas para minimizar os impactos negativos do cativeiro, entre as quais destaca-se o enriquecimento ambiental, com crescimento da utilização de técnicas de condicionamento operante com intuito de facilitar procedimentos de rotina do manejo dos animais. Nesse cenário, o presente estudo teve por finalidade avaliar os efeitos do condicionamento animal sobre o bem-estar animal de onças-pintadas em cativeiro, analisando parâmetros comportamentais e fisiológicos. O estudo foi conduzido com sete onças-pintadas do Criadouro Conservacionista No Extinction. Os animais foram submetidos a um teste de sociabilidade, que agrupou os indivíduos em sociáveis (3), indiferentes (3) e agressivos (1). Foram realizadas observações comportamentais e coletas de saliva para mensuração de cortisol em três tratamentos, compostos por três repetições: linha de base, controle e condicionamento, realizados duas vezes. Quanto a aprendizagem, todos os animais apresentaram respostas adequadas para no mínimo dois comandos, quatro indivíduos chegaram a cinco comandos e todos atingiram mais de $90 \%$ de acertos ao final das dozes sessões. Na primeira fase, não houve diferença no comportamento e na concentração de cortisol entre os tratamentos. Quando o experimento foi 
repetido, as observações comportamentais mostraram que houve diminuição da apatia (animal não responsivo) durante o controle e durante o condicionamento, com aumento significativo nos comportamentos relacionados ao bem-estar e nos valores de cortisol durante o condicionamento, sugerindo que a técnica contribui para a elevação do bem-estar de animais em cativeiro e que o cortisol não indica, necessariamente, ausência de bem-estar. 


\author{
ABSTRACT \\ ANIMAL TRAINING CONTRIBUTION TO WELFARE JAGUARS \\ (Panthera onca) IN CAPTIVITY \\ Liane Cristina Ferez Garcia, Msc. \\ Franscisco Ernesto Moreno Bernal, Prof. Dr. \\ Brasília, DF.
}

The keeping of animals in captivity occurs since antiquity and is sustained for various reasons. Currently, among this reasons, there is the conservation of endangered species such as the Brazilian jaguar, the largest cat in the Americas. It is known that this condition may lead to a decrease in welfare of these animals, especially due to space limitation and lack of environmental stimuli. In this regard, techniques have been considered to minimize the negative impacts of captivity in recent decades, among which stands out the environmental enrichment, alongside with the increasing use of operant conditioning techniques in order to facilitate routine animal maintenance procedures. Given this scenario, the present study aimed to evaluate the effects of the operant conditioning in the welfare of captive Brazilian jaguars, analyzing behavioral and physiological parameters. The study was conducted with seven Brazilian jaguars of No Extinction Conservationist Center. The animals were subjected to a sociability test that ranked the individuals as sociable (3), indifferent (3) and aggressive (1). Behavioral observations were conducted and saliva samples were taken to measure cortisol levels in three phases consisting of three replicates: Baseline, control and during conditioning. As for the learning, all animals showed appropriate responses to at least two commands, four individuals reach the score of five correct responses to different commands and every animals were able to reach over $90 \%$ of correct responses at the end of six sessions. In the first stage, there was no difference in the behavior and concentration of cortisol between treatments. When the experiment were repeated, behavioral observations showed a decrease on inactivity 
(unresponsive animal) during the control and conditioning phases, with a significant increase in the welfare behaviors and cortisol values in the conditioning, suggesting that the technique contributes to the elevation of animal welfare in captivity and that cortisol does not necessarily indicate lack of welfare. 


\section{LISTA DE ILUSTRAÇÕES}

Figura 1.1 Modelo neural simplificado do condicionamento operante................. 20

Figura 2.1 Vista geral de dois dos recintos do Nex.............................................. 44

Figura 2.2 Em destaque, os cambiamentos........................................................ 44

Figura 2.3 Comportamento deitado........................................ 48

Figura 2.4 Comportamento andando............................................................ 48

Figura 2.5 Interação agonística..................................................................... 49

Figura 2.6 Animal apresentando Flehmen........................................................... 49

Figura 2.7 Comportamento bocejar................................................................ 50

Figura 2.8 Um dos animais mordendo o material absortivo para coleta de saliva 51

Figura 2.9 Um dos indivíduos durante sessão de condicionamento.................... 53

Figura 2.10 Freqüência média (incluindo erro padrão) dos comportamentos de atividade para o grupo de animais durante os tratamentos na fase I e fase II......... 55

Figura 2.11 Freqüência média (incluindo erro padrão) dos comportamentos de inatividade para o grupo de animais durante os tratamentos na fase I e fase II.......

Figura 2.12. Freqüência média (incluindo erro padrão) dos comportamentos indicadores de bem-estar para o grupo de animais durante os tratamentos............ 56

Figura 2.13 Freqüência média (incluindo erro padrão) dos comportamentos indicadores de estresse para o grupo de animais durante os tratamentos.

Figura 2.14 Concentração de Cortisol Salivar - ug/dl (incluindo erro padrão) para o grupo de animais durante os tratamentos na fase I e fase II

Figura 3.1 O comportamento típico dos animais classificados como sociáveis.... 78

Figura 3.2 Um dos comportamentos dos animais classificados como indiferentes, que não alteram a expressão de seus comportamentos no sentido de interagir com o ser humano que se aproxima.

Figura 3.3 O comportamento típico dos animais classificados como agressivos... 79

Figura 3.4 Animal durante realização do comando "em pé" e durante realização do comando "senta".

Figura 3.5 Gráfico do desempenho das onças dos três grupos nas sessões de condicionamento.

Figura 3.6 Desempenho dos animais classificados como agressivos..................... 88

Figura 3.7 Desempenho dos animais classificados como indiferentes................. 88

Figura 3.8 Desempenho dos animais classificados como sociáveis...................... 88

Figura 3.9 Gráfico da média de acertos apresentados pelas onças nas sessões de condicionamento nas duas fases do estudo. 


\section{LISTA DE TABELAS}

Tabela 2.1 Descrição dos indivíduos.................................................................... 43

Tabela 2.2 Etograma utilizado para as observações comportamentais.................... 46

Tabela 3. 1 Descrição dos indivíduos .................................................................. 77

Tabela 3. 2 Graus de socialização das onças com humanos. .................................. 78

Tabela 3.3 Descrição dos comandos trabalhados e das respostas consideradas corretas........................................................................................ 80

Tabela 3.4 Resultado do grau de socialização das onças com humanos................... 83

Tabela 3.5 - Comandos desenvolvidos corretamente após o condicionamento......... 84

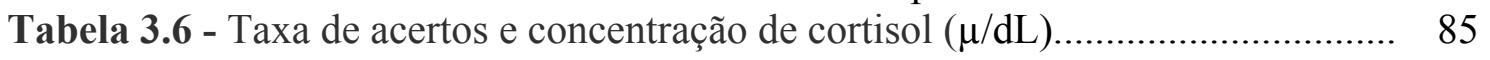




\section{CAPÍTULO 1}

INTRODUÇÃO E REVISÃO DE LITERATURA 


\section{INTRODUÇÃO}

A manutenção de animais em cativeiro tem suas origens históricas na antiguidade, com registros de coleções de animais vivos mantidas por Imperadores Chineses, Astecas e Faraós Egípcios. Essa tradição manteve-se, entre os nobres, até o século 18, em diversas partes do mundo. A história dos zoológicos atuais iniciou-se no final do século 18 e início do século 19, com a criação de zoológicos em Viena (1752), Paris (1793) e Londres (1826). Desde então, muitos outros foram criados na Europa, América do Norte e outras partes do mundo. A primeira razão para a criação dos zoológicos foi o interesse, em parte científico, dos membros da Sociedade de Zoologia, pelos animais e suas formas de vida. Os zoológicos ganharam projeção e se estabelecem por todo o mundo a partir do século 20, inicialmente com objetivos principalmente financeiros (comercial) ou idealistas (cultural, educacional, científico e conservador) assumindo, mais recentemente, quatro pilares ideológicos: Conservação, Pesquisa e Educação Ambiental, além de proporcionar lazer (IUDZ - CBSG, 1993).

Com a crescente expansão da degradação ambiental, a consequente destruição de habitats e a ameaça de extinção a espécies, a manutenção de animais em cativeiro passou a ser uma importante ferramenta para a conservação das espécies (UFAW, 2009). Existem duas abordagens para a conservação: in situ, caracterizada pela manutenção dos animais no ambiente natural, com foco na manutenção desse ambiente e ex situ, que consiste em manter animais em instituições como zoológicos e criadouros conservacionistas, onde devem ser realizados estudos sobre comportamento alimentar, treinamentos para possível reintrodução e reprodução orientada, mantendo-se a variabilidade genética (Andriolo, 2007).

De acordo com Barnoski et al. (2011), com base nos dados disponíveis sobre a biodiversidade e em comparações com registros fósseis, ainda não é possível afirmar que o 
planeta esteja atravessando uma extinção em massa, como as cinco já ocorridas, no entanto, considerando o número de espécies atualmente classificadas como vulneráveis e criticamente em perigo, é provável que a sexta mega extinção ocorra em alguns séculos. Nesse sentido, é necessário planejar ações e alocar os recursos naturais para prevenir a perda da diversidade, ou limitá-la (Dirzo \& Raven, 2003).

Salvar as espécies que se encontram ameaçadas exige esforços em duas frentes principais: reduzir as ameaças e viabilizar as populações (Soulé, 1985). Para que essas frentes obtenham resultados satisfatórios são necessárias pesquisas que procurem identificar a situação de espécies na natureza e a formulação de um programa de manejo específico, que preveja ações voltadas para as populações naturais e em cativeiro, a manutenção do hábitat da espécie e o envolvimento de setores da comunidade através de programas de educação ambiental e políticas públicas (Cassano, 2006).

No Brasil, além dos jardins zoológicos, existem instituições classificadas inicialmente como criadouros conservacionistas, regulamentadas pela Portaria IBAMA 139-N/ 93, e que passam a abrigar animais oriundos de apreensões e resgates, muitas vezes de forma permanente, quando eles não apresentam condições para soltura. Conforme a legislação, essas instituições têm como objetivo acolher esses animais e não são abertas ao público para visitação, exceto para atividades com finalidade educativa.

No entanto, embora a manutenção de animais em cativeiro seja importante para a conservação das espécies, animais em ambientes estéreis, sem complexidade e cuja previsibilidade é alta tendem a apresentar problemas, como o desenvolvimento de alterações comportamentais, tais como estereotipias, quando há diminuição de comportamentos naturais e os poucos comportamentos apresentados são excessivamente apresentados ou qualitativas, quando o animal desempenha comportamentos não observados em condições naturais (Shepherdson, 1998).

O cativeiro pode levar também a desenvolvimento de estresse crônico, geralmente associado à ausência de reprodução e a problemas de imunossupressão (Munck, 1984). Nesse cenário, a saúde e o bem-estar de animais cativos vêm recebendo maior atenção nas últimas décadas (Schetini et al., 2007). A identificação dos fatores estressantes e do seu efeito no bem-estar de animais cativos contribuiu à compreensão dos efeitos biológicos e psicológicos do cativeiro (Acco et al. 1999).

Entre as estratégias para minimizar os efeitos adversos do cativeiro está o treinamento dos animais por meio de técnicas baseadas no condicionamento operante, pelas quais o animal é estimulado a desenvolver alguns comportamentos, que são reforçados positivamente (Laule 
\& Desmond, 1998). Treinar os animais para procedimentos de rotina, tais como entrar e sair de áreas restritas, possibilitar a realização de alguns exames clínicos como auscultação, ultrassonografias e coleta de material biológico (saliva e sangue) pode diminuir o estresse do manejo em cativeiro e auxiliar na coleta de amostras biológicas, possibilitando incrementar as informações a respeito da fisiologia da espécie. Além de diminuir o estresse envolvido em alguns procedimentos simples, o treinamento pode ser enquadrado como enriquecimento social, o que indica seu potencial como técnica para elevação dos índices de bem-estar animal (Young, 2003). Muitos estudos apontam para a importância do enriquecimento ambiental para a elevação do bem-estar animal, baseados em evidências comportamentais e, em alguns casos, baseados na avaliação de parâmetros fisiológicos, especialmente a partir de hormônios corticosteróides associados ao estresse (Möstl \& Palme, 2002), mas há poucos registros de estudos dessa natureza com condicionamento animal, como aponta uma revisão sobre estudos realizados com enriquecimento ambiental visando à diminuição de esteriotipias (Swaisgood \& Shepherdson, 2005).

Os grandes felinos perdem habitat pelo desmatamento e não raramente são abatidos em resposta à predação de animais de produção, uma vez que as presas naturais passaram a ser caçadas pelo homem (Sunquist \& Sunquist, 2002). Com a expansão das atividades antrópicas, como construção de rodovias e de reservatórios para obtenção de energia, cresce o número de animais provenientes de resgates de fauna, que acabam, na maioria das vezes, em cativeiro. No Brasil, a onça-pintada, Panthera onca, é a única representante desse gênero na natureza, e quando mantida em cativeiro, pode apresentar comportamentos esteriotipados comuns a felinos, tais como andar em rotas fixas (pacing), arrancar os próprios pelos, realizar sucção na ponta do rabo ou pata, automutilação (Silva \& Adania, 2007).

A onça-pintada é a espécie alvo do presente estudo, que consistiu na análise do condicionamento como ferramenta para elevação do bem-estar animal, por meio da mensuração de parâmetros comportamentais e hormonais. Foram realizados, ainda, testes comportamentais para estabelecer graus de socialização frente a humanos e sua relação com aprendizado por meio do condicionamento animal. 


\subsection{Justificativa}

Estudos sobre o bem-estar e o comportamento de animais em cativeiro podem elucidar diversas questões importantes em relação a espécies ameaçadas de extinção, como a onçapintada, que consta na lista vermelha da União Internacional para Conservação da NaturezaIUCN como "quase ameaçada" (IUCN, 2013). O conhecimento proveniente desses estudos pode ser aplicado em um primeiro momento para conservação ex situ e posteriormente para elaboração de programas que visam à conservação in situ. Além disso, questões éticas têm sido levantadas quanto à manutenção de animais em cativeiro, sendo essencial que sejam adotadas medidas a fim de minimizar os efeitos negativos do cativeiro e elevar os índices de bem-estar dos animais nessa condição, considerando que o confinamento é sempre contrario a possibilidade expressão do comportamento natural dos animais (Branco, 2007).

O condicionamento vem sendo utilizado em diversas instituições do mundo a fim, especialmente, de facilitar manejos e procedimentos de rotina com os animais. No entanto, algumas questões são fundamentais para a compreensão dos efeitos da aplicação dessa técnica para onças-pintadas: Essa técnica realmente apresenta algum resultado quanto à diminuição do estresse? Existe relação entre a forma de criação, a interação durante o manejo ou devido ao manuseio, com humanos e os efeitos do condicionamento sobre os níveis de bem-estar? O aprendizado dos animais está relacionado à forma como foram criados, então, animais com maior grau de socialização com humanos terão melhor desempenho no aprendizado? Pode o condicionamento contribuir no manejo diário desses animais? É possível que por meio dessa técnica obtenham-se amostras biológicas que possam contribuir para o conhecimento da fisiologia da espécie? Responder a essas questões é essencial para esclarecer os efeitos dessa prática para onças-pintadas em cativeiro e suas possíveis implicações para a espécie.

Além disso, conhecer padrões comportamentais e fisiológicos pode ser uma ferramenta importante no planejamento de programas de conservação para a espécie, especialmente aqueles relacionados à manutenção de animais em cativeiro, que é de extrema importância. É necessário que se busquem estratégias para que a manutenção em cativeiro não seja, em si, um fator impeditivo para a construção do conhecimento sobre a espécie, visto que os baixos níveis de bem-estar animal, que podem decorrer dessa condição, afetam uma série de parâmetros fisiológicos e comportamentais, invalidando a utilização desses indivíduos em cativeiro como modelo para programas de conservação in situ. 


\section{OBJETIVOS}

\subsection{Objetivo geral}

O presente estudo tem por finalidade avaliar, do ponto de vista comportamental e fisiológico, os efeitos do condicionamento de onças-pintadas em cativeiro sobre a facilitação do manejo e o bem-estar animal, bem como avaliar o desempenho desses animais nesse tipo de treinamento.

\subsection{Objetivos específicos}

Estabelecer graus de aproximação dos animais com/aos seres humanos, por meio de testes comportamentais;

Avaliar a aprendizagem e a resposta ao condicionamento dos animais em seus diferentes níveis de socialização com humanos;

Avaliar os efeitos do condicionamento animal sobre os níveis de cortisol;

Avaliar os efeitos do condicionamento animal sobre o comportamento dos animais.

\subsection{Hipótese}

O condicionamento pode melhorar o bem-estar animal de onças pintadas em cativeiro, contribuindo para a diminuição da apresentação de comportamentos patológicos, facilitando os processos adaptativos ao novo ambiente. 


\section{REVISÃO DE LITERATURA}

\subsection{Bem-estar animal}

Existem várias definições para o termo bem-estar animal dentre as quais uma das mais completas e mais objetiva data de 1986, quando Donald Broom resume: "Bem-estar... é o estado de um indivíduo em relação às suas tentativas de adaptar-se ao seu ambiente" (Broom, 1986 apud Broom, 1991).

De acordo com Broom \& Molento (2004), a definição de bem-estar animal deve considerar, ainda, outros conceitos como necessidades, liberdades, adaptação, controle, capacidade de previsão, sofrimento, dor, ansiedade, medo, tédio, saúde e estresse, sendo possível, para sua avaliação, a utilização de indicadores de bem-estar. Dentre os 16 indicadores apresentados, 7 mencionam aspectos relacionados ao comportamento animal: demonstração de uma variedade de comportamentos normais; grau em que comportamentos fortemente preferidos podem ser apresentados; indicadores comportamentais de prazer; tentativas comportamentais de adaptação; doenças comportamentais; grau de aversão comportamental; grau de supressão comportamental. Dessa forma, muitos estudos em cativeiro são baseados em observações comportamentais e, considerando as técnicas de amostragem, de observação e de registro, associadas a um bom treinamento da equipe de observadores é possível a obtenção de resultados significativos (Del-Claro, 2004).

A observação de parâmetros comportamentais é importante, pois o contato de seres humanos com animais silvestres cativos é, de forma geral, muito limitado, fato que dificulta a mensuração de alguns parâmetros fisiológicos que podem ser indicadores de bem-estar.

Os primeiros registros da utilização de técnicas de enriquecimento ambiental datam de 1911, com a colocação de brinquedos para ursos polares, mas sua importância só foi reconhecida por Robert Yerkes, que em 1925 observou que a invenção e instalação de aparatos que pudessem ser utilizados para brincadeiras e trabalho proporcionariam um enriquecimento para primatas cativos. No entanto, na maioria dos zoológicos, os recintos eram construídos com vistas na praticidade para higienização e manutenção, características que tornavam o espaço adequado do ponto de vista físico, porém não consideravam o aspecto psicológico do animal, que passou a ser considerado apenas na década de 90, sinalizando uma nova mudança na relação entre o homem e os animais (UFAW, 1997). 
Um levantamento mostra aumento no número de artigos pulicados sobre o tema enriquecimento ambiental entre 1995 e 2004, mas inicialmente com o enriquecimento ambiental sendo utilizado buscando resolver algum problema induzido por humanos. Estudos cujo objetivo englobava bem-estar animal aumentaram principalmente entre 2000 e 2004 . (Schetini et al., 2007).

Existem diversas formas de promover enriquecimento ambiental, enquadradas em cinco categorias: 1. físico, com alterações no tamanho e formado do recinto; 2. social, com modificação no grupo de indivíduos que dividem o recinto ou relacionando-os direta ou indiretamente com outras espécies; 3. sensorial, estimulando os sentidos; 4. alimentar, que consiste principalmente em alterar a forma como a alimentação é oferecida aos animais, elevando o grau de dificuldade para obtenção do alimento. 5. cognitivo, por meio de treinamento ou atividades que exijam tempo para serem resolvidas. Nessa ultima categoria enquadra-se o condicionamento animal, objeto de estudo desse projeto (Shepherdson, 1998).

O enriquecimento ambiental pode atuar diminuindo comportamentos estereotipados em diversas espécies: leopardos (Markowitz et al., 1995), elefantes (Wells \& Irwin, 2008), lobos guarás (Prado et al., 2007). Beneficamente, pôde-se observar a elevação da expressão de comportamentos desejáveis para felinos (Markowitz \& LaForse, 1987; Jenny \& Schmid, 2002), raposas vermelhas (Kistler et al., 2009) e passeriformes (Fairhust et al., 2011).

Um dos problemas comportamentais relacionados ao cativeiro são as estereotipias, definidas comumente como comportamentos repetitivos e sem função (Mason, 1991, Shepherdson, 1993). No entanto, é possível que determinados comportamentos aparentemente sem função, apresentem efeitos benéficos para o organismo que o desempenha (Mason \& Lathan, 2004), o que faz com que impedir a expressão desses comportamentos seja prejudicial a esse animal. Alem disso, o fato de ser repetitivo não é o que torna um comportamento nocivo, haja visto o exemplo do amassar uma almofada, movimento realizado repetidamente por gatos antes de se deitarem. Assim, Mason (2007) sugere que o termo comportamento estereotipado seja aplicado para comportamentos repetitivos induzidos pela frustração, repetidos na tentativa de lidar com transtornos do Sistema Nervoso Central e utiliza o termo comportamento anormal repetitivo, reservando o termo estereotipado apenas para quando tratar-se de déficits no cativeiro que induzam a frustração.

O desenvolvimento do comportamento estereotipado pode estar ligado a uma das seguintes razões: 
1. A presença constante de estados internos induzidos pelo ambiente do cativeiro, ou de sinais ambientais, que motivam permanentemente uma resposta comportamental especifica;

2. O ambiente cria um estado de estresse que afeta áreas específicas do cérebro, que eliciam sequências comportamentais resultando em expressão anormal desses comportamentos.

3. O ambiente afetou o desenvolvimento do sistema nervoso central durante suas fases iniciais.

4. Em alguns casos, esses comportamentos podem produzir efeitos endógenos que atuam como reforçadores do comportamento, aumentando sua probabilidade de repetição.

Castellon et al. (2012) apresentaram um sistema de avaliação de bem-estar animal para grandes felinos em cativeiro. O estudo identificou indicadores válidos e confiáveis, relacionados a quatro princípios: alimentação, recinto, saúde e comportamento. O protocolo foi desenvolvido e cada indicador de bem-estar foi avaliado em uma escala de 0 a 2 , com aplicação em cinco zoológicos do Chile. Foram definidas quatro categorias de bem-estar: bom, moderado, baixo e muito baixo. Para validação do protocolo foram consultados 15 especialistas por meio de um questionário, dos quais $80 \%$ consideraram os indicadores relevantes e $75 \%$ consideraram a forma de avaliação adequada.

\subsection{Bem-estar, hormônios e estresse}

Os efeitos do enriquecimento ambiental, e possivelmente do condicionamento, sobre os animais podem ser medidos por meio de registros comportamentais ou de medidas fisiológicas, mensurando-se, nesse caso algum esteróide cuja liberação está relacionada a situações ambientais imprevisíveis e que podem colocar em risco o equilíbrio e funcionamento do organismo. Esses fatores ambientais são denominados "estressores", que alteram a homeostase e levam o organismo a apresentar uma cadeia de eventos, denominada "resposta ao estresse" (Möstl \& Palme, 2002), essencial para a sobrevivência, uma vez que todos os ambientes estão em constante modificação, exigindo dos organismos mecanismos fisiológicos e comportamentais que lhes permitam se adaptar às novas circunstâncias que possam surgir. Existem eventos previsíveis, como as alterações relacionadas as estações e 
eventos imprevisíveis, como escassez de alimentos, doenças, aumento do número de predadores. Os eventos imprevisíveis, uma vez que os animais não podem ter se preparado para enfrentá-los, exigem respostas rápidas, caso contrário surgem os sintomas do estresse e eventualmente o óbito (Wingfield \& Kitaysky, 2002).

Essa resposta fisiológica está relacionada à ativação do eixo hipófise-pituitário-adrenal (HPA), que resulta em uma cascata de eventos neuroendócrinos e comportamentais que objetiva manter a integridade física e o equilíbrio entre os sistemas internos. Entre os fenômenos decorrentes dessa resposta está a liberação de glicocorticóides, cuja ação principal é evitar que a energia disponível seja utilizada em processos fisiológicos desnecessários no momento estressante, canalizando-a para a sobrevivência imediata nas situações emergenciais (Sapolsky, 1992). Esse mecanismo eleva a capacidade de sobrevivência somente nos casos em que ocorre a curto prazo (horas a dias), sendo prejudicial nos casos em que é prolongada (dias a semanas). Os efeitos do estresse são supressão da reprodução, diminuição da resposta imune, aumento da gliconeogenese, maior expressão de comportamentos de forrageio, aumento dos comportamentos de fuga durante o dia e de descanso durante a noite. Esses comportamentos indicam que os mecanismos não necessários à sobrevivência imediata foram suprimidos (Wingfield \& Kitaysky, 2002).

A mensuração dos hormônios glicocorticóides pode ser utilizada para monitorar um possível distúrbio fisiológico nos animais, estando presente em diversos estudos para verificar os efeitos de técnicas de enriquecimento ambiental na elevação do bem-estar animal (Möstl \& Palme, 2002). Estudos abrangendo os efeitos da manutenção de animais em cativeiro para primatas não humanos também se utilizaram dessa técnica, considerando-a eficiente para avaliação da atividade adrenocortical em gibões (Pirovino et al 2011). Em lobos, os hormônios glicocorticóides apresentam-se em maior a concentração nos animais de maior posição hierárquica, no entanto esse aumento não está correlacionado aos comportamentos agonísticos como se pressupunha (Vasconcellos et al., 2011).

Esses esteróides, ou seus metabólitos, podem ser encontrados no sangue, na saliva e nas fezes, sendo as últimas mais utilizadas em estudos para auxiliar na avaliação de níveis de bem-estar, uma vez que suas amostras podem ser coletadas de forma não-invasiva, possibilitando coletas sucessivas sem que haja interferência do processo de obtenção da amostra nos resultados encontrados. (Touma et al., 2004, Touma \& Palme, 2005; Schwarzenberger, 2007).

O cortisol é um hormônio pertencente ao grupo dos glicocorticóides, produzido pela região cortical da glândula supra-renal onde é sintetizado a partir da progesterona em reações 
que envolvem enzimas altamente específicas (Stryer, 1996). É o principal glicocorticóide secretado nos mamíferos (Cooke et al., 2004).

A liberação de cortisol está relacionada ao estresse, seja físico ou psicológico, que ativa o eixo hipotalâmico-pituitário-adrenal, HPA, provocando imediatamente um acentuado aumento na secreção do hormônio adrenocorticotrópico, ACTH, pela hipófise anterior, que desencadeia um grande aumento na secreção adrenocortical desse esteróide. A importância dessa elevação possivelmente está relacionada a mobilização de aminoácidos e ácidos graxos para geração de energia, necessária para a síntese de novos compostos, incluindo a glicose. Ainda, o cortisol atua impedindo o desenvolvimento da inflamação, apresentando um efeito global que reduz o processo inflamatório, e em inflamações já estabelecidas auxilia acelerando o processo de regeneração. (Guyton \& Hall, 2006).

O desencadeamento do eixo HPA, não ocorre somente em resposta a situações negativas, assim, o estresse não é, necessariamente, um mecanismo fisiológico danoso. (Moberg, 2000). Alguns eventos positivos para o animal, como a caça, corte e cópula também elevam a liberação dos glicocorticóides (Broom \& Johnson, 1993). Nesse sentido, analisar o comportamento do animal e mensurar os hormônios, de forma concomitante, pode auxiliar na compreensão da resposta do animal a determinados estímulos, possibilitando identificar quais são aversivos e de que forma minimizar esses efeitos, assim como é possível identificar quais são responsáveis por elevar o bem-estar animal. Alguns estudos mostram que o comportamento e o estresse fisiológico dependem do contexto e podem operar de forma independente um do outro (Le Maho et al., 1992).

Pressupõe-se que o estresse seja mínimo quando um animal permanece quieto durante procedimentos de rotina, no entanto, Le Maho et al. (1992) observaram que gansos domésticos, apesar de se manterem calmos durante o manuseio, apresentavam aumento significativo do cortisol após esse procedimento, o que levou os autores a concluírem que a ausência de estresse não deve ser deduzida apenas a partir de observações comportamentais.

$\mathrm{O}$ estresse também se manifesta de maneiras diferentes de acordo com o estímulo e sua duração, como revela um estudo realizado com o passeriforme quebra-nozes, que utilizou enriquecimento ambiental e analisou seus efeitos a curto prazo (10 dias) e a longo prazo (92 dias), verificando que o cortisol aumentou significativamente após a colocação do enriquecimento, mas os valores obtidos para a exposição longa ao enriquecimento são significativamente mais baixos do que os encontrados no grupo controle. Inicialmente, os animais perceberam o enriquecimento como uma mudança no ambiente que causou estresse, com aumento do cortisol. A retirada do enriquecimento apresentou efeitos opostos nos níveis 
de cortisol, que se elevaram quando se tratava de longa exposição e apresentaram redução quando se tratava de curta exposição. O resultado pode ser explicado considerando-se o fato que ao manter o item por um longo período no recinto ele passou a fazer parte desse ambiente, e os animais responderam se habituando ao mesmo e, assim, a sua retirada foi um fator estressante, resultando no aumento nos níveis de cortisol. Já na exposição curta o enriquecimento era o agente estressor, razão pela qual sua retirada diminui os níveis de cortisol (Fairhurst, 2011).

A ativação do eixo HPA depende, ainda, do grau de estresse ao qual os animais são submetidos, apresentando variações, ainda não compreendidas, quando há repetição do estimulo estressor. O comportamento tende a diminuir progressivamente com as novas repetições do estimulo estressor, uma vez que ele deixa de ser novidade, assim, em ratos há diminuição do comportamento exploratório. Diante do estimulo estressor, o comportamento do rato é decorrente do medo gerado pelo estímulo desconhecido e pelo espaço desprotegido, o que motiva a exploração em busca de uma forma de sair desse espaço. Com a repetição, o interesse do animal por explorar tende a diminuir, no entanto ele continua a perceber o ambiente como perigoso e, portanto, o eixo HPA permanece ativado. É possível que a magnitude de ativação do eixo HPA não seja sempre relacionada ao grau de medo e ansiedade gerado pela situação e estudos sobre os efeitos de uma nova exposição a um fator estressante sobre o eixo HPA apresentam resultados inconsistentes, podendo reduzir, manter-se inalterado ou aumentar (Gagliano et al., 2008).

Os estudos que investigam o estresse podem variar quanto à sua duração, que pode ser agudo, repetido ou crônico (Gray 2015). Ambientes novos são comumente utilizados como agentes estressores em estudos sobre as respostas ao estresse, sendo possível alterar as características desse novo ambiente. Assim, ratos expostos a testes apresentavam maiores níveis de corticoesteronas quando expostos a caixas com mais novidades em relação há caixas com menos novidades e os níveis de corticoesterona se elevaram com a repetição da exposição, indicando que houve sensibilização do eixo-HPA (Hennessy, 1991), resultados opostos aos que haviam sido encontrados por De Boer e colaboradores (1990), que encontraram diminuição na concentração de corticosterona em razão da repetição de um estímulo estressor.

A literatura sobre como o eixo HPA responde ao enriquecimento ambiental ainda apresenta inconsistências, sendo necessário compreender melhor como enriquecimento, comportamento e estresse se relacionam, de forma a possibilitar o aprimoramento dos procedimentos de enriquecimento (Fairhurst, 2011). As mudanças comportamentais podem 
estar associadas diretamente ao enriquecimento ambiental, mas as mudanças fisiológicas aparentemente estão mais relacionadas ao fato de haver algo imprevisível no ambiente (Wingfield \& Kitaysky, 2002).

\subsection{Condicionamento}

O condicionamento operante é o processo pelo qual um comportamento tende a acontecer por produzir consequências benéficas para a sobrevivência do organismo, como a obtenção do alimento, por exemplo. Pode ser ainda, que determinado comportamento seja reforçado por reduzir uma condição potencialmente prejudicial. Quando um comportamento tem o tipo de conseqüência chamada reforço há maior probabilidade de ele ocorrer novamente. O poder do reforço está relacionado à sua importância evolutiva, ou seja, à sobrevivência, e não à sensação por ele provocada, que é apenas um produto colateral (Skinner, 1974).

O condicionamento envolve a capacidade de aprender a executar um comportamento específico frente a um estímulo particular, enquadrado como aprendizagem estímulo-resposta. A aprendizagem pode ser definida como o processo pelo qual as experiências modificam o comportamento, pois mudam a forma de perceber o ambiente e executar comportamentos, alterando fisicamente a estrutura do sistema nervoso, alterando circuitos neurais que participam da percepção e execução desses comportamentos. A função primária da capacidade de aprender é desenvolver comportamentos adaptados a um ambiente em constante mudança, o que é crucial para a sobrevivência de qualquer organismo. A aprendizagem pode ser perceptiva, estímulo-resposta, motora e relacional (Carlson, 2002).

$\mathrm{Na}$ ausência do reforço, o comportamento tende a se tornar raro ou extinto. Em alguns casos, a ausência de reforço pode causar reações agressivas, caracterizando um quadro de frustração. Para evitar que o comportamento seja extinto ou que o animal desenvolva frustração, os esquemas de razão variável, são particularmente interessantes. Nesses esquemas, o reforço ocorre após um numero variável de respostas, mas a próxima resposta a ser reforçada não pode ser prevista pelo animal, o que o incentiva a permanecer respondendo (Skinner, 1974).

De acordo com Carlson (2002), o processo de reforço fortalece a conexão entre os circuitos neurais envolvidos na percepção (ex. a visão do bastão) e aqueles envolvidos no 
movimento (como a resposta de tocar o focinho no bastão), como ilustra a figura 1.1. Nesse sentido, estudos encontraram conexão entre a plasticidade sináptica e o aprendizado (Tye et al., 2002).

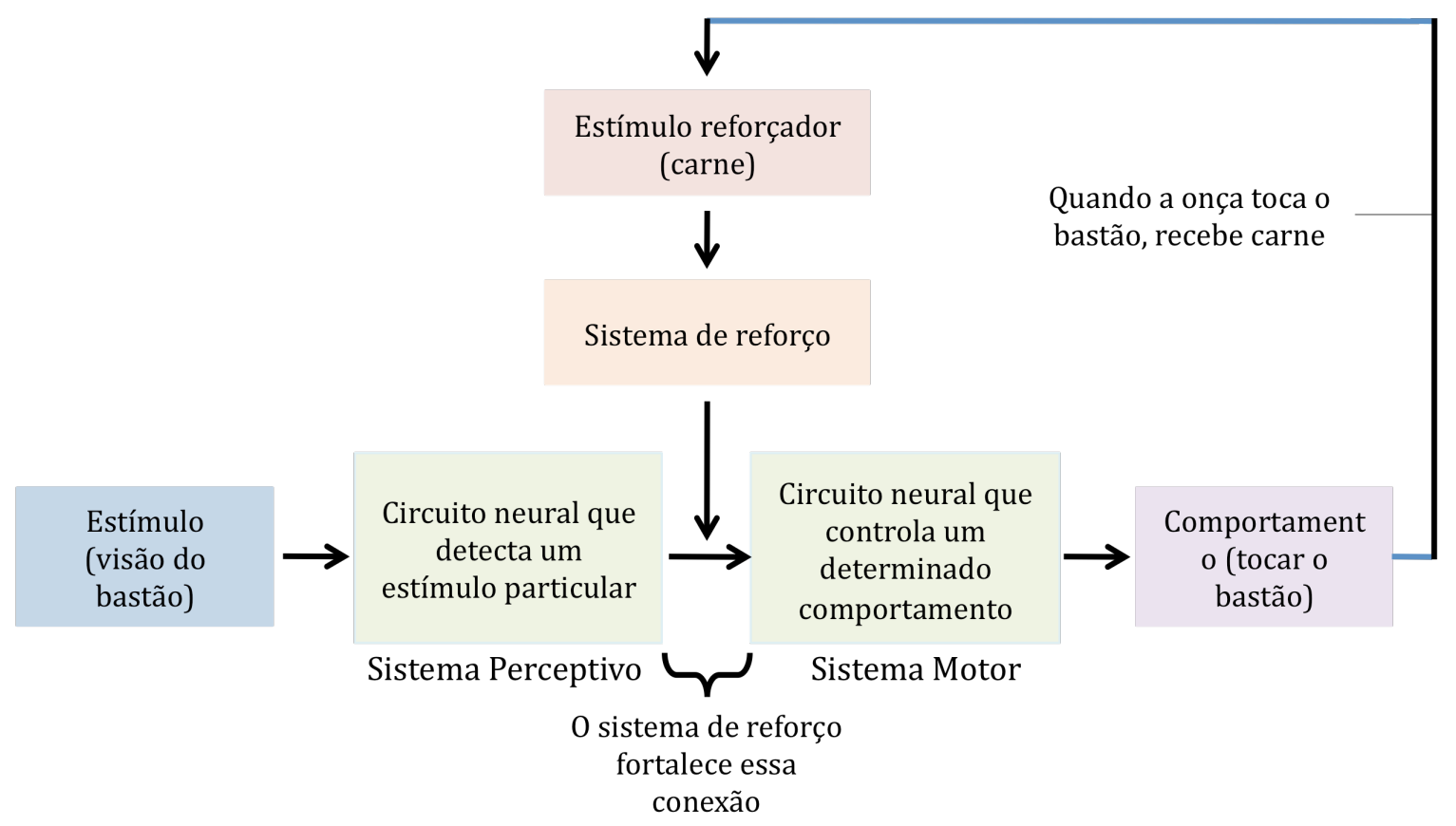

Figura 1.1 Modelo neural simplificado do condicionamento operante (Adaptado de Carlson, 2002).

A utilização do treinamento de animais por meio de técnicas de condicionamento operante, também chamado de treinamento com reforço positivo, ou positive reinforcement training (PRT) ganhou ênfase nas últimas duas décadas, sendo amplamente utilizado em primatas não humanos especialmente em laboratórios, onde são treinados para executar atividades que auxiliam na rotina (Veeder, 2009), em procedimentos veterinários (Lambeth, 2006), facilitam a pesquisa (Bassett, 2003), promovem bem-estar para os animais (Bloomsmith, et al. 1994) e melhoram a interação social (Schapiro, et al., 2001).

Durante o treino com reforço positivo os animais são recompensados quando apresentam comportamentos desejáveis, o que possibilita a dessensibilização para diversos procedimentos, pois reduz o estresse e o medo associado a essas situações, uma vez que os animais passam a expressar escolhas e cooperar com os procedimentos (Lambeth, 2006), o que pode otimizar a rotina de trabalho em laboratórios (Bassett, et al. 2003).

Chimpanzés que voluntariamente se apresentavam para receber injeção contendo anestésicos apresentaram valores significativamente mais baixos das medidas fisiológicas relacionadas ao estresse do que os animais que receberam anestésicos por meio de dardos (Lambeth, 2006). 
O PRT também se mostrou eficiente na diminuição da agressividade de macacos rhesus em relação aos humanos, melhorando a relação entre homem e animal. Também foram comparados os efeitos quando havia um único treinador e uma equipe, não tendo sido encontrada diferença significativa entre esses tratamentos. (Minier et al., 2011).

Embora a maior parte dos estudos seja realizada com primatas não humanos, Heidereich (2007), descreve que o treinamento pode ser realizado com aves, especialmente citando papagaios, facilitando procedimentos clínicos como exame tátil, amostragem cloacal, ultrassonografia, radiografia, aferição de temperatura cloacal, nebulização, máscara para anestesia, vacinação e coleta de sangue. Passeriformes também foram estudados, com resultados que sugerem uma complexa relação entre cognição, tipo de personalidade e sexo, para a espécie chapim-real (Parus major,) na qual foi encontrada correlação entre a performance e a personalidade, mas não entre essa e a velocidade com que aprendiam a responder, além de terem sido encontrando também diferenças individuais na aprendizagem (Guillette et al., 2015).

Os répteis também podem ser treinados, conforme indicam os resultados encontrados em um estudo realizado com píton (Python molurus bivitattus), os quais mostram que esses animais são capazes de responder a estímulos condicionados, exibem sensibilidade para discriminar estímulos e respondem às contingências de reforçamento de acordo com as bem estabelecidas teorias de aprendizagem (Emer et al. 2015).

A utilização do PRT para facilitar o manejo e procedimentos veterinários com animais em zoológicos vem aumentando na ultima década, mas ainda existem poucos estudos que avaliem o impacto do treinamento sobre o comportamento e bem-estar dos animais (Melfi, 2013), o que ainda torna incipiente o conhecimento dos efeitos dessa prática sobre o bemestar animal. Assim, levanta-se a questão sobre ser adequado o enquadramento desse tipo de técnica como enriquecimento ambiental, conforme proposto pela literatura clássica sobre o assunto (Shepherdson, 1998, Young, 2003).

Nesse sentido, Melfi (2013) apresenta cinco hipóteses, que podem analisar se o condicionamento pode ser considerado como enriquecimento ambiental:

1. O condicionamento oferece oportunidade de aprendizagem e essa é considerada uma forma de enriquecimento, sendo definida como uma mudança no comportamento, resultante de prática ou experiência, que quando é conduzida por um ser humano é chamada de treinamento (Mellen \& Ellis, 1996). A aprendizagem aparentemente está associada a outros benefícios, como o aumento de comportamentos exploratórios e a preferência por procurar pelo alimento, ou obtê-lo de maneiras mais trabalhosas, ainda 
que existam itens alimentares disponíveis, numa vasilha, por exemplo, como encontrou Vasconcelos (2009) em um teste de escolha realizado para lobos-guarás.

2. O condicionamento proporciona os mesmos resultados que o "enriquecimento ambiental convencional (EAC)", ou seja, atua provocando uma mudança positiva no comportamento do animal, mas as estratégias, ainda que obtenham resultados semelhantes, são bastante diferentes, o cenário do condicionamento possui pouca flexibilidade, controle e uma contingência artificial entre o comando e o comportamento, comparado ao enriquecimento ambiental convencional, no qual as respostas do animal ao estimulo ocorrem de acordo com uma contingência não imposta, determinada pelo seu comportamento, desempenhado de forma natural, Coleman \& Maier (2010) encontraram que o PRT em fêmeas adultas de macaco rhesus (Macaca mulatta) poderia atuar diminuindo a expressão de estereotipias, pelo menos a curto prazo, uma vez que a redução foi significativa no primeiro mês do experimento, mas não nos três meses subsequentes. Além disso, os resultados encontrados sugerem que o PRT pode ser mais eficiente para reduzir as estereotipias em alguns indivíduos do que em outros, um resultado semelhante ao encontrado em estudos com o EAC.

3. O condicionamento é um enriquecimento pois melhora a interação homem-animal, desde que se considere o pressuposto de que essa relação seja positiva para o animal, o condicionamento poderá ser considerado um enriquecimento, embora ainda existam poucos estudos sobre o assunto, é conhecido que o medo de pessoas pode retardar o processo de aprendizagem de animais em PRT, como registrado por Bassett e colaboradores (2003) que observou uma variação considerável na velocidade com a qual saguis aprendem a responder aos comandos, sendo o medo de pessoas um fator que retarda o processo. $\mathrm{O}$ tempo para que saguis realizassem os comandos de tocar o bastão variou entre 2 a 12 sessões, o que representa 20 minutos a 2 horas e para urinar a variação foi de 3 a 13 sessões, 30 minutos a 2 horas e 10 minutos.

4. O condicionamento provoca uma mudança dinâmica na rotina dos animais e, portanto, equipara-se a um enriquecimento ambiental. Nesse caso, é importante que se considerem dois pontos de vista: o primeiro é que existem inúmeros fatores de mudança, como o clima, captura, a interação com um inseto, por exemplo, o segundo é que mudanças na rotina não necessariamente serão beneficas, e os estudos apresentam, ainda, conclusões contraditórias sobre o que é melhor para o bem-estar dos animais, se um ambiente prevísivel ou imprevisível. De qualquer forma, o que vai 
fazer com que o PRT ofereça mudanças na rotina dos animais é o planejamento, uma vez que um programa de treinamento deve contar com objetivos bem definidos, responsabilidade, avaliação e aprimoramento do treino e preparação continua dos profissionais (Perlman, 2012).

5. O condicionamento facilita o uso dos EAC, pois a maioria das espécies pode ser treinada para entrar em áreas restritas, possibilitando o acesso dos profissionais ao recinto para colocação, manutenção ou retirada de itens de CEE, facilitando a prática. Bloomsmith (1998) treinou chimpanzés para entrarem voluntariamente em seus abrigos, observando que as fêmeas aprenderam em menos sessões, os machos adultos foram os animais que apresentaram o menor desempenho e, quando houve mudança de treinador, imediatamente após a troca houve um pequeno decréscimo na performance, mas que não se apresentou significativo no decorrer das sessões.

De acordo com essas hipóteses, fica evidente que o condicionamento pode sim ser enquadrado como enriquecimento ambiental, dependendo de como é planejado e aplicado, bem como dos resultados alcançados com os animais, e que são necessárias pesquisas com condicionamento para conhecer seu papel para os animais cativos e seu potencial enquanto enriquecimento ambiental (Melfi, 2013).

Em um estudo que investigou o efeito do PRT sobre o bem-estar de chimpanzés, foram observadas alterações comportamentais, consideradas benéficas, durante todo o dia, não somente nos procedimentos veterinários, diretamente relacionados ao treinamento. Também houve aumento nas interações sociais positivas entre os membros do grupo, entre os animais e seus tratadores, alem de redução de estresse e anormalidades. O bem-estar psicológico do grupo apresentou grande elevação, mas foram observadas profundas diferenças individuais, especialmente relacionadas à posição hierárquica de cada membro (Pomerantz, 2009).

\subsection{Condicionamento e Conservação}

A expressão de comportamentos naturais é importante para a conservação da espécie e fundamental para o bem-estar animal em cativeiro (Melfi \& Thomas, 2005). Os animais mantidos em cativeiro são importantes fontes de informação, como recursos para a pesquisa, e 
o conhecimento obtido através da observação e estudo de espécimes em cativeiro pode ser usado para promover a conservação, sendo os programas de reintrodução uma ajuda para espécies ameaçadas de extinção (Kohn, 1994).

Frankham et al. (1986) sugerem que o treinamento de primatas não humanos acelera sua “domesticação", resultando em decréscimo da expressão de comportamentos naturais, o que traz implicações negativas para a conservação e bem-estar dos animais, o que sugere a necessidade de estudos que investiguem as implicações do PRT sobre o comportamento dos animais fora das sessões de treino, buscando responder se existe diminuição nos comportamentos naturais. Alguns comportamentos anormais estão relacionados ao ambiente inadequado, são percebidos negativamente pelo publico e podem indicar mudanças psicológicas que impeçam o sucesso desses animais em uma reintrodução (Mason et al., 2007).

Por essa razão, Melfi \& Thomas (2005) realizaram um estudo com macacos colobos, no qual analisaram o padrão comportamental dos animais antes do treino e por três meses após treino. Os resultados mostraram que os comportamentos sociais, proximidade entre os animais e atividade não foram afetados pelo treino. Os comportamentos de aproximação com humanos, ao contrário das expectativas, sofreram redução, em relação ao público, à equipe e inclusive ao cuidador, que realiza os treinamentos. Essa diminuição ocorreu possivelmente em razão do aumento na previsibilidade, ou seja, os animais passaram a reconhecer quando seriam recompensados, dessa forma, deixaram de se aproximar sempre que o cuidador estivesse próximo. Essa redução foi considerada benéfica, especialmente ao se considerar que a interação com humanos, principalmente com o público, pode estar associada a baixo-bemestar de primatas (Hosey, 2000). Assim, os autores concluíram que o condicionamento não foi considerado prejudicial à conservação da espécie.

A respeito dos efeitos da previsibilidade para os animais cativos existem posicionamentos divergentes, possivelmente em virtude da variação existente nos objetivos e forma de condução dos estudos sobre o assunto. A previsibilidade pode ser temporal, quando determinado evento ocorre sempre no mesmo horário ou pode estar relacionada a sinais que sempre antecedem determinado evento, independendo do horário em que ele ocorra (Basset \& Buchanan-Smith, 2007).

A maioria dos estudos que buscam verificar os efeitos da previsibilidade se baseia na utilização de reforço negativo, com testes que incluem choques, com o diferencial de possuir ou não um evento que sinaliza aos animais sobre sua ocorrência. De acordo com alguns estudos, os choques não sinalizados são mais estressantes em estudos a curto prazo, e menos 
estressantes em estudos longos. Nos estudos curtos os choques provocam excitação e uma possível exaustão psicológica, enquanto os intervalos entre os choques, quando eles são sinalizados, atuam como um período seguro, diminuindo o estresse. Nos estudos longos, a falta de adaptação aos choques, ainda que previsíveis, acaba levando à exaustão, o que não ocorre em animais já adaptados à ameaça constante de choque, quando não são sinalizados. Para outros autores, não existe essa diferenciação entre curto e longo prazo, e os choques são mais aversivos quando há imprevisibilidade. Além disso, quando se trata dos comportamentos relacionados à alimentação, diminuir a previsibilidade sobre a forma com que o alimento é oferecido, alterando itens, local e maneira de disponibilizá-lo eleva a expressão de comportamentos naturais, como os exploratórios e manipulativos, sugerindo que nesses casos a falta de previsibilidade é benéfica para o bem-estar dos animais. (Basset \& BuchananSmith, 2007)

Assim como encontrado por Melfi \& Thomas (2005), o PRT pode elevar a previsibilidade, uma vez que desenvolve a habilidade do animal de aprender sobre as consequências de suas ações e, portanto, como agir para controlar esses eventos, sendo assim tem potencial para elevar o bem-estar animal (Basset \& Buchanan-Smith, 2007)

É necessário, segundo Frankham et al. (1986), que se considere os propósitos da manutenção de cada espécie em cativeiro, bem como sua destinação. Os animais cujo objetivo seja a reintrodução devem ser mantidos com o menor contato possível com seres humanos, sendo nesses casos, não recomendado o PRT. Para os animais que não serão reintegrados ao ambiente natural, ainda que façam parte de programas de reprodução em cativeiro, a utilização de estratégias que aumentem sua adaptação à condição de cativo e minimizem o estresse do cativeiro, são altamente recomendáveis, como o enriquecimento ambiental e o PRT.

\subsection{Referente à espécie estudada: onça-pintada}

A espécie ocorre das planícies costeiras do México ao norte da Argentina, tendo sido extinta nos Estados Unidos. Ocorre em todos os biomas brasileiros, mas exige, como hábitat básico, áreas com alto grau de conservação, grande suprimento de presas e suprimento de água abundante. É o maior felídeo do continente americano, podendo medir entre 188,2 a $207,0 \mathrm{~cm}$ e pesar entre 61 a $158 \mathrm{~kg}$. Indivíduos que vivem em áreas abertas parecem ser 
maiores do que aqueles que vivem em áreas fechadas, possivelmente em virtude de uma maior disponibilidade de alimento nesses ambientes. A coloração é amarelada com pintas pretas na cabeça, pescoço e patas, essas pintas formam rosetas nos ombros, flancos e costas. Não são raros indivíduos melânicos, nos quais as rosetas podem ser observadas quando em contraste com a luz. De hábitos predominantemente noturnos e terrestres são hábeis escaladores e nadadores (Reis et al., 2010).

Quanto à escolha do hábitat, preferem áreas de vegetação densa e florestas primárias, evitando áreas ocupadas por humanos e pastagens abertas (Cullen Junior et al., 2013). A dieta é composta principalmente por vertebrados de médio e grande porte, como antas, capivaras, catetos, queixadas, veados, pacas, tamanduás-bandeira e jacarés. Existem relatos de predação de preguiças, cágados (Salera-Jr et al., 2009) e peixes. A área de vida dos machos pode chegar a $158 \mathrm{~km}^{2}$, na qual são sobrepostas várias áreas de fêmeas. A espécie está na Lista da Fauna Brasileira Ameaçada de Extinção (Reis et al., 2010).

A longo prazo, as maiores ameaças a espécie têm sido a fragmentação de habitats, pois as áreas de ocupação humana impedem a dispersão dos indivíduos, fazendo com que cada fragmento isolado contenha uma população pequena que já sofre os efeitos da deriva genética (Haag, 2010) e a caça ilegal, que ocorre em razão das onças predarem o gado de fazendas, também como prática desportiva (Rosas-Rosas \& Valdez, 2010) e inclusive em áreas protegidas (Carvalho Jr. \& Morato, 2013). No Cerrado, a ameaça está relacionada ao crescimento do agronegócio, que leva a perda do habitat, especialmente para monoculturas de soja, e à redução da capacidade de suporte do ambiente, uma vez que as presas potenciais também têm sofrido reduções consideráveis com a degradação do habitat e com a caça (MMA, 2010).

Apesar da ameaça sofrida pela espécie, um estudo realizado por Ruiz-Garcia et al. (2006) com 84 animais, de populações da Colômbia, Guatemala, Paraguai, Peru, Bolívia, Venezuela e Brasil, analisou sua estrutura genética, por meio de 12 microsatelites, e os resultados encontrados sugerem que a conectividade dessas populações, em termos gênicos, se mantinha intacta no inicio dos anos 2000.

Petracca et al. (2013) avaliaram a utilização de corredores ecológicos por onças pintadas e embora tenham encontrado registros da utilização dessas áreas pelos animais, a presença de invasões agrícolas foi um fator limitante para essa utilização, reforçando a importância da gestão dessas áreas, não apenas sua criação.

A preservação dos habitats e o controle da caça são fundamentais para a conservação in situ de onças e a manutenção de uma população em instituições zoológicas é importante 
para a conservação ex situ, mantendo o recurso genético e, ainda, atuando na sensibilização do público quanto à importância ecológica da espécie (Conforti et al., 2011).

Em felinos cativos, em situação de estresse crônico em cativeiro, Carlstead (1993) observou redução nos comportamentos exploratórios, aumento da reação de alerta e grande permanência em repouso ou em esconderijos. Possivelmente pelo fato de que os carnívoros desenvolveriam mais comportamentos anormais em cativeiro, especialmente o pacing (Mason et al. 2007), derivado da frustração de não desempenhar os comportamentos de caça, como a procura pela presa e sua captura. (Mason \& Mendl, 1997)

Para onça-pintada uma revisão realizada por Clubb \& Mason (2007) registrou 3 sites com dados de comportamento estereotipado e 8 artigos, totalizando 9 individuos com estereotipias. O tempo de atividade encontrado para a espécie em cativeiro foi de $54,30 \%$ do dia (Clubb \& Mason, 2007).

Em estudo conduzido por Castro (2009) com as onças do Criadouro Conservacionista No extinction "Nex", o comportamento pacing foi observado, no entanto, ocorria com a aproximação do observador, indicando uma possível interação causal entre esses fatos.

O primeiro estudo publicado sobre cortisol salivar em onças foi realizado em 2009, comparando os níveis desse glicocorticóide em onças cativas no Jardim Zoológico de Brasília e no Nex, com resultados médios de $6 \mu \mathrm{g} / \mathrm{dl}$ para o primeiro grupo e $1 \mu \mathrm{g} / \mathrm{dl}$ para o segundo (Montanha et al., 2009).

Montanha et al. (2011) encontraram diminuição nos níveis de cortisol com aplicação de enriquecimento ambiental para as onças pintadas no Nex, com valores médios de 365,78 $\mathrm{nmol} / \mathrm{L}(13 \mu \mathrm{g} / \mathrm{dL})$ para os valores basais, $153,75 \mathrm{nmol} / \mathrm{L}(5,5 \mu \mathrm{g} / \mathrm{dL})$ e $148,78 \mathrm{nmol} / \mathrm{L}(5,4$ $\mu \mathrm{g} / \mathrm{dL}$ ) para imediatamente e bem após os enriquecimentos, respectivamente. Um outro estudo, com coletas de sangue após anestesia, analisou o sangue de 8 onças pintadas e o valor médio foi de $166 \mathrm{nmol} / \mathrm{L}$, ou $6 \mu \mathrm{g} / \mathrm{dL}$ (Nogueira, 1997).

A utilização dos metabólitos fecais para avaliação da atividade adrenal foi registrada, mostrando-se adequada para a espécie a partir de estudo que comparou os dados extraídos dessas amostras com análises do plasma sanguíneo, coletado mediante anestesia. O mesmo estudo encontrou elevação significativa da concentração de cortisol apos a realização de anestesia e eletroejaculação (Morato et al., 2004). 


\section{REFERÊNCIAS}

ACCO, A.; PACHALY, J.R.; BACILA, M.. Síndrome do Estresse em Animais - revisão. Arquivos de Ciências Veterinárias e Zoologia da UNIPAR, v. 2, n. 1, p. 71-76, 2009.

ALTMANN, J.. Observational study of behavior: sampling methods. Behaviour v. 49, p. 227-265, 2973.

ANDRIOLO, A. Desafios para a conservação da fauna. In: CUBAS, Z.S., SILVA J.C.R.; CATÃO-DIAS J.L. (Eds.) Tratado de Animais Selvagens - Medicina Veterinária. São Paulo: Roca. 2007, p. 19-25.

BARNOSKI, A.D.; MATZKE, N.; TOMIYA, S.; WOGAN, G.O.U.; SWARTZ, B.; QUENTAL, T.B.; MARSHALL, C.; MCGUIRE, J.L.; LINDSEY, E.L.; MAGUIRE, K.C.; MERSEY, B.; FERRER, E.A.. Has the Earth's sixth mass extinction already arrived? Nature, v. 471, p. 51-57, 2011.

BASSETT, L.; BUCHANAN-SMITH, H.M.; MCKINLEY, J.; SMITH T.E.. Effects of training on stress-related behavior of the common marmoset (Callithrix jacchus) in relation to coping with routine husbandry procedures. Journal of Applied Animal Welfare Science, v.6, n.3, p. 209-220, 2003.

BLOOMSMITH M.A.; LAULE G.E.; ALFORD P.L.; THURSTON R.H.. Using training to moderate chimpanzee aggression during feeding. Zoo Biology, v. 13, n.6, p. 557-566, 1994.

BLOOMSMITH, M.A.; STONE, A.M.; LAULE, G.E.. Positive Reinforcement Training to Enhance the Voluntary Movement of Group-housed Chimpanzees Within Their Enclosures Zoo Biology, v. 17, n. 4, p. 333-341, 1998.

BRANCO, A.M. Ética e Legislação. In: CUBAS, Z.S., SILVA J.C.R.; CATÃO-DIAS J.L. (Eds.) Tratado de Animais Selvagens - Medicina Veterinária. São Paulo: Roca. 2007, p. 214.

BRANDO, A.I.C.A. Animal learning and training: implications for animal welfare. The Veterinary Clinics of North America Exotic Practice, v.15, n.3, p. 387-398, 2012.

BROOM, D.M. Animal welfare: concepts and measurement, Journal of Animal Science, v.69, n.10, p. 4167-4175, 1991. 
BROOM, D.M.; MOLENTO, C.F.M.. Bem-Estar Animal: conceitos e questões relacionadas revisão. Archives of Veterinary Science, v. 9, n. 2, p. 1-11, 2004.

CARLSTEAD, K.; BROWN J.L.; STRAWN, W.. Behavioral and physiological correlates of stress in laboratory cats. Applied Animal Behavior Science, v. 38, n.2, p.143-158, 1993 a.

CARVALHO JR, E. A. R C.; MORATO, R. G.. Factors affecting big cat hunting in Brazilian protected areas. Tropical Conservation Science, v. 6, n. 2, p. 303-310, 2013.

CASSANO, C. R. Ecologia e conservação da preguiça-de-coleira (Bradypus torquatus Illiger, 1811) no sul da Bahia. Ilhéus, BA. Bahia: Programa de Pós-Graduação em Zoologia da Universidade Estadual de Santa Cruz, 2006. 127p. Dissertação (Mestrado em Zoologia) Programa de Pós-Graduação em Zoologia da Universidade Estadual de Santa Cruz, 2006.

CASTELLON, M.F.L.F.; GIMPEL, J.; BUSTOS, C.; ZAPATA, B.. (2012). Indicadores de bem-estar em grandes felinos. In: XXX ENCONTRO ANUAL DE ETOLOGIA, 30., 2012, Ribeirão Preto. Anais do XXX Encontro Anual de Etologia, SBET, 2012.

CLUBB, R.; MASON, G.J.. Natural behavioural biology as a risk factor in carnivore welfare: How analysing species differences could help zoos improve enclosures. Applied Animal Behaviour Science, v. 102, n.3-4, p.303-328, 2007.

COLEMAN, K.; MAIER, A.. The use of positive reinforcement training to reduce stereotypic behavior in rhesus macaques. Applied Animal Behaviour Science, v. 124, n.3-4, p. 142-148, 2010 .

CONFORTI V.A; MORATO, R.G.; AUGUSTO, A.M.; SOUSA, L.O.; AVILLA, D.M. BROWN, J.L, REEVES, J.J.. Noninvasive Monitoring of Adrenocortical Function in Captive Jaguars (Panthera onca). Zoo Biology v. 31, n. 4, p. 426-441, 2011.

COOKE, P.S.; HOLSBERGER, D.R., WITORSCH, R.J., SYLVESTER, P.W., MEREDITH, J.M., TREINEN, K.A.. Thyroid hormone, glucocorticoids, and prolactin at the nexus of physiology, reproduction, and toxicology. Toxicology and Applied Pharmacology, v. 194, n. 3, p. 309-335, 2004.

CULLEN JUNIOR, L.C.; SANA, D.A.; LIMA F.; ABREU. K.C.; UEZU. A.. Selection of habitat by the jaguar, Panthera onca (Carnivora: Felidae), in the upper Paraná River, Brazil. Zoologia, v. 30 n. 4, p. 379-387, 2013.

DIRZO, R.; RAVEN, P.H.. Global state of biodiversity and loss. Annual Review Environment Resources, v. 28, p. 137-167, 2003.

DEL CLARO, K. Comportamento Animal: Uma introdução à ecologia comportamental. Editora Livraria Conceito: Jundiaí - SP,. 2004. 132p.

DE BOER, S.F.; KOOPMANS, S.J.; SLANGEN, J.L.; VAN DER GUGTEN, J.. Plasma Catecholamine, Corticosterone and Glucose Responses to Repeated Stress in Rats: Effect of Interstressor Interval Length. Physiology \& Behavior, v. 47, n. 6, p. 1117-1124, 1990.

EMER, S.A.; MORA, C.V.; HARVEY, M.T.; GRACE, M.S.. Predators in training: operant 
conditioning of novel behavior in wild Burmese pythons (Python molurus bivitattus). Animal Cognition, v. 18, n. 1, p. 269-278, 2015.

FAIRHURST, G.D.; FREY M.D.; REICHERT, J.F.; SZELEST, I.; KELLY, D.M.; BORTOLOTTI G.R.. Does environmental enrichment reduce stress? An integrate measure of corticoesterone from feathers provides a novel perspective. Plos one, v.6, n.3. p. 1-10, 2011.

FRANKHAM, R.; HEMMER, H.; RYDER, O.A.; COTHRAN, E.G.; SOULÉ, M.E.; MURRAY, N.D.; SNYDER, M.. Selection in captive populations. Zoo Biology, v.5, n.2, p. 127-138, 1986.

GAGLIANO H.; FUENTES S.; NADAL R.; ARMARIO A.. Previous exposure to immobilisation and repeated exposure to a novel environment demonstrate a marked dissociation between behavioral and pituitary-adrenal responses. Behavioural Brain Research, v. 187, n. 2, p. 239-245, 2008.

GRAY J.M.; CHAOULOFF F.; AND HILL M.N.. To Stress or Not to Stress: A Question of Models. Current Protocols in Neuroscience, v.70, p. 8.33.1-8.33.22, 2015.

GUILLETTE, L.M.; HAHN, A.H.; HOESCHELE, M.; PRZYSLUPSKI, A; STURDY, C.B; Individual differences in learning speed, performance accuracy and exploratory behaviour in black-capped chickadees. Animal Cognition, v.18, p.165-178, 2015.

GUYTON, A.C.; HALL, J.E.. Introdução à endocrinologia. In: Tratado de fisiologia médica: Rio de Janeiro: Elsevier. 2006. p.905-917.

HAAG T.; SANTOS A.S.; SANA D.A.; MORATO R.G.; CULLEN L.JR.; CRAWSHAW P.G. JR.; DE ANGELO C, DI BITETTI M.S.; SALZANO F.M.; EIZIRIK E.. The effect of habitat fragmentation on the genetic structure of a top predator: loss of diversity and high differentiation among remnant populations of Atlantic Forest jaguars (Panthera onca). Molecular Ecology, v.19, n.22, p. 4906-4921, 2010.

HEIDENREICH, B.. An Introduction to Positive Reinforcement Training and Its Benefits. Journal of Exotic Pet Medicine, v. 16, n. 1, p. 19-23, 2007.

HENNESSY MB. Sensitization of the plasma corticosterone response to novel environments. Physiology \& Behaviour, v. 50, p. 1175-1179, 1991.

HOSEY, G.R.. Zoo animals and their human audiences: What is the visitor effect? Animal Welfare, v.9, n. 4, p. 343-357, 2000.

IBAMA, Portaria n.139 de 29 de novembro de 1993. Diário Oficial da República Federativa do Brasil, Poder Executivo, Brasília, DF, 31 dez. 1993. Seção I, pág. 21541.

IUCN 2013. IUCN Red List of Threatened Species. Version 2013.2. $<$ www.iucnredlist.org $>$. Downloaded on 29 April 2014.

IUDZ (The world zôo organization) - CBSG The captive breeding specialist group, 1993. The world Zoo Conservation Strategy: The Role of the zoos and aquaria of the world in Global Conservation, Chicago Zoological Society USA.1993. 
JENNY, S.; SCHMID, H. (2002). Effect of feeding boxes on the behaviour of stereotyping Amur tigers (Panthera tigris altaica) in the Zurich Zoo, Zurich, Switzerland. Zoo Biology, v. 21, n.6, p. 573-584, 2002.

KISTLER, C.; HEGGLIN, D.; WÜRBEL, H.; KÖNIG, B.. Feeding enrichment in an opportunistic carnivore: The red fox. Applied Animal Behaviour Science, v.116, n. 2-4, p. 260-265, 2009.

KOHN, B. (1994). Zoo animal welfare. Revue scientifique et technique (International Office of Epizootics), v.13, n. 1, p. 233-245, 1994.

LAMBETH, S.P.; HAU, J., PERLMAN, J.E.; MARTINO, M.; SCHAPIRO, S.J.. Positive reinforcement training affects hematologic and serum chemistry values in captive chimpanzees (Pan troglodytes). American Journal of Primatology, v. 68, n.3, p. 245-256, 2006.

LAULE, G.; DESMOND T.. (1998). Positive reinforcment training as an enrichment strategy. In: D. J. Shepherdson, J. D. Mellen \& M. Hutchins (Orgs.) 1998. Second Nature: environmental enrichment for captive animals. Washington: Smithsonian Institution Press. 302-313.

LE MAHO Y.; KARMANN H.; BRIOT D.; HANDRICH Y.; ROBIN J.P.; MIOSKOWSKI, E.; CHEREL, Y.; FARNI, F.. Stress in birds due to routine handling and a technique to avoid it. The American Journal of Physiology, v. 263, n. 4, p. R775-R781, 1992.

MARKOWITZ, H.; ADAY, C.; GAVAZZI, A.. Effectiveness of acoustic prey-environmental enrichment for a captive African leopard (Panthera pardus). Zoo Biology, v. 14, n. 4 371379, 1995.

MARKOWITZ, H.; LAFORSE, S.. Artificial prey as Behavioral enrichment devices for felines. Applied Animal Behaviour Science, v. 18, n. 1, p. 31-43, 1987.

MASON, G.J.. Stereotypies a critical review. Animal Behaviour, v. 41, v.6, p. 1015-1038, 1991.

MASON, G.J.; LATHAM, N.R.. Can't stop, won't stop: is stereotypy a reliable animal welfare indicator, Animal Welfare, v. 13, n.12, p. S57-S69, 2004.

MASON, G.; CLUBB R.; LATHAM, R.; VICKERY S.. Why and how should we use environmental enrichment to tackle stereotypic behaviour? Applied Animal Behaviour Science, v. 102, p. 163-188, 2007.

MELLEN, J.D. AND ELLIS, S. Animal learning and husbandry training. In: KLEINMAN, D.G., ALLEN, M.E., THOMPSON, K.V., LUMPKIN, S., AND HARRIS, H. (Eds). Wild Mammals in Captivity: Principles and Techniques. Chicago: University of Chicago Press, 1996. p. 88-99.

MELFI, V.. Is training zoo animals enriching? Applied Animal Behaviour Science. v. 147, n. 3-4, p. 299-305, 2013. 
MELFI V. A.; THOMAS S.. Can training zoo-housed primates compromise their conservation? A case study using Abyssinian colobus monkeys (Colobus guereza), Anthrozoös, v. 18, n. 3 p. 304-317, 2005.

MINIER, D.E.; TATUM, L.; GOTTLIEB D.H.; CAMERON, A.; SNARR, J.; ELLIOT, R.; COOK, A.; ELLIOT, K.; BANTA, K.; HEAGERTY, A.; MCCOWAN, B.L.. Human-directed contra-aggression training using positive reinforcement with single and multiple trainers for indoor-housed rhesus macaque, Applied Animal Behaviour Science, v.132, n.3-4, p. 178186, 2011.

MMA. 2010. Sumário executivo do plano de ação nacional para conservação da onça pintada. Disponível em $<$ http://www.icmbio.gov.br/portal/biodiversidade/faunabrasileira/plano-de-acao/1344-plano-de-acao-para-conservacao-da-onca-pintada.html> Acesso em 20/07/2013.

MOBERG, G.P. Biological response to stress: implications for animal welfare. In: MOBERG, G.P.; MENCH, J. A. (Ed.) The biology of animal stress. New York: CABI Publishing, 2000. p. 123-146.

MONTANHA, J. C.; SILVA, S. L.; BOERE, V.. Comparison of salivary cortisol concentrations in Jaguars kept in captivity with differences in exposure to the public. Ciência Rural, v. 39, n. 6, p. 1745-7451, 2009.

MORATO, R.G.; BUENO, M.G.; MALMHEISTER, P.; VERRESCHI, I.T.N.; BARNABE, R.C.. Changes in the fecal concentrations of cortisol and androgen metabolites in captive male jaguars (Panthera onca) in response to stress. Brazilian Journal of Medical and Biological Research, v. 37, n. 12, p. 1903-1907, 2004.

MÖSTL, E.; PALME, R.. Hormones as indicators of stress. Domestic Animal Endocrinology, v.23, n.1-2, p. 67-74, 2002.

MUNCK, A.; GUYRE, P. M.; HOLBROOK, N. I.. Physiological functions of glucocorticoids in stress and their relationship to pharmacological actions. Endocrinology Reviews, v. 5, n. 1, p. 25-44, 1984.

NOGUEIRA, G.P.; SILVA, J.C.. Plasma cortisol levels in captive wild felines after chemical restraint, Brazilian Journal of Medical and Biological Research, v.30, n.11, p.1359-1361, 1997.

NEX (2013) Quem somos. Disponível em < http://www.nex.org.br> Acesso em 18/07/2013.

PERLMAN, J.E.; BLOOMSMITH, M. A.; WHITTAKER, M. A.; MCMILLAN, J.L.; MINIER, D.E.; MCCOWAN, B.. Implementing positive reinforcement animal training programs at primate laboratories. Applied Animal Behaviour Science, v. 137, n. 3-4 114$126,2012$.

PETRACCA, L.S.; HERNÁNDEZ-POTOSME, S.; OBANDO-SAMPSON, L.; SALOMPÉREZ,R.; QUIGLEY, H.; ROBINSON, H.S.. Agricultural encroachment and lack of enforcment threaten connectivity of range-wide jaguar (Panthera onca) corridor. Journal for 
Nature Conservation, v. 22, n. 5, p. 436-444, 2014.

PIROVINO, M.; HEISTERMANN, M.; ZIMMERMANN, N; ZINNG, R.; CLAUSS, M.; CODRON, D.; KAUP, F.; STEINMETZ, H.W.. Fecal Glucocorticoid Measurements and Their Relation to Rearing, Behavior,and Environmental Factors in the Populationof Pileated Gibbons (Hylobatespileatus) Held in European Zoos. International Journal of Primatology, v.32, n.5, p. 1161-1178, 2011.

POMERANTZ, O.; TERKEL, J.; 2009. Effects of positive reinforcement training techniques on the psychological welfare of zoo-housed chimpanzes (Pan troglodytes). American Journal of Primatology, v.71, n. 8, p. 687-695.

PRADO, A.M.; VASCONCELLOS, A.S..; ADES, C. (2007). Behavioral enrichment reduces stereotypic pacing in maned wolves (Chrysocyon brachyurus). Proceedings of the Eighth International Conference on Environmental Enrichment (pp. 311-312). San Diego, CA.

PRYOR, K. Don't shoot the dog!: The New Art of Teaching and training. Gloucestershire, Ringpress Books Ltd, 2002, 202p.

REIS, N.R.; PERACCHI, A.L.; PEDRO, W.A.; LIMA I. P.. Mamíferos do Brasil. Technical Books: Londrina., 2010, 439p.

ROSAS-ROSAS, O.C.; VALDEZ R.. The role of landowners in jaguar conservation in Sonora, México. Conservation Biology v. 24, n. 2 p. 366-371, 2010.

RUIZ-GARCIA, M.; PAYÁN, E.; MURILlO, A.; ALVAREZ, D.. DNA microsatellite characterization of the jaguar (Panthera onca) in Colombia. Genes and Genet Systems, v. 81, p. 115-127, 2006.

SALERA-JR., G.; PORTELINHA, T.C.G.; MALVASIO, A.. Predação de fêmeas adultas de Podocnemis expansa Schweigger (Testudines, Podocnemididae) por Panthera onca Linnaeus (Carnivora, Felidae), no Estado do Tocantins, Biota Neotropica, v. 9, n. 3, p. 387-391, 2009.

SAPOLSKY, R. Endocrinology of the Stress-response. In: J. B. BECKER, S. M. BREEDLOVE; D. CREWS; MCCARTHY, M.M. (Eds.) Behavioral Endocrinology. 2ed. London: Cambridge, 2002. p.409-450.

SAUDARGAS, R. A.; DRUMMER, L. C.. Single subject (small n) research designs and zoo research. Zoo Biology, v.15, p. 173-181, 1996.

SAS Institute. SAS statistical package for Windows v. 8.0. SAS Institute, Cary, NC, 1999.

SCHAPIRO, S.; PERLMAN, J.E.; BOUDREAU, B.A.. Manipulating the Affiliative Interactions of Group-Housed Rhesus Macaques Using Positive Reinforcement Training Techniques. American Journal of Primatology, v.55, n. 3, p. 137-149, 2001.

SCHETINI C.A.; C., CIPRESTE, C.F.; YOUNG, R.J.. Environmental enrichment: a GAP analysis, Applied Animal Behaviour Science, v.102, n.3-4, p. 329-343, 2007.

SCHWARZENBERGER, F.. The many uses of non-invasive faecal steroid monitoring in zoo 
and wild life species, International ZooYearbook, v.41, n. 1, p. 52-74, 2007.

SHEPHERDSON, D. J. Tracing the path of enviromental enrichment in zoos. In: D. J. SHEPHERDSON, D.; MELLEN, J.; HUTCHINS, M. (Eds.) Second Nature: environmental enrichment for captive animals, Washington: Smithsonian Institution Press, 1998. p.01-12.

SILVA, C.R.S.; ADANIA, C.H. Carnívora - Felidae (Onça, Suçuarana, Jaguatirica, Gato-domato). In: CUBAS, Z.S.; SILVA J.C.R.; CATÃO-DIAS J.L. Tratado de Animais Selvagens - Medicina Veterinária. Editora Roca. São Paulo, 2007. p.505-546.

SILVA, Rodrigo Oliveira (2011). Enriquecimento ambiental cognitivo e sensorial para onças-pintadas (Panthera onca) sedentárias em cativeiro induzindo redução de níveis de cortisol promovendo bem-estar. Brasília: Instituto de Psicologia da Universidade de Brasília, 2011. 58p. Dissertação (Mestrado em Ciências do Comportamento) - Departamento de Processos Psicológicos Básicos, Instituto de psicologia da Universidade de Brasília, 2011.

SKINNER, B. F. Sobre o Behaviorismo. São Paulo: Editora Cultrix, 1974, 209p.

SOULÉ M.. What is Conservation Biology?, Bioscience, v.35, n.11, p. 727-734, 1985.

STRYER, L. Biossíntese de lipídeos de membrana e esteróides. In: Bioquímica, Rio de Janeiro: Guanabara Koogan, 1996, p.651-678.

SUNQUIST, M.E.; SUNQUIST, F. Wild cats of the world. Ed. University of Chicago Press: Chicago, 2002, 462p.

SWAISGOOD, R.R.; SHEPHERDSON, D.J.. Scientific approaches to enrichment and stereotypies in zoo animals: What's been done and where should we go next? Zoo Biology, v. 24, n. 6, p. 499-518, 2005.

TEIXEIRA, P.T.; PADUA, J.T.. Avaliaçao dos níveis de cortisol, tiroxina, triiodotironina e glicose como indicativos de estresse em cavalos puro sangue ingles de corrida, antes e após a competição. Ciência Animal Brasileira, v.3, n.1, p. 39-48, 2002.

TOUMA, C., PALME R.; SASCHER, N.. Analyzing corticosterone metabolites in fecal samples of mice: a noninvasive technique to monitor stress hormones. Hormones and behavior, v. 45, n.1, p. 10-22, 2004.

TOUMA, C.; PALME, R. Measuring Fecal Glucocorticoid Metabolites in Mammals and Birds: The Importance of Validation. Annals of the New York Academy of Sciences, v.1046, n.1, p. 54-74, 2005.

TYE, K.M.; STUBER, G.D; RIDDER, B.D.; BONCI, A.; JANAK, P.H.. Rapid strengthening of thalamo-amygdala synapses mediates cue-reward learning, Nature, v.453, n. 7199, p. 1253-1256, 2008.

UFAW - Universities Federation For Animal Welfare. (1997). Guia para o enriquecimento das condições ambientais do cativeiro (S. Celotti, Trad.). Sociedade Zoófila Educativa. São Paulo. 
UMEDA, T.; HIRAMATSU, R.; IWAOKA, T.; SHIMADA, T.; MIURA, F.; SATO, T.. Use of saliva for monitoring unbound free cortisol levels in serum. Clinica Chimica Acta, v. 110, n.1-2, p. 245-253, 1981.

VASCONCELLOS, A.S.; ADANIA, C.H.; ADES, C.; Contrafreeloading in maned wolves: implications for their management and welfare. Applied Animal Behaviour Science, v.140 n.1-2, p.85-91, 2012.

VASCONCELlOS, A.S.; VIRÁNYIL, Z.; RANGE, F.; MOSTL, E.; ADES, C.; KOTRSCHAL, K.. Social interactions and non-invasive stress monitoring in captive timber wolves (Canis lupus). Journal of Veterinary Behavior; Clinical Applications and Research, v. 6, n. 1, p. 71-72, 2011.

VASCONCELLOS, Angélica da Silva. O estímulo ao forrageamento como fator de enriquecimento ambiental para lobos guarás: efeitos comportamentais e hormonais. São Paulo: Instituto de Psicologia da Universidade de São Paulo, 2009. 137p. Tese (Doutorado em Psicologia Experimental) - Instituto de Psicologia da Universidade de São Paulo, 2009.

VEEDER, C.L.; BLOOMSMITH, M.A.; MCMILLAN, J.L.; PERLMAN, J.E.; MARTIN, A.L.. Positive Reinforcement Training to Enhance the Voluntary Movement of GroupHoused Sooty Mangabeys (Cercocebus atys atys). Journal of the American Association for Laboratory Animal Science, v. 48, n. 2, p.192-195, 2009.

WELLS, D.L.; IRWIN, R.M.. Auditory stimulation as enrichment for zoo-housed Asina Elephants (Elephas maximus). Animal Welfare, 17, n.4 p. 335-340, 2008.

WINGFIELD J.C.; KITAYSKY A.S.. Endocrine responses to unpredictable environmental events: Stress or anti-stress hormones? Integrative e Comparative Biology v. 42, n.3, p. 600-609, 2002.

YOUNG, R. J. Environmental enrichment for captive animals. Ed. Blackwell Science: Oxford, 2003. 228p. 
CAPÍTULO 2

EFEITOS DO CONDICIONAMENTO SOBRE O BEM-ESTAR DE ONÇAS PINTADAS (Panthera onca) EM CATIVEIRO 


\title{
RESUMO
}

\section{EFEITOS DO CONDICIONAMENTO SOBRE O BEM-ESTAR DE ONÇAS PINTADAS (Panthera onca) EM CATIVEIRO}

\author{
Liane Cristina Ferez Garcia, MSc. \\ Francisco Ernesto Moreno Bernal, Prof. Dr. \\ Brasília, DF.
}

A onça pintada é o maior felino das Américas e diante da ameaça de extinção e da redução das áreas naturais, manter a espécie em cativeiro pode ser importante para sua conservação. Sabe-se que essa condição pode ter como consequência a redução no bem-estar desses animais, especialmente devido à limitação espacial e carência de estímulos ambientais. Nesse sentido, nas últimas décadas têm sido buscadas técnicas para minimizar os impactos negativos do cativeiro, entre as quais se destaca o enriquecimento ambiental, com crescimento da utilização de técnicas de condicionamento operante no intuito de facilitar procedimentos de rotina do manejo dos animais. Nesse cenário, o presente estudo teve por finalidade avaliar os efeitos do condicionamento sobre o bem-estar de onças-pintadas em cativeiro, analisando parâmetros comportamentais e fisiológicos. O estudo foi conduzido com sete onças-pintadas do criadouro conservacionista No Extinction. Os dados foram coletados entre os meses de agosto a outubro de 2013 (fase I), com repetição nos mesmos meses de 2014 (fase II). Foram realizadas observações comportamentais e coletas de saliva para mensuração de cortisol em quatro tratamentos, compostos por três repetições: linha de base (LB), controle (CT), condicionamento (CD) e pós condicionamento (PC). De acordo com as observações comportamentais, na primeira fase, atividade, inatividade e estresse não apresentaram diferença significativa entre os tratamentos, com observações apenas para os comportamentos de bem-estar animal $(P=0,0284)$, que também apresentaram diferença na segunda fase $(P=0,0004)$, assim como, para parâmetros como atividade $(P<0,0001)$ e inatividade 
$(P<0,0001)$. Para o cortisol, na fase I não houve diferença significativa entre os três tratamentos. Na fase II o modelo apresentou diferença $(P<0,0001)$, aumentando nos tratamentos CD e PC. A elevação do cortisol apresentou correlação positiva com os comportamentos de bem-estar, e a concentração do esteróide diminuiu no pós treino, indicando que o estresse fisiológico gerado pelo condicionamento tenha sido pontual e possivelmente positivo. Sugere-se que os efeitos do condicionamento sejam estudados também a longo prazo, mas os comportamentos associados ao bem-estar animal apresentados indicam que o condicionamento pode atuar melhorando a qualidade de vida dos animais cativos.

Palavras-chave: bem-estar, treinamento, felinos sul-americanos, recintos, cortisol. 


\author{
ABSTRACT \\ EFFECTS OF CONDITIONING ON THE WELFARE OF JAGUAR (Panthera onca) \\ IN CAPTIVITY \\ Liane Cristina Ferez Garcia, MSc. \\ Franscisco Ernesto Moreno Bernal, Prof. Dr. \\ Brasília, DF.
}

The Brazilian jaguar is Americas' largest cat and faced with the threat of extinction and to keeping animals in captivity is an important tool for the conservation. It is well known that the captivity can have drastic consequences on the welfare of animals, especially due to space limitations and lack of environmental stimulation. In recent decades, techniques have been considered to minimize the negative impacts of captivity, among which stands out the environmental enrichment and operant conditioning in order to facilitate handling routine procedures. In this scenario, the present study aimed to evaluate the effects of the animal conditioning on the welfare of Brazilian jaguars in captivity, analyzing behavioral and physiological parameters. The study was conducted with seven Brazilian jaguars of the Nex Conservation Breeding Center, between August and November of 2013 and in the same months in 2014. Behavioral observations were performed and saliva samples were collected in order to measure the cortisol levels in four steps, consisting of three replications: baseline, control, conditioning and post training. According to behavioral observations in the first phase, activity, inactivity and stress did not differ significantly between treatments, with remarks only to the behavior of animal welfare $(\mathrm{p}=0.0284)$, which also showed differences in the second phase $(p=0.0004)$ as well as to parameters like activity $(p<0.0001)$, sleep ( $p$ $<0.0001)$. For cortisol in Phase 1, there was no statistical difference between the three treatments. For Phase 2, the model was different $(\mathrm{p}<0.0001)$ and post hoc Tukey test showed that the increase in the cortisol concentration in the conditioning treatments and after training was significant in relation to the baseline and control. According to behavioral observations in 
the first phase, activity, inactivity and stress did not differ significantly between treatments, with remarks only to the behavior of animal welfare $(\mathrm{p}=0.0284)$, which also showed differences in the second phase $(p=0.0004)$ as well as to parameters like activity $(p<0.0001)$, sleep $(\mathrm{p}<0.0001)$. For cortisol in Phase 1, there was no statistical difference between the three treatments. As for the Phase 2 model was different $(\mathrm{p}<0.0001)$ and post hoc Tukey test showed that the increase in the cortisol concentration in the conditioning treatments and after training was significant in relation to the LB and CT. There was no statistical difference between treatments baseline and control, or between the CD and PC stages. The increased level of cortisol was positively correlated with the welfare behavior, and the concentration of the steroid reduces after training, indicating that the physiological stress generated by conditioning was punctual, similar to that found in studies of environmental enrichment, which are increasing followed by a gradual decrease in these values after implementation of environmental enrichment, suggesting that conditioning effects are also studied in the long term, but the behaviors associated with animal welfare presented already indicate that the conditioning can act improving the quality of life of animals captives.

Keywords: welfare, animal training, South American feline, enclosures, cortisol. 


\section{INTRODUÇÃO}

Manter animais em cativeiro é uma importante ferramenta para a conservação das espécies (Gippoliti, 2011), especialmente diante da crescente expansão da exploração ambiental, que tem como conseqüência a destruição de habitats e a ameaça de extinção a espécies (UFAW, 1997). É sabido que animais em ambientes sem complexidade e cuja previsibilidade é alta tendem a apresentar problemas, como o desenvolvimento de alterações comportamentais (Shepherdson, 1998) e o desenvolvimento de estresse crônico, geralmente associado à ausência de reprodução e à imunossupressão (Munck, 1984) diminuindo sua perspectiva de vida. A saúde e o bem-estar de animais cativos são essenciais para o sucesso de programas de conservação (Swaisgood, 2010).

Entre as estratégias para minimizar os efeitos adversos do cativeiro está o treinamento dos animais por meio de um conjunto de técnicas baseadas no condicionamento operante, pelas quais o animal é estimulado a desenvolver alguns comportamentos, que são reforçados positivamente (Laule, 1998). O uso do treinamento com reforço positivo, ou positive reinforcement training (PRT), ganhou ênfase nas últimas duas décadas, sendo amplamente utilizado em primatas não humanos em zoológicos e laboratórios, que podem ser treinados para executar comportamentos que auxiliam na rotina (Veeder, 2009), bem como em procedimentos veterinários (Lambeth, 2006). Além disso, podem melhorar a relação entre cuidador e animal (Bassett et al., 2003), promover bem-estar para os animais (Bloomsmith et al., 1994), possibilitar ao animal exercer certo controle sobre o ambiente (Basset et al., 2007) e melhorar a interação social (Schapiro et al., 2001). Treinar os animais para procedimentos de rotina e realização de alguns exames clínicos pode diminuir o estresse do cativeiro e auxiliar na coleta de amostras biológicas, facilitando o desenvolvimento de pesquisas (Bassett et al., 2003), além de ser enquadrado como enriquecimento ambiental social ou cognitivo (Young, 2003). 
Para conhecer como o cativeiro afeta a reprodução e saúde animal foi necessário o desenvolvimento de métodos para mensuração do estresse de animais cativos, e dados mais significativos foram obtidos por estudos que combinam a análise de comportamento e medidas fisiológicas (Brown, 2006). Nesse sentido, estudos apontam para a importância do enriquecimento ambiental para a elevação do bem-estar animal, baseados em evidências comportamentais e em parâmetros físiológicos, especialmente a partir de hormônios corticoesteróides associados ao estresse (Möstl \& Palme, 2002), coletados por meio de métodos não invasivos, a partir das fezes, urina ou saliva, minimizando o efeito da própria coleta sobre os dados obtidos (Lasley \& Kirkpatrick, 1991, Touma et al., 2004, Touma \& Palme, 2005; Schwarzenberger, 2007, Montanha, 2009, Vasconcelos, 2011). Os efeitos do condicionamento sobre a concentração do hormônio cortisol foram avaliados para macacos Rhesus, observando-se sua redução após 3 semanas de condicionamento, sugerindo que é necessário um tempo inicial de adaptação ao experimento (Lee et al., 2013). No entanto, são escassos registros de estudos dessa natureza com condicionamento, mais estudado sobre outros aspectos, principalmente com primatas não humanos (Veeder, 2009, Basset et al., 2003, Coleman, 2010, Perlman, 2012), além de passeriformes (Guillette, 2015) e serpentes (Emer, 2015).

A onça-pintada, Panthera onca, vem sofrendo declínio populacional causado principalmente pela fragmentação de habitats (Sunquist; Sunquist, 2002, Haag et al., 2010) e pela caça ilegal (Rosas-Rosas \& Valdez, 2010), inclusive em áreas protegidas (Carvalho \& Morato, 2013). Quando em cativeiro, pode apresentar problemas comportamentais comuns a felinos, tais como redução nos comportamentos exploratórios, aumento da reação de alerta e grande permanência em repouso ou em esconderijos (Carlstead, 1993), andar em rotas fixas (pacing), arrancar os próprios pelos, realizar sucção na ponta do rabo ou pata, automutilação (Silva, 2007).

A onça-pintada é a espécie alvo do presente estudo, que consistiu em investigar, por meio de parâmetros comportamentais e fisiológicos, a hipótese de que o condicionamento atua na diminuição do estresse, provocando diminuição no hormônio cortisol e modificação no padrão comportamental, elevando a expressão de comportamentos associados ao bem-estar animal. 


\section{MATERIAL E MÉTODO}

\subsection{Local do experimento}

O estudo foi conduzido no Criadouro Conservacionista No Extinction "NEX", nos meses de agosto a outubro de 2013 e 2014. O Criadouro esta localizado no Município de Corumbá de Goiás a $80 \mathrm{~km}$ de Brasília. O local no momento do estudo contava com 12 onças pintadas (Panthera onca) e 8 suçuaranas (Puma concolor), além de outros felídeos silvestres. O NEX tem como finalidade a preservação dos felídeos da fauna silvestre ameaçados de extinção, proteção contra a caça e atua integrando as populações rurais mais carentes ao trabalho de defesa e preservação, por meio da conscientização, treinamento e educação ambiental (NEX, 2013).

\subsection{Animais e instalações}

O estudo foi realizado com 7 onças pintadas (Panthera onca) que faziam parte do Criadouro Conservacionista NEX e cuja caracterização (sexo, idade e origem) está descrita na tabela 2.1 .

Tabela 2.1 Descrição dos indivíduos que participaram do estudo

\begin{tabular}{cccc}
\hline Nome & Sexo & $\begin{array}{c}\text { Idade } \\
\text { (anos) }\end{array}$ & Origem (local provável) \\
\hline Sansão & Macho & 12 & Nascido em cativeiro \\
\hline Dalila & Fêmea & 12 & Nascido em cativeiro \\
\hline Carlota & Fêmea & 12 & Nascido em cativeiro \\
\hline Xingu & Macho & 5 & Possivelmente Nascido em cativeiro \\
\hline Gaya & Fêmea & 1 & Nascido em cativeiro \\
\hline Brutus & Macho & 5 & Mato Grosso (capturado filhote) \\
\hline Xamã & Macho & 3 & Nascido em cativeiro \\
\hline
\end{tabular}


Os animais estavam agrupados em casais, em recintos que possuem entre $100 \mathrm{~m}^{2} \mathrm{e}$ $400 \mathrm{~m}^{2}$. Todos os recintos dispõem de área verde, lago artificial, cambiamentos, plataformas para exploração vertical e vegetação (Figura 2. 1). Os animais eram alimentados diariamente, no fim da tarde, com aproximadamente $3 \mathrm{~kg}$ de carne suína por indivíduo, oferecida no interior do cambiamento, área destinada ao manejo desses animais, considerando que a entrada de tratadores no recinto só ocorre com os animais nos cambiamentos, devidamente travados (Figura 2. 2).

O único indivíduo com alteração era o Brutus, que apresentava deficiência visual, possivelmente relacionada a deficiência nutricional durante o desenvolvimento do animal. Todos os outros apresentavam boa condição de saúde, sem nenhuma patologia.

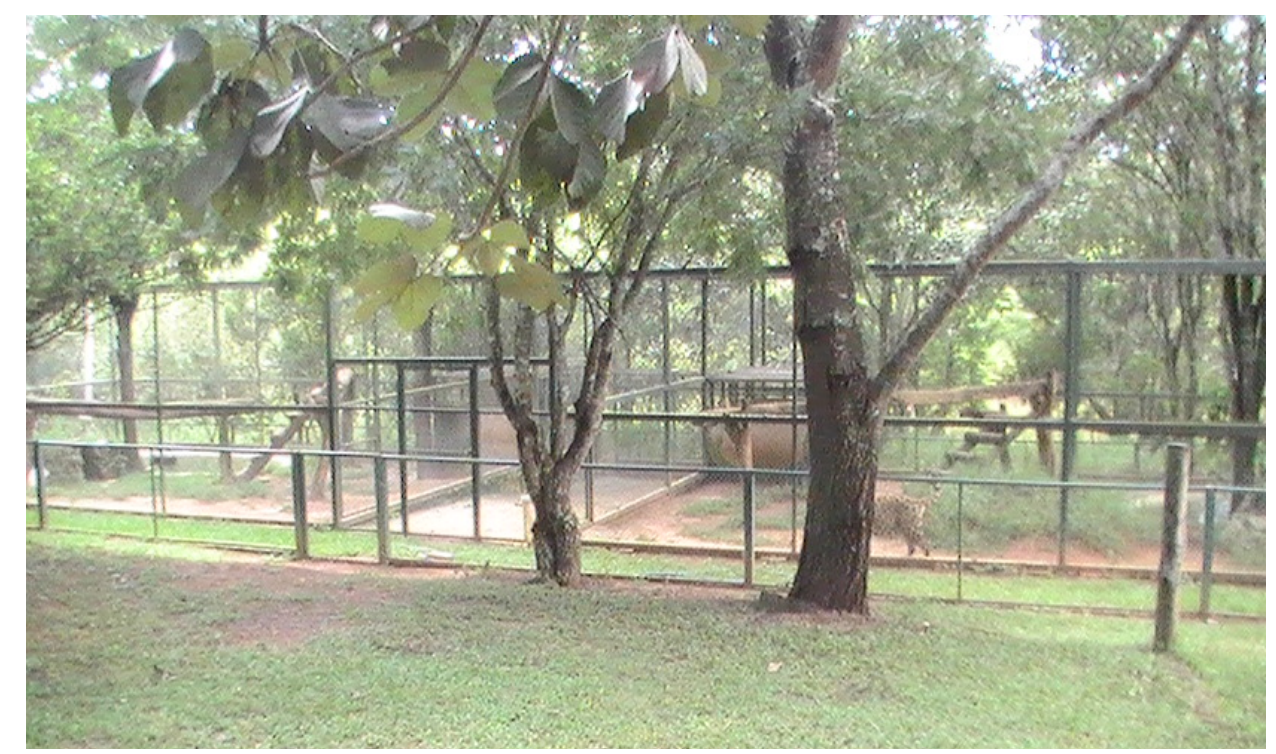

Figura 2. 1 Vista geral de dois dos recintos do Nex.

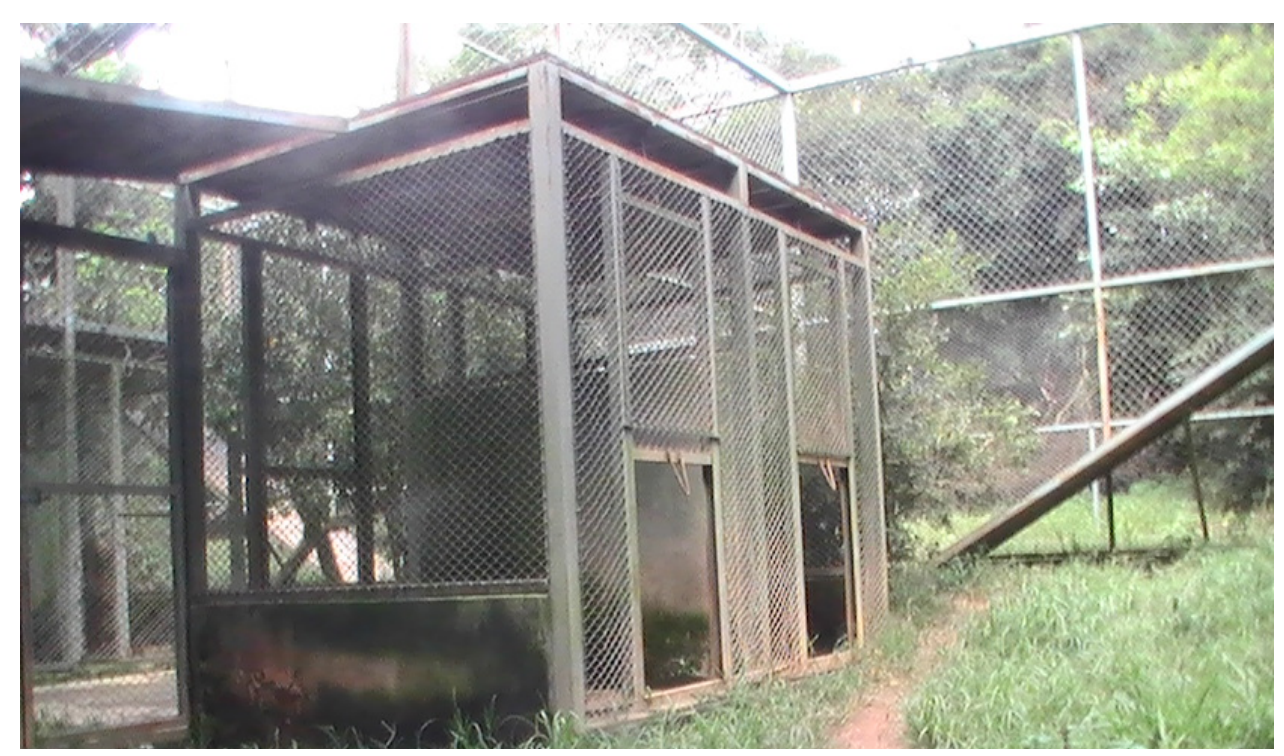

Figura 2. 2 Em destaque, os cambiamentos. 


\subsection{Avaliação dos efeitos do Condicionamento}

Com a finalidade de eliminar o efeito de variáveis extra-estudo e de aumentar sua validade interna foi adotada a condição experimental sugerida por Saudargas e Drummer (1996), que consiste na repetição do experimento, com realização das fases linha de base e enriquecimento (condicionamento) duas vezes.

O delineamento experimental contou com duas fases, a primeira realizada entre agosto e outubro de 2013 e a segunda no mesmo período de 2014. Cada uma contou com três tratamentos, compostos por três repetições (dias de coleta) para cada um dos sete animais, com intervalo de sete dias entre os tratamentos.

A linha de base (LB) caracterizava-se pela realização das observações comportamentais e realização de coleta de saliva, sem nenhuma intervenção.

Os animais normalmente receberam alimentação diariamente no fim da tarde. Durante o condicionamento os animais receberam pequenas porções de carne como recompensa. A fim de verificar se os efeitos obtidos nessa fase eram provenientes dessa alimentação fracionada foi realizada uma fase denominada controle (CT), na qual os animais receberam pequenas porções de carne duas vezes durante o período de observação, nos mesmos horários em que serão realizadas as sessões de condicionamento, mas sem nenhum tipo de comando ou interação.

Durante o tratamento condicionamento $(\mathrm{CD})$ os animais receberam as sessões de treinamento, descritas adiante.

Ao repetir o estudo em 2014, foi acrescentado um quarto tratamento, após o treino (PT), que consistiu na realização de uma nova linha de base, para avaliar os efeitos da técnica após sua aplicação.

\subsubsection{Observações comportamentais}

Os animais foram observados de forma direta, entre 13:30 e 15:30 horas, utilizando-se o método do animal focal que é indicado para estudos nos quais é possível identificar os indivíduos (Altmann, 1973; Del Claro, 2004). O intervalo adotado foi de um minuto. Os quatro observadores foram previamente treinados a identificar os animais e os comportamentos, utilizando-se como base o etograma (Tabela 2.2) elaborado a partir de observações preliminares, realizadas pelo método ad libitum e comparando com resultados encontrados em estudos anteriores (McPhee, 2002, Castillo-Guevara, 2012). 
Tabela 2.2: Etograma utilizado para as observações comportamentais

\begin{tabular}{|c|c|c|}
\hline $\begin{array}{l}\text { Categol } \\
\text { comp }\end{array}$ & $\begin{array}{l}\text { ias e Padrões } \\
\text { rtamentais }\end{array}$ & Descrição do comportamento \\
\hline \multirow{4}{*}{ Inatividade } & Sentado SE & $\begin{array}{l}\text { Animal sentado, com os membros posteriores } \\
\text { encostados sobre o solo e os membros anteriores } \\
\text { elevados, apenas apoiados. }\end{array}$ \\
\hline & Parado PA & $\begin{array}{l}\text { Animal na posição em pé, apoiado sobre os quatro } \\
\text { membros. }\end{array}$ \\
\hline & Deitado DE & $\begin{array}{l}\text { Animal com o corpo apoiado no substrato, com a } \\
\text { cabeça elevada. É possível ver que o animal está } \\
\text { com os olhos abertos (Figura 2.3). }\end{array}$ \\
\hline & Dormindo DO & $\begin{array}{l}\text { Animal com o corpo apoiado no substrato, com a } \\
\text { cabeça encostada, é possível ver que o animal está } \\
\text { com os olhos fechados. }\end{array}$ \\
\hline \multirow{4}{*}{ Locomoção } & Andar AN & $\begin{array}{l}\text { Animal se desloca em uma direção específica, } \\
\text { aparentemente com objetivo (Figura 2.4). }\end{array}$ \\
\hline & Correr $\mathbf{C O}$ & $\begin{array}{l}\text { Animal se desloca em uma direção específica, } \\
\text { aparentemente com objetivo, mas é possível } \\
\text { observar que os membros permanecem } \\
\text { simultaneamente fora do chão. }\end{array}$ \\
\hline & Subir $\mathbf{S}$ & Animal desloca-se para estrutura elevada. \\
\hline & Descer D & Animal desloca-se, descendo de estrutura elevada. \\
\hline \multirow{3}{*}{ Movimentação } & $\begin{array}{l}\text { Levantar-se sobre } 2 \\
\text { patas } \mathbf{L 2 p}\end{array}$ & $\begin{array}{l}\text { Animal eleva os membros anteriores, } \\
\text { permanecendo com apenas dois membros apoiados } \\
\text { no solo. }\end{array}$ \\
\hline & Autolimpeza AUT & $\begin{array}{l}\text { Animal passa a língua no próprio pelo } \\
\text { repetidamente. }\end{array}$ \\
\hline & Rolar no solo RS & $\begin{array}{l}\text { Animal deita e rola sobre o substrato, tocando-o } \\
\text { alternadamente com as regiões dorsal, lateral e } \\
\text { ventral. }\end{array}$ \\
\hline \multirow{4}{*}{ Exploração } & Farejando $\mathbf{F}$ & $\begin{array}{l}\text { O animal movimenta o focinho e nota-se alteração } \\
\text { na respiração. }\end{array}$ \\
\hline & Mexendo $\mathbf{M}$ & $\begin{array}{l}\text { Animal toca com as patas em objeto ou qualquer } \\
\text { elemento compositor do recinto ou nele inserido. }\end{array}$ \\
\hline & Olhando $\mathbf{O}$ & $\begin{array}{l}\text { Animal direciona o olhar fixamente, } \\
\text { frequentemente seguindo visualmente o que está } \\
\text { olhando. }\end{array}$ \\
\hline & Flehman FH & $\begin{array}{l}\text { Expressão facial na qual o animal abre levemente a } \\
\text { boca, elevando o lábio superior e respirando } \\
\text { (Figura 2.5) }\end{array}$ \\
\hline \multirow{2}{*}{ Ingestão } & Bebendo Água BA & $\begin{array}{l}\text { O animal aproxima a boca da lâmina d'água e } \\
\text { ingere água. É possível observar a movimentação } \\
\text { da língua. }\end{array}$ \\
\hline & Comendo COM & $\begin{array}{l}\text { Animal ingerindo alimento, é possivel ouvir } \\
\text { quando corta a carne e observar o movimento da } \\
\text { mandíbula durante a mastigação. }\end{array}$ \\
\hline
\end{tabular}




\begin{tabular}{|c|c|c|}
\hline \multirow{8}{*}{ Interação } & $\begin{array}{l}\text { Interação agonística } \\
\text { IAG }\end{array}$ & $\begin{array}{l}\text { Os animais interagem com agressividade, com } \\
\text { ataques e dentes a mostra (Figura 2.6) }\end{array}$ \\
\hline & $\begin{array}{l}\text { Interação amistosa } \\
\text { IAM }\end{array}$ & $\begin{array}{l}\text { Os animais interagem, por meio de lambeduras, } \\
\text { brincadeiras, aproximação. }\end{array}$ \\
\hline & Interação Sexual TM & $\begin{array}{l}\text { O macho posiciona-se sobre a fêmea, tentando } \\
\text { assumir a posição de cópula. }\end{array}$ \\
\hline & Cópula $\mathbf{C P}$ & $\begin{array}{l}\text { O macho posiciona-se sobre a fêmea, assumindo a } \\
\text { posição de cópula. }\end{array}$ \\
\hline & $\begin{array}{l}\text { Interação com } \\
\text { humanos IH }\end{array}$ & $\begin{array}{l}\text { Animal aproxima-se da grade na presença de } \\
\text { humanos. Pode encostar e permitir o toque. }\end{array}$ \\
\hline & $\begin{array}{l}\text { Comportamento } \\
\text { lúdico } \mathbf{C L}\end{array}$ & $\begin{array}{l}\text { O animal manifesta, sozinho, atividade } \\
\text { comportamental de forma lúdica, com brincadeiras, } \\
\text { podendo manipular objetos como galhos ou } \\
\text { brinquedos introduzidos no recinto. }\end{array}$ \\
\hline & Perseguir PS & Animal anda ou corre atrás de outro. \\
\hline & Vocalizar V & $\begin{array}{l}\text { Toda e qualquer emissão de som produzido } \\
\text { vocalmente pelo animal, tais como rugidos e } \\
\text { esturros. }\end{array}$ \\
\hline \multirow{4}{*}{ Marcação } & Urinar $\mathbf{U}$ & $\begin{array}{l}\text { Animal urina na posição agachado ou esguichando } \\
\text { para trás. }\end{array}$ \\
\hline & Defecar DEF & Processo fisiológico de eliminação das fezes. \\
\hline & Afiar unhas AU & $\begin{array}{l}\text { Animal afia as unhas em troncos ou outros } \\
\text { elementos do recinto. }\end{array}$ \\
\hline & Esfregar Face EF & $\begin{array}{l}\text { Animal encosta a face, iniciando com a região } \\
\text { lateral da boca e exerce pressão, esfregando a } \\
\text { cabeça sobre a superfície de elementos do recinto, } \\
\text { como a tela. }\end{array}$ \\
\hline \multirow{5}{*}{ Outros } & Bocejar BOC & $\begin{array}{l}\text { Animal abre a boca, com ampla separação das } \\
\text { mandíbulas, em ação incontrolada, acompanhada } \\
\text { de uma respiração profunda (Figura 2.7). }\end{array}$ \\
\hline & Se coçar $\mathbf{C C}$ & $\begin{array}{l}\text { Animal se coça utilizando os membros ou } \\
\text { esfregando-se em elementos do recinto. }\end{array}$ \\
\hline & $\begin{array}{l}\text { Condicionamento } \\
\text { CD }\end{array}$ & Animal participa de sessão de treinamento. \\
\hline & Recebendo carne $\mathbf{R C}$ & Animal recebe carne pela tela do recinto. \\
\hline & $\begin{array}{l}\text { Lambendo e } \\
\text { mordendo grade }\end{array}$ & Animal passa a língua ou morde a grade do recinto. \\
\hline \multirow{3}{*}{$\begin{array}{l}\text { Possível } \\
\text { estresse }\end{array}$} & Pacing PE & $\begin{array}{l}\text { Animal anda de um lado para o outro, ou utiliza } \\
\text { repetidamente a mesma rota de deslocamento, sem } \\
\text { objetivo aparente (Mason, 1993) }\end{array}$ \\
\hline & $\begin{array}{l}\text { Chupar ou morder a } \\
\text { cauda (CMC) }\end{array}$ & $\begin{array}{l}\text { Animal lambe excessivamente, ou morde a região } \\
\text { da cauda. }\end{array}$ \\
\hline & $\begin{array}{l}\text { Permanecer } \\
\text { escondido (PES) }\end{array}$ & $\begin{array}{l}\text { Animal permanece dentro de toca ou esconderijo, } \\
\text { não sendo possível visualizá-lo durante a maior } \\
\text { parte da observação. }\end{array}$ \\
\hline
\end{tabular}




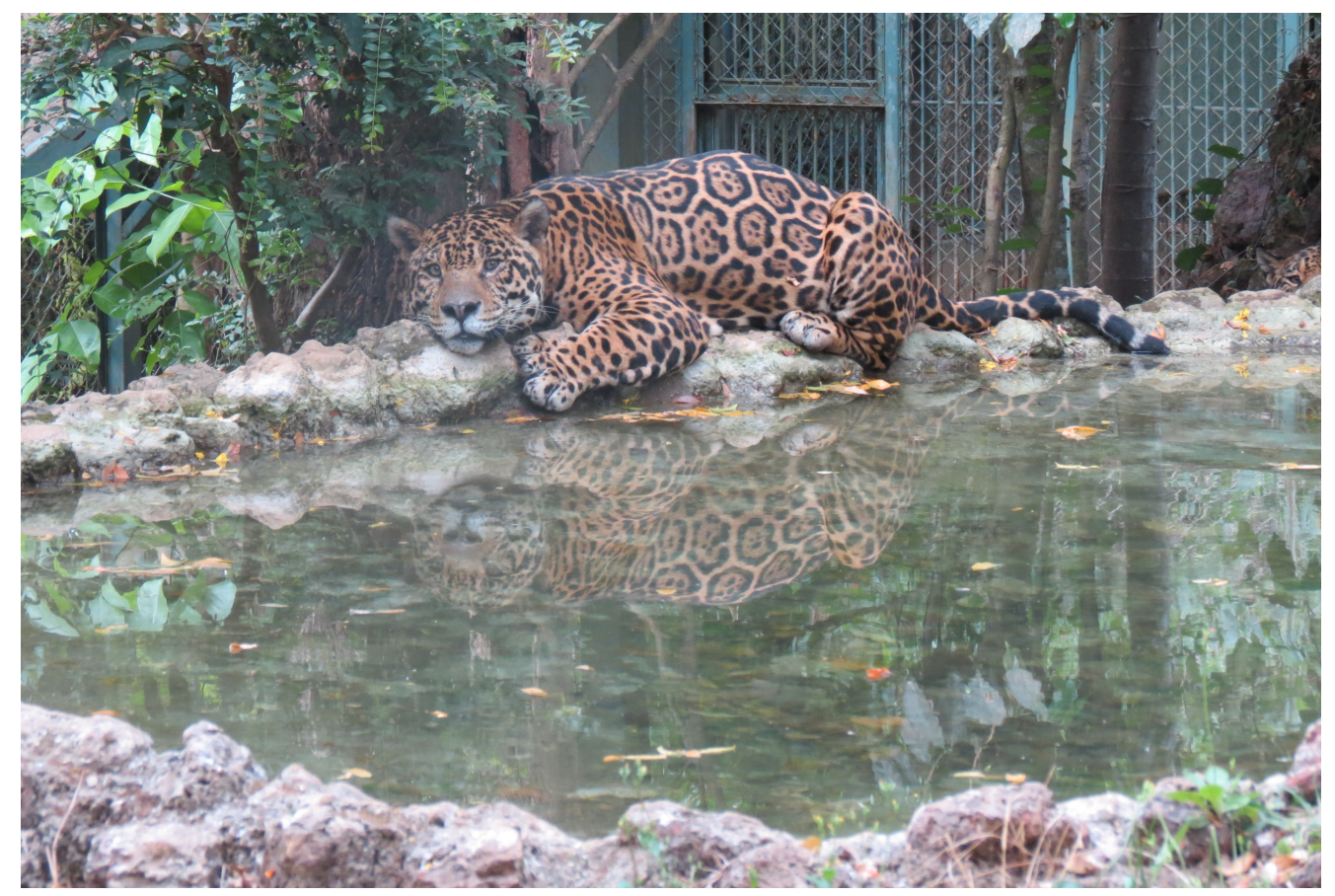

Figura 2.3. Comportamento deitado.

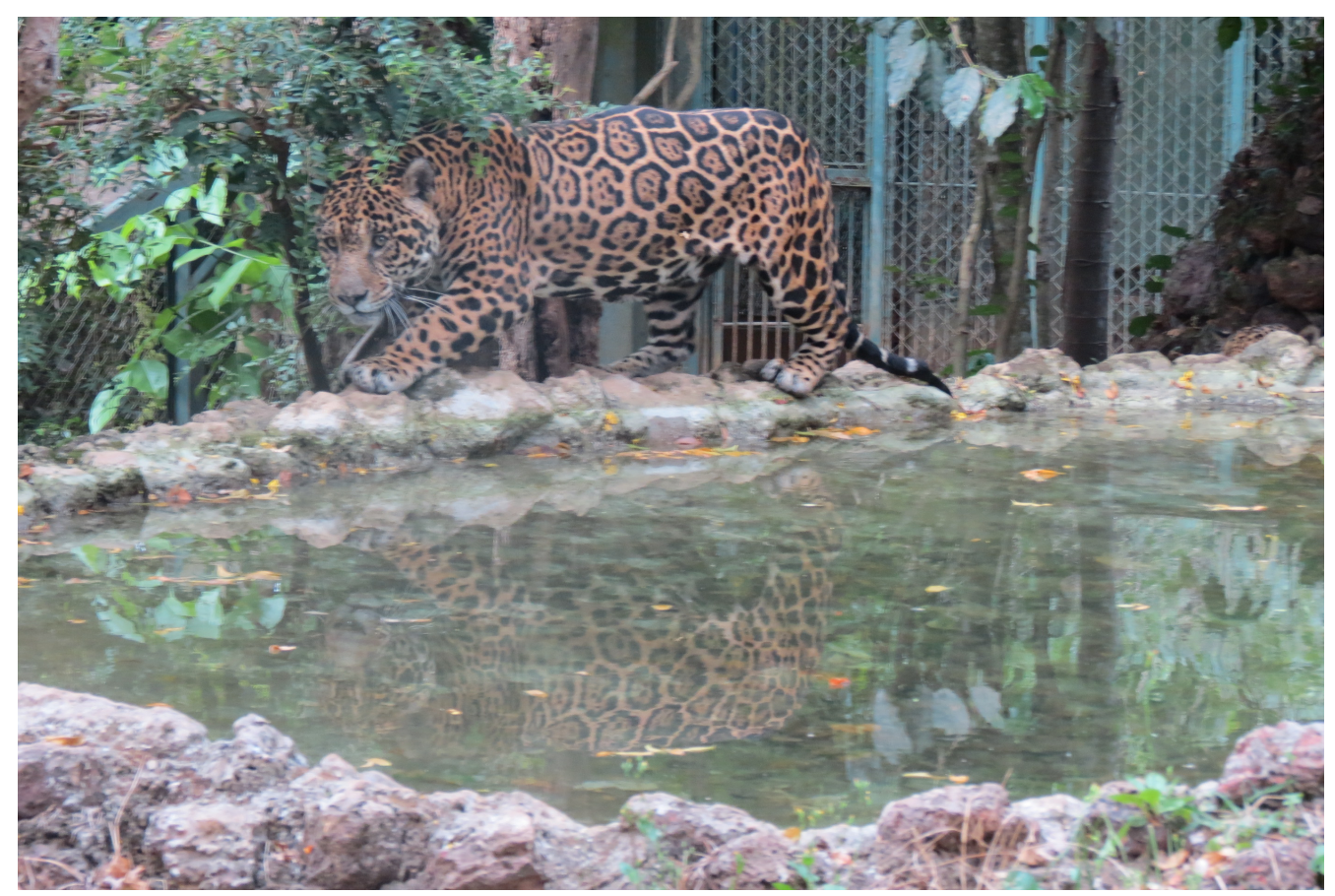

Figura 2.4. Comportamento andando. 


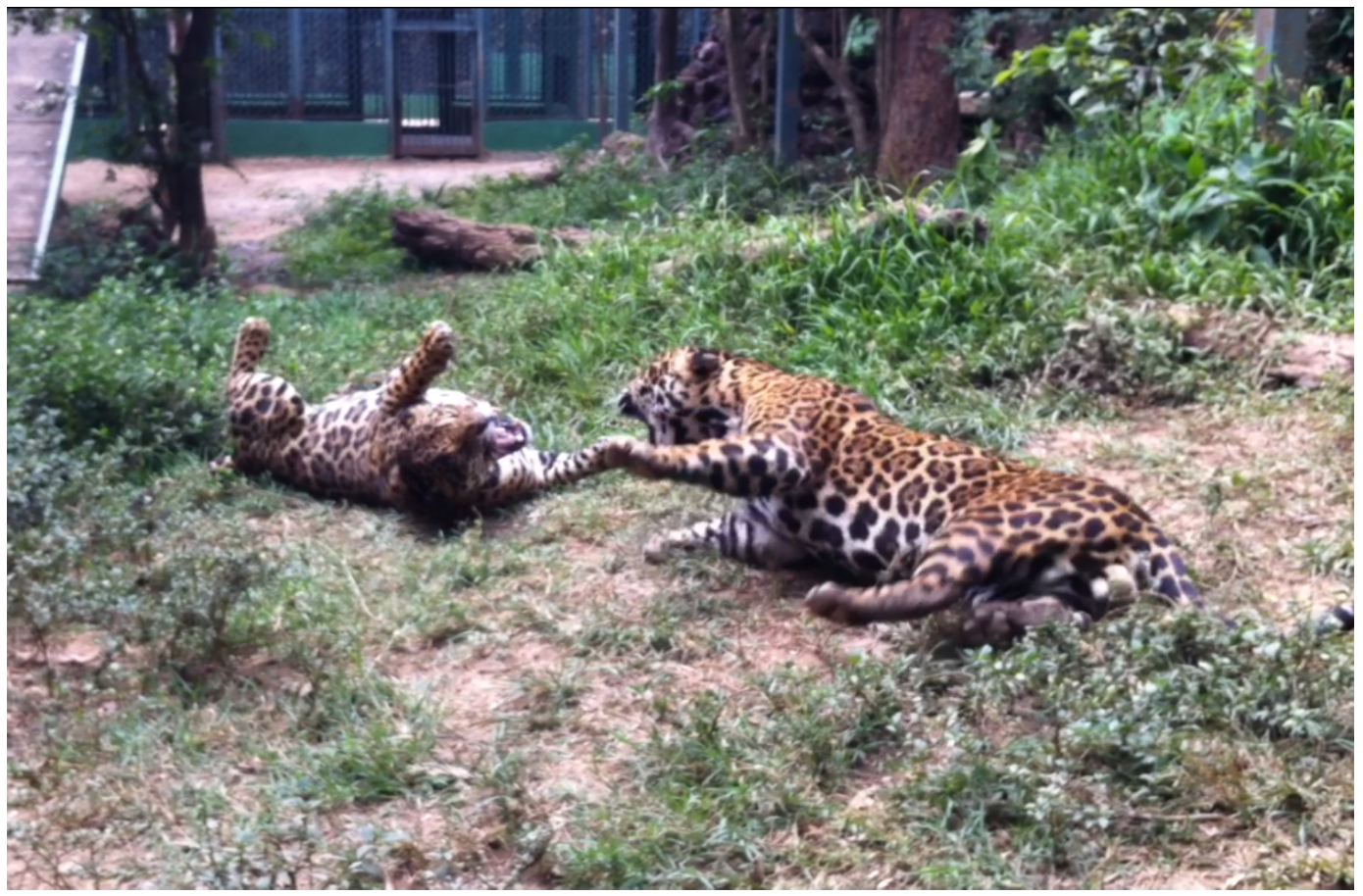

Figura 2.5. Interação agonística.

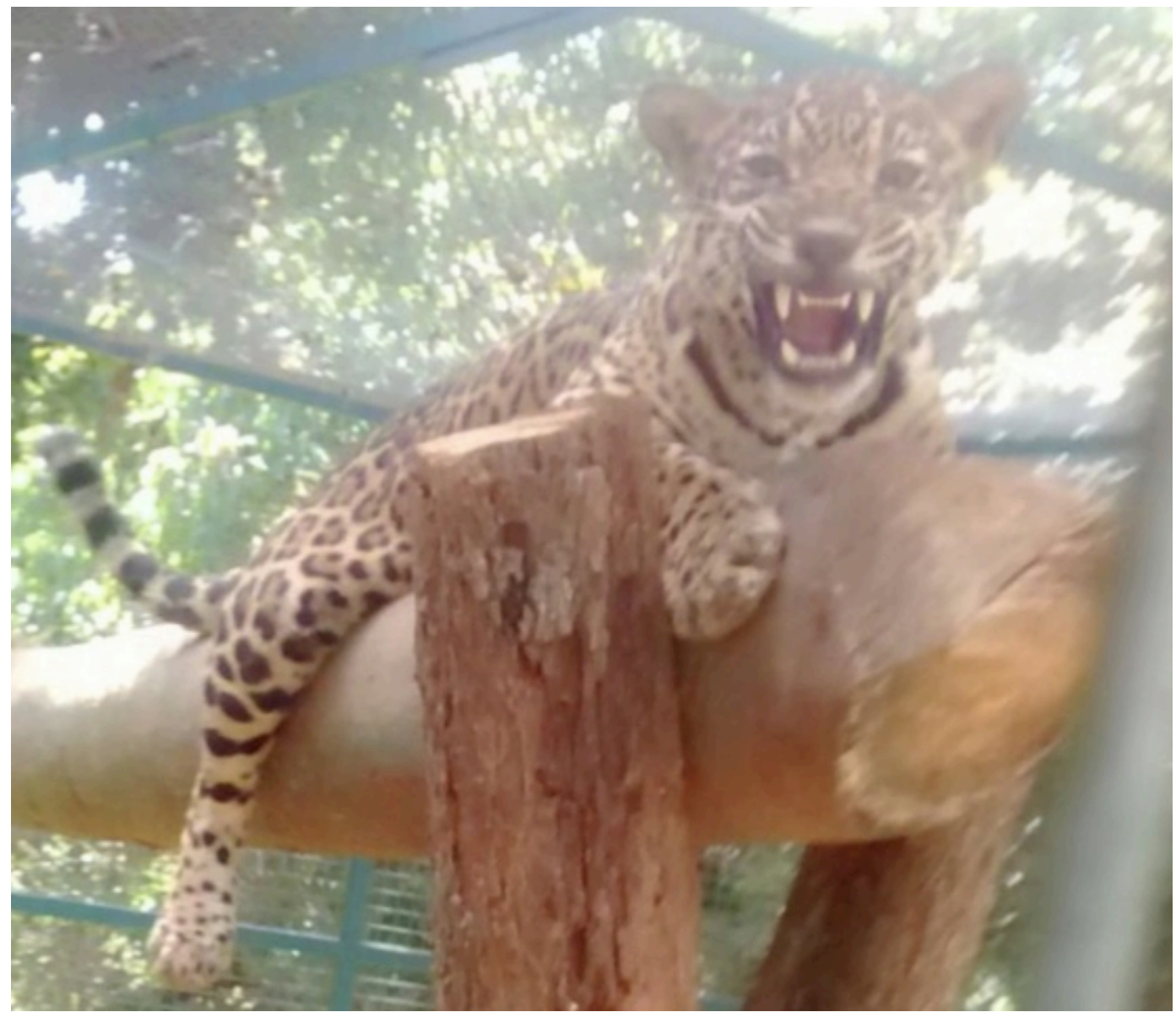

Figura 2.6. Animal apresentando Flehman. 


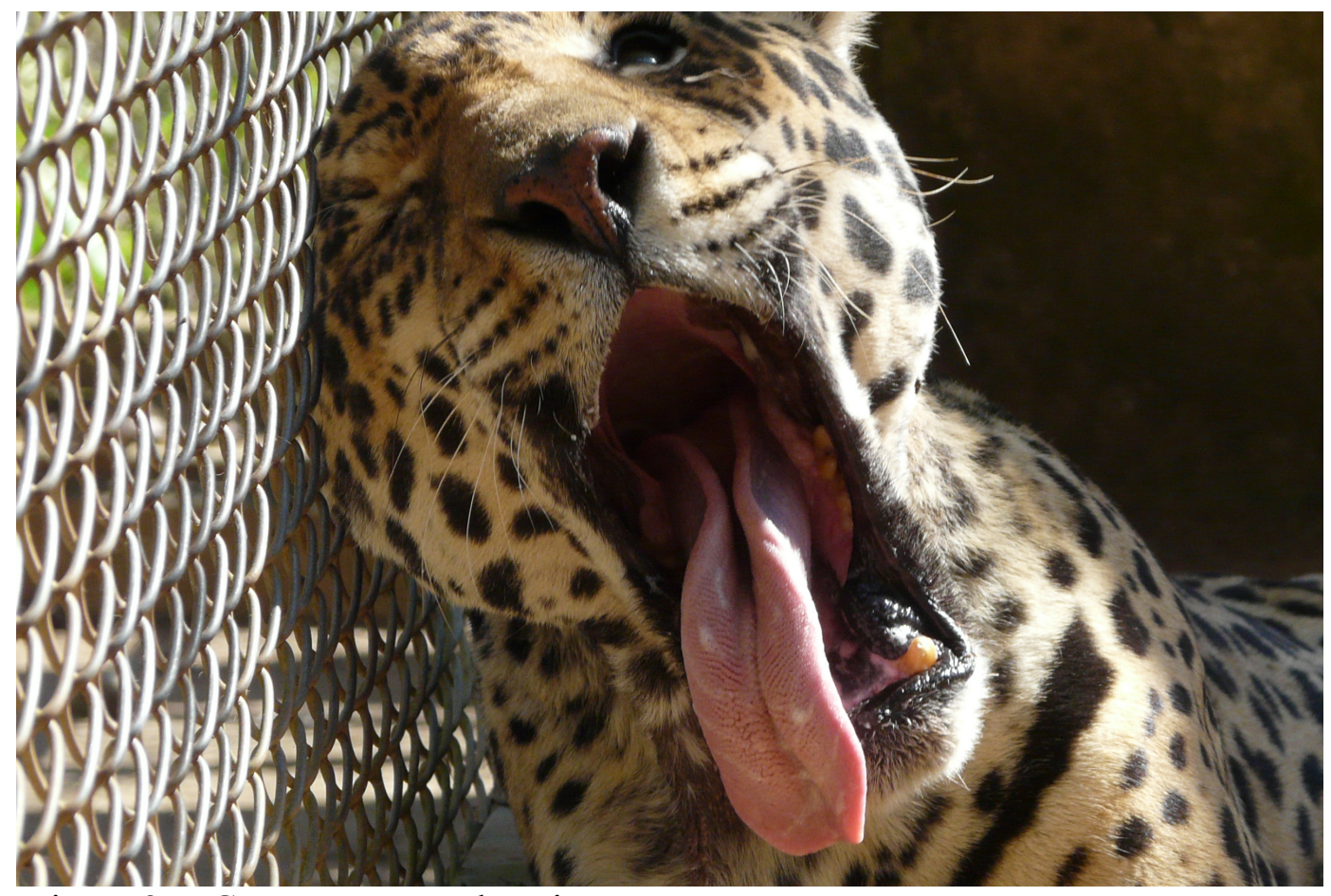

Figura 2.7. Comportamento bocejar.

A expressão de determinados comportamentos pode indicar estresse ou bem-estar animal. Assim, para a análise dos resultados, os comportamentos foram agrupados em duas categorias, considerando o enquadramento proposto por Carsltead (1993), sendo que uma delas reunia os indicativos de estresse: pacing, manter-se escondido, chupar a cauda e a outra era composta pelos comportamentos associados ao bem-estar-animal: exploratórios e de interação não agonística.

\subsubsection{Coleta de saliva}

As coletas de saliva foram realizadas no fim da tarde (16:30 horas), de forma similar ao que foi realizado por Silva (2011). Para a realização da coleta de saliva (Figura 2.8) foram utilizados mastigadores confeccionados com material inerte e absortivo. Cada mastigador é composto de $30 \mathrm{~cm}$ de mangueira de incêndio com camada dupla de tecido sintético revestida internamente por borracha vulcanizada, amarrado a uma corda e oferecido ao animal pelas grades do recinto, sempre de forma a não tocar o chão do recinto. A utilização desse material para coleta de saliva e mensuração de cortisol em onças pintadas foi descrita por Montanha et 
al. (2009) e Silva (2011), que consideraram a quantidade e a qualidade do material obtido satisfatórias, além disso, o método de coleta não provocou nenhuma alteração nos padrões comportamentais pré e pós-coleta (Silva, 2011). Antes da utilização, o material para coleta foi higienizado e esterilizado.

Previamente ao experimento os animais foram estimulados a morder os mastigadores, que inicialmente foram impregnados com sangue e pedaços de carne, para despertar interesse. O procedimento de coleta era realizado dentro do período limite de 5 minutos, entre o início da apresentação da mangueira ao animal e seu recolhimento. Após o animal ter mastigado o material, foram coletados fragmentos de $2 \mathrm{~cm}$ x $4 \mathrm{~cm}$, armazenados em frascos para centrifugação em caixa térmica para posterior processamento em laboratório, qual seja, centrifugação a $3000 \mathrm{rpm}$ durante 5 minutos. A saliva era então transferida para um microtubo devidamente identificado e congelada até a realização das análises.

A dosagem de cortisol foi realizada no Laboratório de Bem-estar animal da Universidade de Brasília, utilizando-se os kits The EIAsy Way-CORTISOL ${ }^{\circledR}$ (Diagnostics Biochem Canadá Inc.) na fase 1 e Cortisol Test System-EIA ${ }^{\circledR}$ 3625-300 (Monobind Inc.), ambos importados pela USA Diagnóstica na fase 2, específicos para quantificação de cortisol pelo método de ensaio imunoenzimático (ELISA).

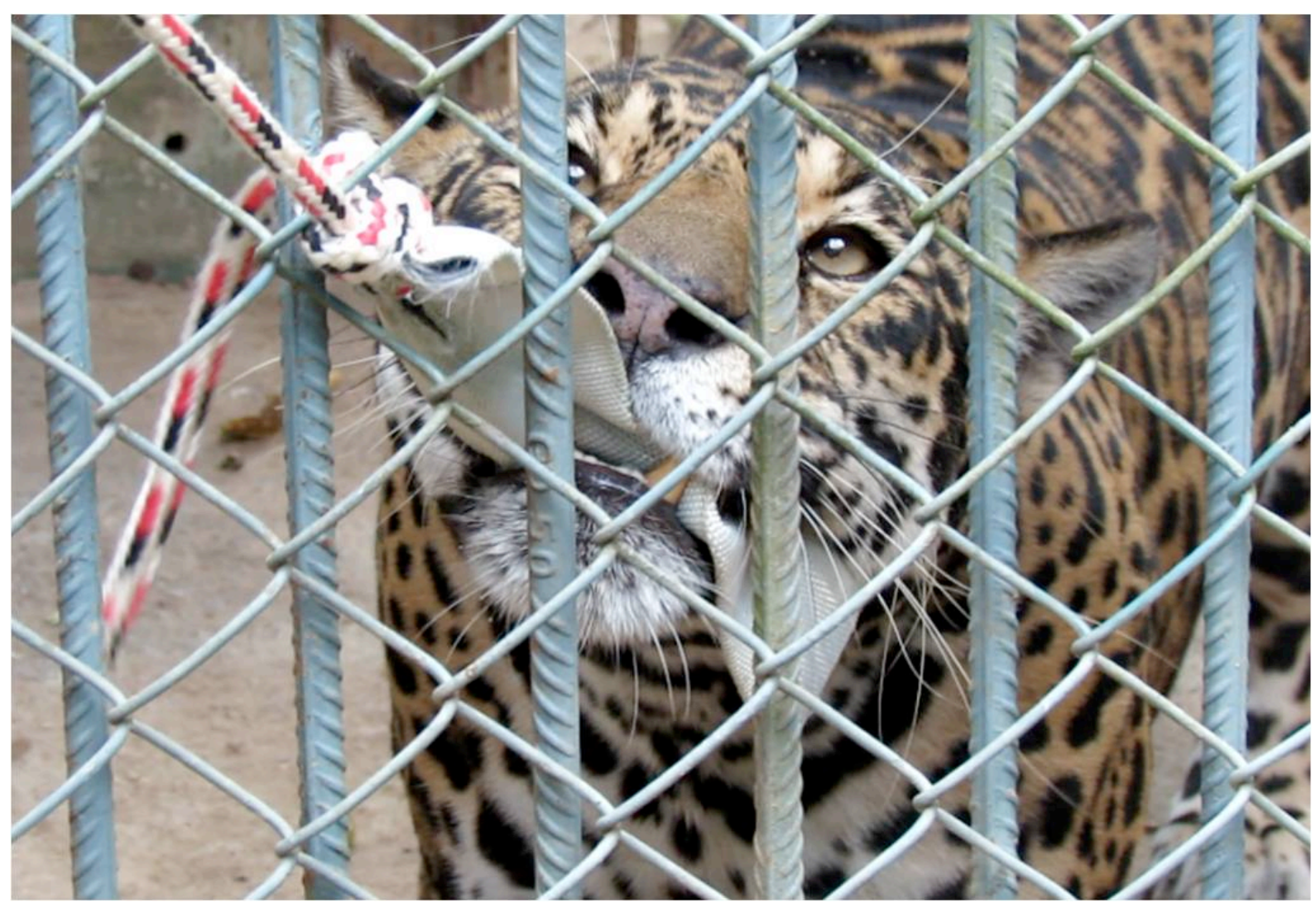

Figura 2.8. Um dos animais mordendo o material absortivo durante coleta de saliva. 


\subsubsection{Condicionamento}

As atividades de condicionamento animal (Figura 2.9) foram realizadas em 2 sessões diárias com cada um dos animais. Cada sessão com duração aproximada de 10 minutos, realizada ao longo das duas horas do período de observação, respeitando o intervalo de uma hora entre as duas sessões e de pelo menos 15 minutos entre a segunda sessão e a coleta de saliva.

A técnica utilizada para o treinamento baseia-se nos princípios do condicionamento operante, descrito por Skinner (1974) e adaptado para diversos animais por Pryor (2002). Como reforço primário, foram utilizados 20 pequenos pedaços de carne por sessão, oferecidos ao animal com utilização de uma pinça metálica longa $(20 \mathrm{~cm})$, totalizando 200 gramas de carne bovina por sessão. Foi utilizado o clicker, um aparelho que emite um estalo ao ser pressionado, como reforço secundário e um bastão com ponta arredondada foi utilizado como "target", ou seja, o alvo no qual o animal deveria encostar o focinho para realizar os comportamentos. Em virtude de um dos animais apresentar deficiência visual, a extremidade do bastão recebeu uma sinalização olfativa, com aplicação de essência artificial de mel. Os comandos trabalhados foram:

1. Aproximação (vem)

2. Bastão (encostar o focinho no alvo)

3. Segue (seguir o bastao)

4. Fica (permanecer com o focinho encostado no alvo)

5. Em pé (levantar-se sobre os dois membros posteriores)

6. Senta (assumir a posição sentado)

Durante esse tratamento, o aprendizado de cada animal foi acompanhado a cada sessão, com registro do número de comportamentos aprendidos ao final das 02 sessões diárias. Cada fase contou com 3 dias, portanto, foram 6 sessões de condicionamento por fase totalizando 12 sessões no experimento.

Cada comando foi considerado correto mediante resposta imediata do animal, sendo repetido para fixação e então sucedido pelo próximo comando a ser trabalhado, de acordo com a escala acima. Ao fim da última sessão de cada dia de trabalho, todos os comandos foram repetidos, para que pudessem ser fixados pelo animal. Da mesma forma, a primeira sessão do dia sempre era iniciada pelos comandos já aprendidos. Todas as sessões foram filmadas e as imagens transferidas para um HD externo ao fim de cada dia de trabalho. 


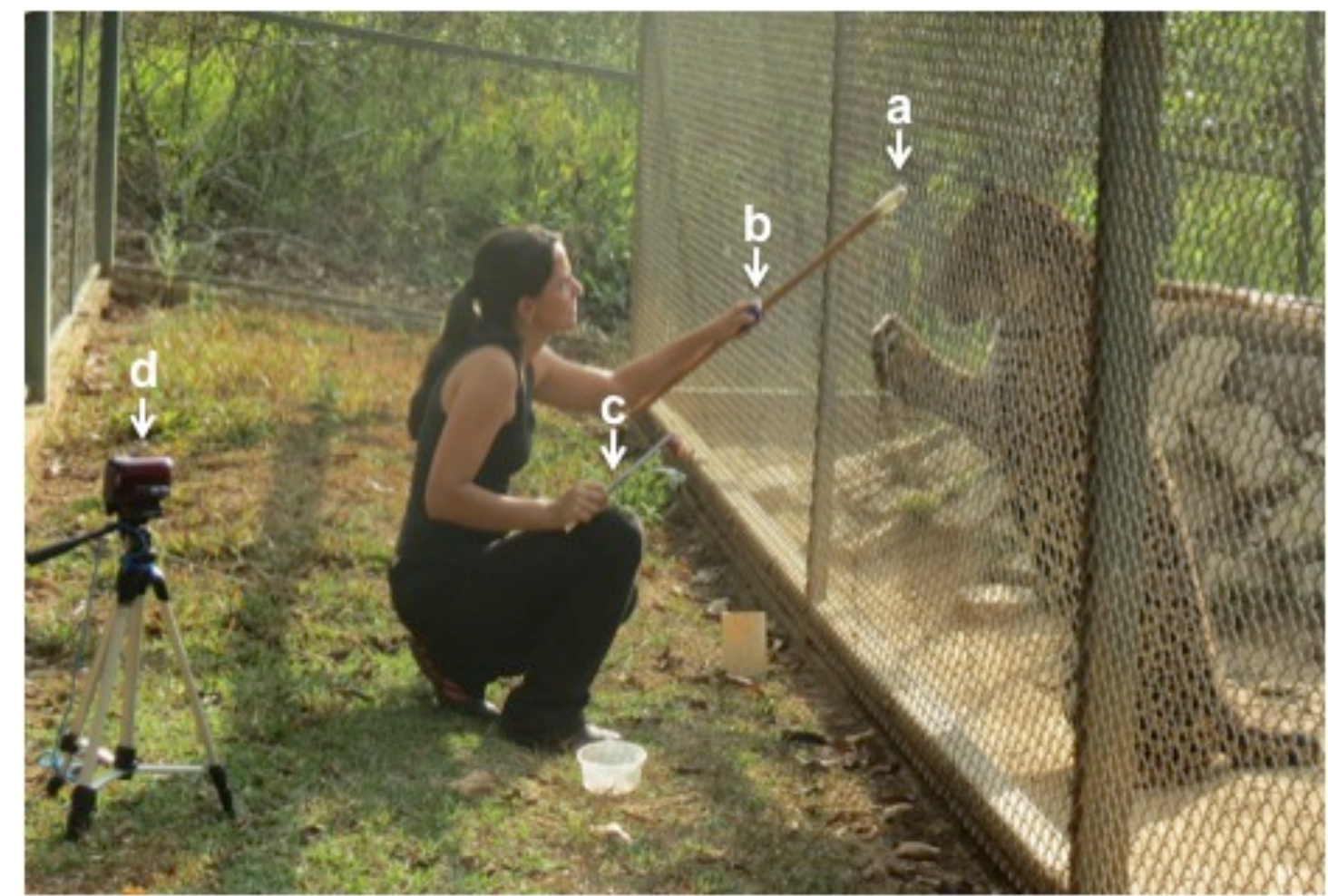

Figura 2.9. Um dos indivíduos durante sessão de condicionamento. a) bastão utilizado, b) clicker, c) pinça para alimentação e d) câmera utilizada para registrar a sessão.

\subsubsection{Análises Estatísticas}

As análises estatísticas foram realizadas utilizando-se o software SAS ${ }^{\circledR}$ (Cary, North Carolina). Os dados obtidos foram analisados quanto à normalidade, aqueles que apresentaram distribuição normal foram submetidos à análise de variância pelo comando PROC GLM com posterior aplicação do teste de Tukey para comparação das médias. O nível de significância foi de $5 \%$.

Para análise, os dados dos valores de cortisol passaram por transformação raiz quadrada, gerando os valores convencionados como "cortran".

Os dados comportamentais, que não apresentam distribuição normal foram analisados pelo teste não paramétrico de Kruskal-Wallis, com análise da diferença mínima significativa (dms) para identificar os tratamentos que diferiram.

A fim de conhecer o comportamento das variáveis em questão foi realizada uma análise de correlação por meio do teste de Spearman, em razão da existência dos dados não paramétricos. 


\section{RESULTADOS E DISCUSSÃO}

\subsection{Observações comportamentais}

Os dados obtidos por meio das observações comportamentais possibilitam análises comparativas mais abrangentes, como as que permitem traçar o padrão de atividade e inatividade dos animais, bem como análises detalhadas, que permitiram que peculiaridades comportamentais de cada indivíduo podem ser consideradas (Matos, 1990).

Para esse estudo, foram considerados os dados do grupo de animais. Na primeira fase, os dados para atividade, inatividade e estresse não apresentaram diferença significativa entre os tratamentos, que foi observada apenas nos comportamentos associados ao bem-estar animal $(P=0,0284)$.

$\mathrm{Na}$ segunda fase, foram encontradas diferenças entre os tratamentos para os parâmetros atividade $(P<0,0001)$, inatividade $(P<0,0001)$ e bem-estar animal $(P=0,0004)$. Os dados comportamentais das duas fases são apresentados nas figuras 2.10, 2.11, 2.12 e 2.13.

Nas duas fases, não houve diferença significativa nos parâmetros comportamentais em função do sexo dos animais. 

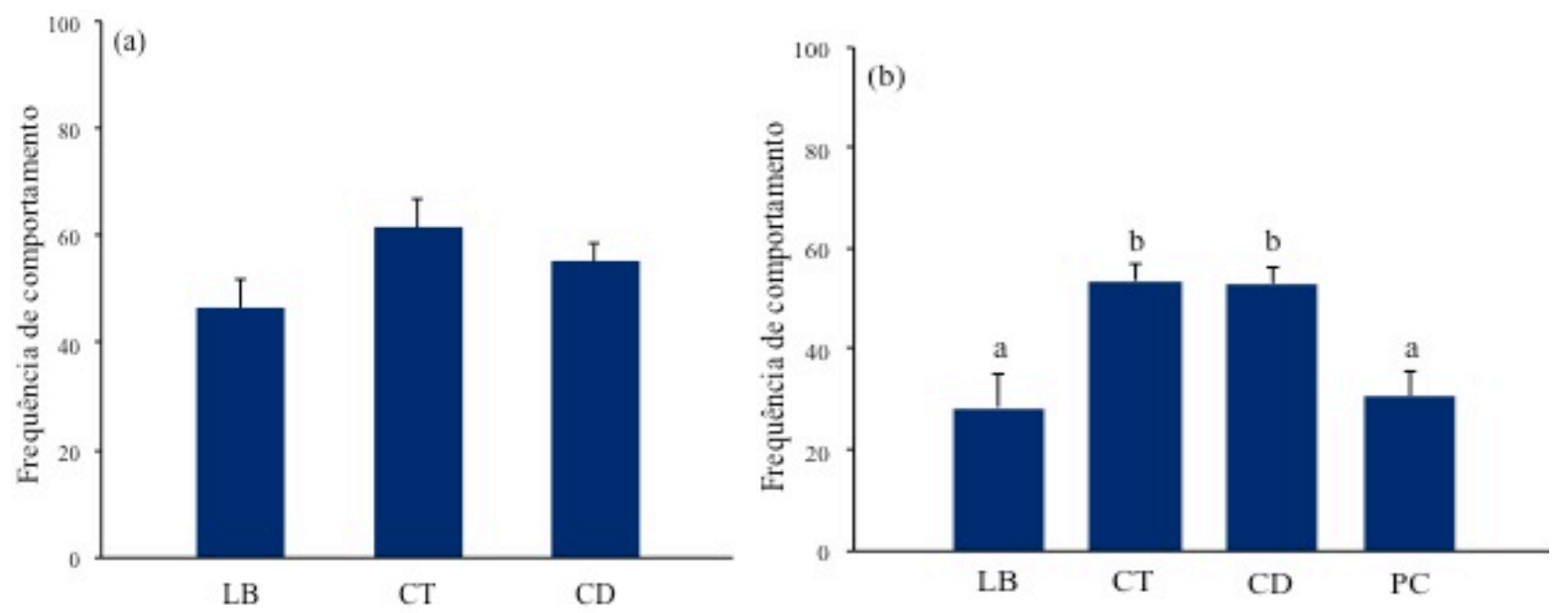

Figura 2.10. Freqüência média (incluindo erro padrão) dos comportamentos de atividade para o grupo de animais durante os tratamentos na fase I (a) e fase II (b). Barras com letras diferentes apresentaram diferença significativa $(P<0,0001)$. LB $=$ Linha de Base, $\mathrm{CT}=$ Controle, $\mathrm{CD}=$ Condicionamento, $\mathrm{PC}=$ Pós-Condicionamento.
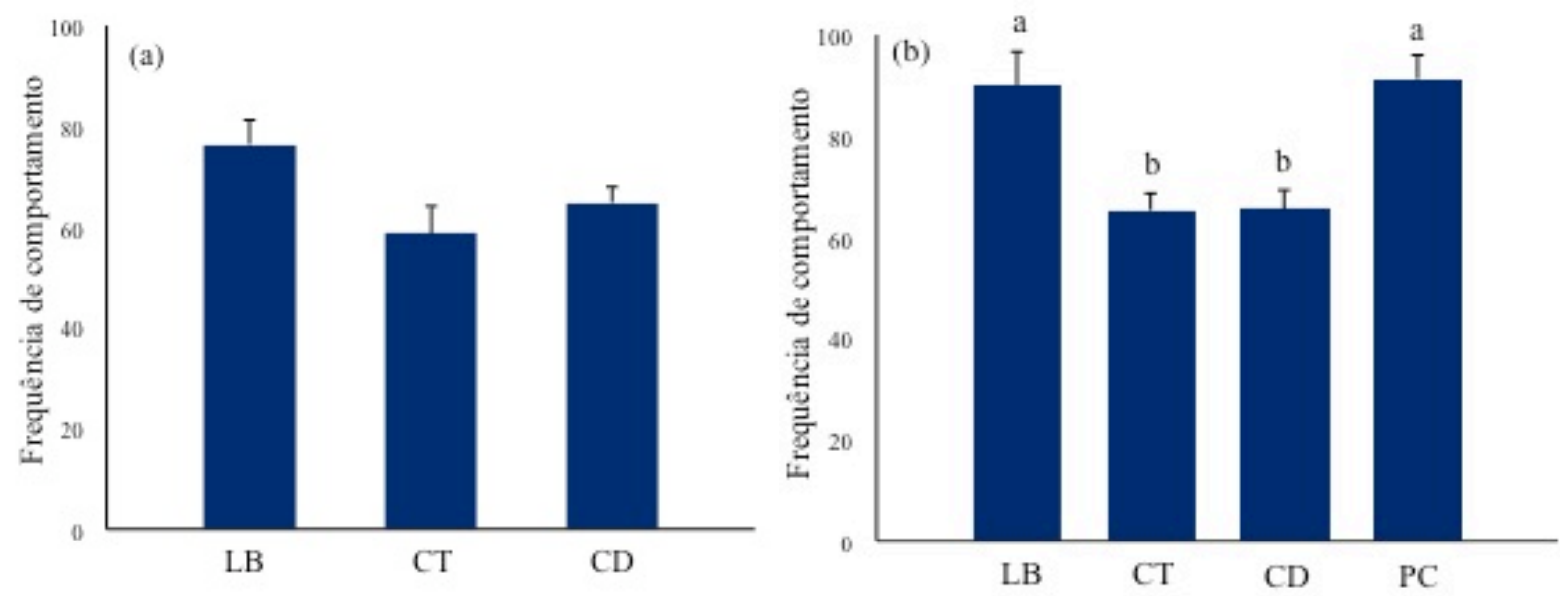

Figura 2.11. Freqüência média (incluindo erro padrão) dos comportamentos de inatividade para o grupo de animais durante os tratamentos na fase I (a) e fase II (b). Barras com letras diferentes apresentaram diferença significativa $(P<0,0001)$. LB $=$ Linha de Base, $\mathrm{CT}=$ Controle, $\mathrm{CD}=$ Condicionamento, $\mathrm{PC}=$ Pós-Condicionamento. 

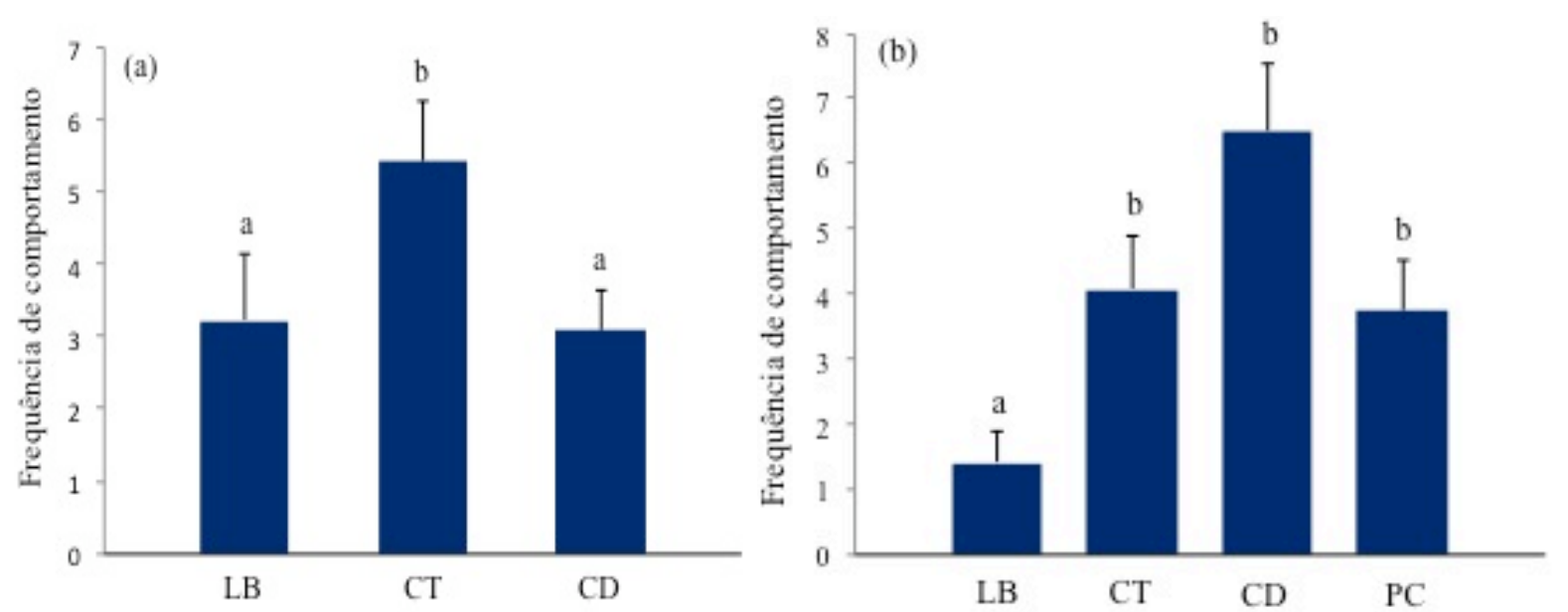

Figura 2.12. Freqüência média (incluindo erro padrão) dos comportamentos indicadores de bem-estar para o grupo de animais durante os tratamentos na fase I (a) e fase II (b). Barras com letras diferentes apresentaram diferença significativa $(P=0,0004) . \mathrm{LB}=$ Linha de Base, $\mathrm{CT}=$ Controle, $\mathrm{CD}=$ Condicionamento, $\mathrm{PC}=$ Pós-Condicionamento.

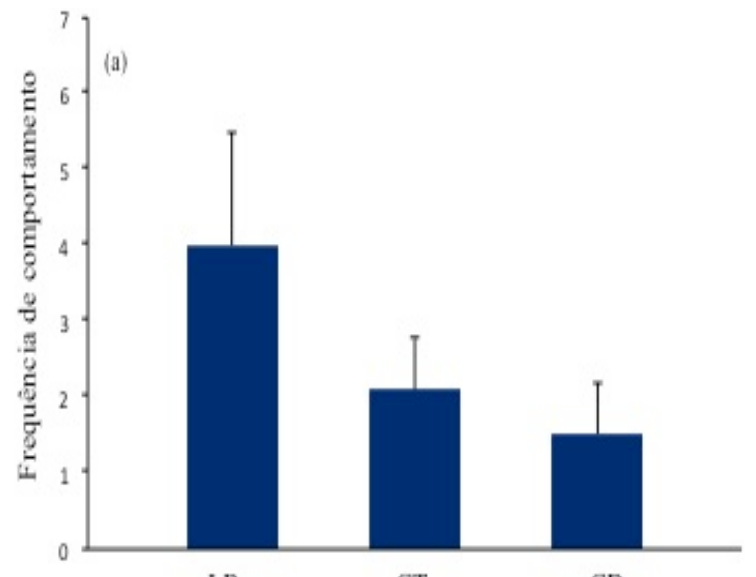

LB

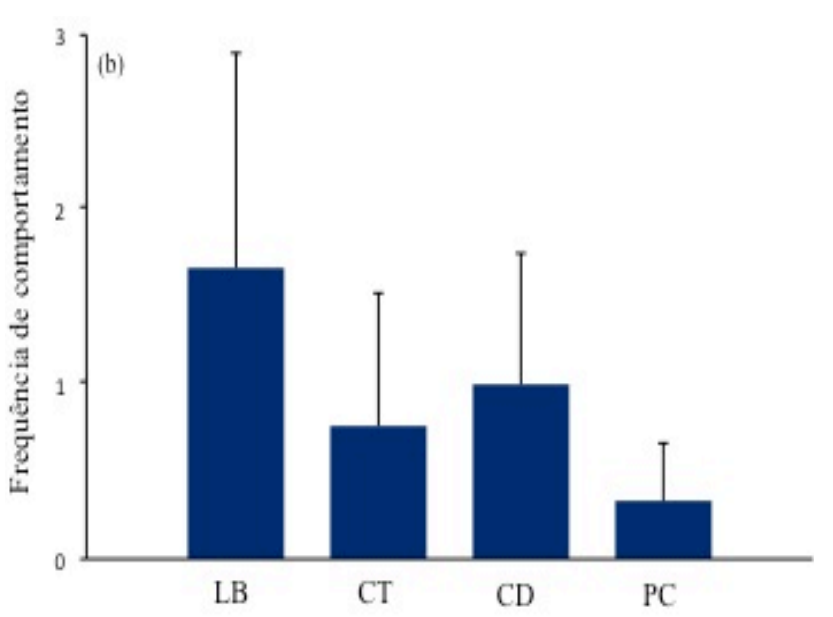

CD

PC

Figura 2.13. Freqüência média (incluindo erro padrão) dos comportamentos indicadores de estresse para o grupo de animais durante os tratamentos na fase I (a) e fase II (b). LB = Linha de Base, $\mathrm{CT}=$ Controle, $\mathrm{CD}=$ Condicionamento, $\mathrm{PC}=$ Pós-Condicionamento.

\subsection{Cortisol}

Os resultados para a concentração de cortisol entre as fases apresentaram uma grande diferença nos valores em razão dos kits (The EIAsy Way-CORTISOL ${ }^{\circledR} /$ Diagnostics Biochem Canadá Inc. na fase 1 e Cortisol Test System-EIA ${ }^{\circledR}$ 3625-300/Monobind Inc na fase 2), que embora tenham sido adquiridos do mesmo laboratório e sob a mesma especificação, apresentavam detalhes técnicos que acabaram gerando dados em grandezas diferentes, impossibilitando a comparação dos dados entre as fases I e II. No entanto, para cada fase as 
análises laboratoriais foram realizadas todas com o mesmo kit, de forma que os dados dos tratamentos da mesma fase puderam ser comparados. Tal circunstância, ocorreu em virtude do lapso temporal de um ano entre as duas fases, não sendo possível manter os kits em estoque por possuírem prazo de validade, além do fato de que não se poderia prever que a empresa iniciaria a comercialização de uma nova marca de kits.

Quanto à concentração de cortisol para a Fase 1, o modelo não apresentou diferença estatística entre os três tratamentos. Já para a Fase 2 o modelo apresentou diferença $(P<0,0001)$ e o teste post hoc Tukey mostrou que o aumento na concentração de cortisol nos tratamentos condicionamento e pós-treino foi significativa em relação à linha de base e controle. Não houve diferença estatística entre os tratamentos linha de base e controle, nem entre as fases controle e condicionamento.

Nas duas fases, não houve diferença significativa nos valores de cortisol entre os sexos.
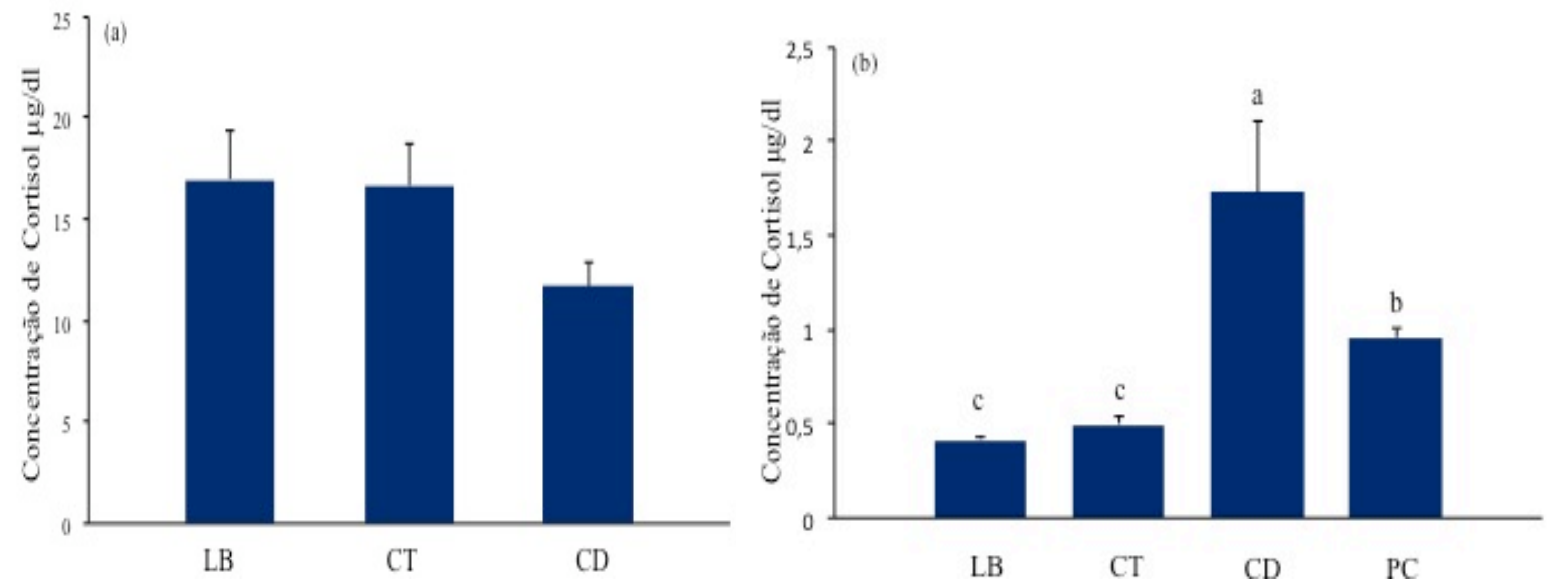

Figura 2.14. Concentração de Cortisol Salivar - ug/dl (incluindo erro padrão) para o grupo de animais durante os tratamentos na fase I (a) e fase II (b). Barras com letras diferentes apresentaram diferença significativa $(P<0,0001) \mathrm{LB}=$ Linha de Base, $\mathrm{CT}=$ Controle, $\mathrm{CD}=$ Condicionamento, $\mathrm{PC}=$ Pós-Condicionamento.

\subsection{Comportamento e Cortisol.}

Na fase I houve correlação positiva de $0,28(P=0,0215)$ entre os comportamentos associados ao bem-estar animal e de atividade, correlação negativa de $0,26(P=0,0337)$ entre 
os comportamentos de inatividade e estresse e correlação negativa de $0,35(P=0,0043)$ entre inatividade e comportamentos associados ao bem-estar animal.

$\mathrm{Na}$ fase II houve correlação positiva de $0,25(P=0,0191)$ entre o cortisol e os comportamentos associados ao bem-estar animal, correlação positiva de $0,30 \quad(P=0,0049)$ entre atividade e comportamentos associados ao bem-estar animal e correlação negativa de $0,31(P=0,0033)$ entre inatividade e comportamentos associados ao bem-estar animal.

Em função da hipótese assumida, os resultados rejeitam que o condicionamento atue na diminuição do hormônio cortisol, pelo menos a curto prazo, e corroboram a hipótese de que a prática provoca modificação no padrão comportamental, elevando a expressão de comportamentos associados ao bem-estar animal. Na primeira fase, a única alteração encontrada foi na expressão de comportamentos associados ao bem-estar animal, que aumentou durante o tratamento controle. Possivelmente, nessa primeira exposição, o fracionamento da alimentação dos animais, possa ter atuado como um fator estimulante, de forma semelhante a um enriquecimento alimentar, uma vez que esse consiste em alterar a forma como o alimento é oferecido aos animais (Shepherdson, 1998).

Em relação à inatividade, tanto o controle quanto o condicionamento provocaram diminuição nos comportamentos enquadrados nessa categoria, o que pode ser interpretado de forma positiva uma vez que eles são considerados indicadores de baixo bem-estar. Além disso, esses resultados se assemelham aos dos estudos realizados com enriquecimento ambiental, que mostraram diminuição da frequência desse tipo de comportamento para onças pintadas (Silva, 2009) e outros felinos, como gato-leopardo (Carlstead et al., 1993a), leões e tigres (Silva, 2014).

A inatividade apresentou correlação negativa com os comportamentos indicadores de bem-estar, corroborando que a falta de atividade indica baixo bem-estar. Ao diminuir a frequencia de inatividade dos animais com os tratamentos, houve ganho na qualidade dos comportamentos expressados, com aumento daqueles associados ao bem-estar, tais como os exploratórios e de interação não agonística (Carsltead, 1993b).

Os comportamentos de atividade e de bem-estar apresentaram correlação positiva, o que significa que a modificação provocada no padrão comportamental dos animais pelos tratamentos é relevante para a qualidade de vida dos animais, uma vez que houve substituição de comportamentos de inatividade por comportamentos de atividade, bem como por aqueles relacionados ao bem-estar.

Quanto à concentração de cortisol, na primeira fase não houve diferença entre os tratamentos, indicando que a técnica não exerceu efeitos sobre o parâmetro fisiológico 
analisado, ainda que tenham sido observados efeitos comportamentais. Na segunda fase, no entanto, o tratamento condicionamento provocou aumento signficativo nos valores de cortisol, que voltaram a diminuir na fase pós-treino. Esse aumento sugere que tenha ocorrido um pico de estresse, seguido de uma diminuição. É possivel que esse aumento inicial seja decorrente do estímulo gerado pelo condicionamento e gradativamente apresente diminuição, até atingir valores semelhantes ou inferiores aos da linha de base, como o que é descrito por Fairshust (2011) em estudo realizado com outra espécie animal. No referido estudo, o cortisol aumentou significativamente após a colocação de enriquecimento ambiental, mas em longo prazo, os valores obtidos são significativamente mais baixos do que os encontrados no grupo controle.

O aumento do cortisol poderia ser explicado ao se considerar o condicionamento como um fator novo, um estimulo diferente apresentado aos animais, partindo do principio de que mudanças fisiológicas estão relacionadas a elementos imprevísiveis no ambiente (Wingfield \& Kitaysky, 2002). No entanto, na primeira exposição ao condicionamento, ou seja, na fase I do experimento, não houve aumento do cortisol, de forma que na fase II não parece adequado considerar sobre imprevisibilidade ou fator novo, pois os animais já haviam tido experiencia prévia com o treino. Na fase II, ao observarem a treinadora se aproximar do recinto, os animais já se encaminavam para perto da tela, onde era realizado o treino, indicando que havia uma associação positiva com essa prática. Além disso, os animais apresentaram bom desempenho na fase II, apesar de transcorrido um ano desde os primeiros treinos. Pressupõese assim que o condicionamento possa ter provocado um estado de estresse positivo nos animais da mesma forma como já tinha sido observado por Moberg, (2000), de forma semelhante a eventos naturais, como a caça, por exemplo (Broom \& Johnson, 1993), especialmente porque houve correlação positiva entre a concentração de cortisol e os comportamentos de bem-estar.

Outros estudos também encontraram associação entre o aumento na concentração desses esteróides e sinais de elevação no bem-estar. Em estudo com enriquecimento ambiental para porcos houve aumento nos níveis de cortisol, mas os parâmetros comportamentais indicam que houve melhora no bem-estar, com diminuição da inatividade e dos comportamentos sociais prejudiciais e agressivos (Beattie et al., 2000). Resultados semelhantes foram obtidos com camundongos expostos a condições de enriquecimento, com aumento na concentração de corticosterona e com parâmetros comportamentais indicando efeitos positvos, com aumento nos comportamentos de "brincadeira" e nos comportamentos sociopositivos (Marashi et al., 2003). 
Assim, a interpretação das alterações encontradas, sejam comportamentais ou fisiológicas depende do contexto no qual elas ocorreram. O aumento na concentração dos glicocorticóides pode representar um indicador de sucesso. Essa elevação na concentração pode ser causada, por exemplo, pela necessidade de resolver problemas, decorrentes do enriquecimento (Vasconcellos \& Ades, 2012).

O fato do tratamento controle também apresentar alguns efeitos benéficos sugere que o simples oferecimento do alimento fracionado pelo tratador pode melhorar a qualidade de vida do animal. Essa simples prática possivelmente atue melhorando a relação homemanimal, uma preocupação que vem crescendo quando se trata da manutenção de animais cativos, do bem-estar e segurança de ambos (Hosey, 2008). A utilização do condicionamento animal para animais cativos tem sido difundida nos zoológicos, trazendo benefícios, que incluem uma mudança no método empregado, com utilização de reforço positivo e intensificação da percepção da linguagem corporal do animal, no sentido de evitar as respostas de medo e os comportamentos agressivos (Brando, 2012). 


\section{CONCLUSÃO}

O condicionamento operante aplicado a onças pintadas em cativeiro apresentou resultados positivos, uma vez que elevou a freqüência de comportamentos associados ao bemestar animal e diminuiu a inatividade, o que sugere que a prática tenha potencial para melhorar a qualidade de vida de animais cativos. Estudos que considerem os efeitos do condicionamento a longo prazo poderão ser importantes para esclarecer como os elementos da tríade condicionamento, comportamento e estresse se relacionam. No entanto, os resultados obtidos mostram que o condicionamento pode modificar os padrões comportamentais e fisiológicos, contribuindo para o conhecimento a respeito dos efeitos do condicionamento sobre o bem-estar animal de onças-pintadas, indicando a receptividade desses animais para a técnica. 


\section{REFERÊNCIAS}

ALTMANN, J.. Observational study of behavior: sampling methods. Behaviour v. 49, p. 227-265, 2973.

BASSETT, L.; BUCHANAN-SMITH, H.M.; MCKINLEY, J.; SMITH T.E.. Effects of training on stress-related behavior of the common marmoset (Callithrix jacchus) in relation to coping with routine husbandry procedures. Journal of Applied Animal Welfare Science, v.6, n.3, p. 209-220, 2003.

BASSETT, L.; \& BUCHANAN-SMITH, H. M.. Effects of predictability on the welfare of captive animals. Applied Animal Behaviour Science, v. 102, n. 3-4, p. 223-245, 2007.

BEATTIE, V.E.; O'CONNEL, N.E.; KILPATRICK, D.J.; MOSS, B.W.. Influence of environmental enrichment on welfare-related behavioural and physiological parameters in growing pigs. Animal Science, v.70, n. 3, p. 443- 450, 2000.

BLOOMSMITH M.A.; LAULE G.E.; ALFORD P.L.; THURSTON R.H.. Using training to moderate chimpanzee aggression during feeding. Zoo Biology, v. 13, n.6, p. 557-566, 1994.

BRANDO, A.I.C.A. Animal learning and training: implications for animal welfare. The Veterinary Clinics of North America Exotic Practice, v.15, n.3, p. 387-398, 2012.

BROOM, D. M.; JOHNSON, K. G. Stress and Animal Welfare. London: Chapman and Hall, 1993.

BROWN, J.L.. Comparative endocrinology of domestica and nondomestic felids. Theriogenology, v. 66, n. , 2006, p. 25-36.

CARLSTEAD, K.; BROWN, J. L.; SEIDENSTICKER, J.. Behavioral and adrenocortical responses to environmental changes in leopard cats (Felis bengalensis). Zoo Biology, v. 12, p. 321-331, 1993a.

CARLSTEAD, K.; BROWN J.L.; STRAWN, W.. Behavioral and physiological correlates of stress in laboratory cats. Applied Animal Behavior Science, v. 38, n.2, p.143-158, 1993 b.

CARVALHO JR, E. A. R C.; MORATO, R. G.. Factors affecting big cat hunting in Brazilian protected areas. Tropical Conservation Science, v. 6, n. 2, p. 303-310, 2013. 
CASTILLO-GUEVARA, C.; UNDA-HARP, K., LARA， C.; SERIO-SILVA， J.C.. Enriquecimiento ambiental y su efecto en la exhibición de comportamientos estereotipados en jaguares (Panthera onca) del parque Zoológico "Yaguar Xoo", Oaxaca. Acta Zoológica Mexicana (n.s.), v. 28, n. 2, p. 365-377, 2012.

COLEMAN, K.; MAIER, A.. The use of positive reinforcement training to reduce stereotypic behavior in rhesus macaques. Applied Animal Behaviour Science, v. 124, n.3-4, p. 142-148, 2010 .

DEL CLARO, K. Comportamento Animal: Uma introdução à ecologia comportamental. Editora Livraria Conceito: Jundiaí - SP,. 2004. 132p.

EMER, S.A.; MORA, C.V.; HARVEY, M.T.; GRACE, M.S.. Predators in training: operant conditioning of novel behavior in wild Burmese pythons (Python molurus bivitattus). Animal Cognition, v. 18, n. 1, p. 269-278, 2015.

FAIRHURST, G.D.; FREY M.D.; REICHERT, J.F.; SZELEST, I.; KELLY, D.M.; BORTOLOTTI G.R.. Does environmental enrichment reduce stress? An integrate measure of corticoesterone from feathers provides a novel perspective. Plos one, v.6, n.3. p. 1-10, 2011.

GIPPOLITI, S.. Zoos and conservation in the XXI Century: overlooked meeting points between ecology and social sciences? Museologia Scientifica nuova serie, v.5 n. 1-2, p. 168$176,2011$.

GUILLETTE, L.M.; HAHN, A.H.; HOESCHELE, M.; PRZYSLUPSKI, A; STURDY, C.B; Individual differences in learning speed, performance accuracy and exploratory behaviour in black-capped chickadees. Animal Cognition, v.18, p.165-178, 2015.

HAAG T.; SANTOS A.S.; SANA D.A.; MORATO R.G.; CULLEN L.JR.; CRAWSHAW P.G. JR.; DE ANGELO C, DI BITETTI M.S.; SALZANO F.M.; EIZIRIK E.. The effect of habitat fragmentation on the genetic structure of a top predator: loss of diversity and high differentiation among remnant populations of Atlantic Forest jaguars (Panthera onca). Molecular Ecology, v.19, n.22, p. 4906-4921, 2010.

HOSEY, G. A preliminary model of human-animal relationships in the zoo. Applied Animal Behaviour Science, v. 109, n. 2-4, p. 105-127, 2008.

LAMBETH, S.P.; HAU, J., PERLMAN, J.E.; MARTINO, M.; SCHAPIRO, S.J.. Positive reinforcement training affects hematologic and serum chemistry values in captive chimpanzees (Pan troglodytes). American Journal of Primatology, v. 68, n.3, p. 245-256, 2006.

LASLEY, B.L.; KIRKPATRICK J.F.. Monitoring ovarian function in captive and freeranging wildlife by means of urinary and fecal steroids. Journal of Zoo and Wildlife Medicine, v. 22, n.1, p.22-31, 1991.

LAULE, G.; DESMOND T.. (1998). Positive reinforcment training as an enrichment strategy. In: D. J. Shepherdson, J. D. Mellen \& M. Hutchins (Orgs.) 1998. Second Nature: environmental enrichment for captive animals. Washington: Smithsonian Institution Press. 302-313. 
LEE, J.J.; SHIN, J.S, LEE, J.E.; JUNG, W.Y.; LEE, G.; KIM, M.S.; PARK, C.G.; KIM, S.J.. Changes of $\mathrm{N} / \mathrm{L}$ ratio and cortisol levels associated with experimental training in untrained rhesus macaques, Journal of Medical Primatology, v. 42, n. 1, p. 10-14, 2013.

MARASHI, V.; BARNEKOW, A.; OSSENDORF, E.; SACHSER, N.. Effects of different forms of environmental enrichment on behavioral, endocrinological, and immunological parameters in male mice. Hormones and Behavior, v. 43, n. 2, p. 281-292, 2003.

MASON G. Forms of stereotypic behaviour. In: Lawrence A.B.; Rushen J., (Ed.) Stereotypic animal behaviour: fundamentals and applications to welfare. Wallingford: $U K: C A B$ International. 1993. p.7-40.

MATOS, M.A.. Controle experimental e controle estatístico: a filosofia do caso único na pesquisa comportamental. Ciência e Cultura, v.42, n.8 p.585-592, 1990.

MCPHEE, M.E.. Intact Carcasses as Enrichment for Large Felids: Effects on On- and OffExhibit Behaviors. Zoo Biology, v. 21, n. 1, p. 37-47, 2002.

MOBERG, G.P. Biological response to stress: implications for animal welfare. In: MOBERG, G.P.; MENCH, J. A. (Ed.) The biology of animal stress. New York: CABI Publishing, 2000. p. 123-146.

MONTANHA, J. C.; SILVA, S. L.; BOERE, V.. Comparison of salivary cortisol concentrations in Jaguars kept in captivity with differences in exposure to the public. Ciência Rural, v. 39, n. 6, p. 1745-7451, 2009.

MÖSTL, E.; PALME, R.. Hormones as indicators of stress. Domestic Animal Endocrinology, v.23, n.1-2, p. 67-74, 2002.

MUNCK, A.; GUYRE, P. M.; HOLBROOK, N. I.. Physiological functions of glucocorticoids in stress and their relationship to pharmacological actions. Endocrinology Reviews, v. 5, n. 1, p. 25-44, 1984.

NEX (2013). Quem somos. Disponível em <http://www.nex.org.br> Acesso em 18/05/13.

PERLMAN, J.E.; BLOOMSMITH, M. A.; WHITTAKER, M. A.; MCMILLAN, J.L.; MINIER, D.E.; MCCOWAN, B.. Implementing positive reinforcement animal training programs at primate laboratories. Applied Animal Behaviour Science, v. 137, n. 3-4 114$126,2012$.

PRYOR, K. Don't shoot the dog!: The New Art of Teaching and training. Gloucestershire, Ringpress Books Ltd, 2002, 202p.

ROSAS-ROSAS, O.C.; VALDEZ R.. The role of landowners in jaguar conservation in Sonora, México. Conservation Biology v. 24, n. p. 366-371, 2010.

SAUDARGAS, R. A.; DRUMMER, L. C.. Single subject (small n) research designs and zoo research. Zoo Biology, v.15, p. 173-181, 1996. 
SCHAPIRO, S.; PERLMAN, J.E.; BOUDREAU, B.A.. Manipulating the Affiliative Interactions of Group-Housed Rhesus Macaques Using Positive Reinforcement Training Techniques. American Journal of Primatology, v. 55, n. 3, p. 137-149, 2001.

SCHWARZENBERGER, F.. The many uses of non-invasive faecal steroid monitoring in zoo and wild life species. International ZooYearbook, v. 41, n. 1, p. 52-74, 2007.

SHEPHERDSON, D. J. Tracing the path of enviromental enrichment in zoos. In: D. J. SHEPHERDSON, D.; MELLEN, J., HUTCHINS, M. (Eds.) Second Nature: environmental enrichment for captive animals, Washington: Smithsonian Institution Press, 1998. p.01-12.

SILVA, C.R.S.; ADANIA, C.H. Carnívora - Felidae (Onça, Suçuarana, Jaguatirica, Gato-domato). In: CUBAS, Z.S.; SILVA J.C.R.; CATÃO-DIAS J.L. Tratado de Animais Selvagens - Medicina Veterinária. Editora Roca. São Paulo, 2007. p.505-546.

SILVA, R.O. (2011). Enriquecimento ambiental cognitivo e sensorial para onçaspintadas (Panthera onca) sedentárias em cativeiro induzindo redução de níveis de cortisol promovendo bem-estar. Brasília, Instituto de Psicologia da Universidade de Brasília, 2011. 58p. Dissertação (Mestrado em Ciências do Comportamento) - Departamento de Processos Psicológicos Básicos, Instituto de psicologia da Universidade de Brasília, 2011.

SILVA, T. B. B.; ABREU, J. B.; GODOY, A. C.; CARPI, L.C.F.G.. Enriquecimento ambiental para felinos em cativeiro. Atas de Saúde Ambiental - ASA, v. 2, n.3, p. 44-52, 2014.

SKINNER, B. F. Sobre o Behaviorismo. São Paulo: Editora Cultrix, 1974, 209p.

SUNQUIST, M.E.; SUNQUIST, F. Wild cats of the world. Chicago: University of Chicago Press, 2002. 462p.

SWAISGOOD, R. R.. The conservation-welfare nexus in reintroduction programmes: a role for Sensory ecology. Animal Welfare, v. 19, n. 2, p. 125-13, 2010.

TOUMA, C., PALME R.; SASCHER, N.. Analyzing corticosterone metabolites in fecal samples of mice: a noninvasive technique to monitor stress hormones. Hormones and behavior, v. 45, n.1, p. 10-22, 2004.

TOUMA, C.; PALME, R. Measuring Fecal Glucocorticoid Metabolites in Mammals and Birds: The Importance of Validation. Annals of the New York Academy of Sciences, v.1046, n.1, p. 54-74, 2005.

UNIVERSITIES FEDERATION FOR ANIMAL WELFARE - UFAW. Guia para o enriquecimento das condições ambientais do cativeiro ( $\mathrm{S}$. Celotti, Trad.). Sociedade Zoófila Educativa: São Paulo, 1997.

VASCONCELLOS, A.S.; VIRÁNYIL, Z.; RANGE, F.; MOSTL, E.; ADES, C.; KOTRSCHAL, K.. Social interactions and non-invasive stress monitoring in captive timber wolves (Canis lupus). Journal of Veterinary Behavior; Clinical Applications and Research, v. 6, n. 1, p. 71-72, 2011. 
VASCONCELLOS, A.S.; ADES, C.. Possible limits and advances of environmental enrichment for wild animals. Revista de Etologia, v. 11, n. 1, p. 37-45, 2012.

VEEDER, C.L.; BLOOMSMITH, M.A.; MCMILLAN, J.L.; PERLMAN, J.E.; MARTIN, A.L.. Positive Reinforcement Training to Enhance the Voluntary Movement of GroupHoused Sooty Mangabeys (Cercocebus atys atys). Journal of the American Association for Laboratory Animal Science, v. 48, n. 2, p.192-195, 2009.

WINGFIELD J.C.; KITAYSKY A.S.. Endocrine responses to unpredictable environmental events: Stress or anti-stress hormones? Integrative and Comparative Biology v. 42: p. 600$609,2002$.

YOUNG, R. J. Environmental enrichment for captive animals. Oxford: Blackwell Science, 2003. 228p. 


\section{CAPÍTULO 3}

CONDICIONAMENTO OPERANTE APLICADO A ONÇAS-PINTADAS

(Panthera onca) CATIVAS 


\title{
RESUMO
}

\section{CONDICIONAMENTO OPERANTE APLICADO A ONÇAS-PINTADAS (Panthera onca) CATIVAS}

\author{
Liane Cristina Ferez Garcia, MSc. \\ Francisco Ernesto Moreno Bernal, Prof. Dr. \\ Brasília, DF.
}

A crescente preocupação com o bem-estar de animais mantidos em cativeiro tem levado as instituições a aprimorarem as suas práticas de manejo, incorporando atividades que visam elevar a qualidade de vida dos animais, como o enriquecimento ambiental e técnicas que buscam, principalmente, facilitar os procedimentos de rotina, como o condicionamento. $\mathrm{O}$ uso do condicionamento é cada vez mais crescente nas instituições, sendo importante estudos que permitam conhecer como se comportam diferentes espécies, a fim de investigar, por exemplo, o quanto as diferenças individuais interferem no desempenho. Por meio do treinamento, é possível elevar a qualidade de vida e facilitar o manejo e acesso aos animais, possibilitando avanços em pesquisas que visem a conservação das espécies ameaçadas, como a onça pintada. Esse estudo teve como objetivo analisar a resposta de indivíduos dessa espécie ao condicionamento, analisando o desempenho individual e sua relação com a concentração de cortisol salivar e a faixa etária dos animais. $\mathrm{O}$ experimento foi conduzido com oito animais (4 machos e 4 fêmeas), submetidos a um teste inicial para classificação quanto ao temperamento e então a 12 sessões de condicionamento nas quais foram treinados comandos básicos, como encostar o focinho no bastão, ficar parado e seguir o bastão. Os animais foram classificados como sociáveis (3), indiferentes (3) e agressivos (2). Todos os animais responderam corretamente aos comandos iniciais, e cinco deles atingiram 5 comandos assimilados. Os dois indivíduos agressivos apresentaram o desempenho mais baixo, com maior demora para a realização correta do comando inicial. Os animais responderam de forma satisfatória aos 
treinos, assim, é possível que o condicionamento seja utilizado para onças pintadas cativas como estratégia para facilitar o manejo, minimizando o estresse envolvido em alguns procedimentos de rotina, melhorando a qualidade da relação homem-animal e contribuindo na elevação dos níveis de bem-estar.

Palavras-chave: Bem-estar, condicionamento, Felinos sul-americanos, cortisol, cativeiro. 


\author{
ABSTRACT \\ ANIMAL TRAINING TO CAPTIVE JAGUAR \\ (Panthera onca) \\ Liane Cristina Ferez Garcia, MSc. \\ Francisco Ernesto Moreno Bernal, Prof. Dr. \\ Brasília, DF.
}

Increased concerns with the captive animal welfare has driven institutions to hone their management practices by incorporating activities that aim to increase the quality of life of animals, such as environmental enrichment and techniques that primarily seek to facilitate routine procedures such as animal training. The use of conditioning is increasingly growing in institutions, and are important studies that provide knowledge about how different species behave in order to investigate, for example, as individual differences interfere with the performance. By means of training, it can elevate the quality of life and facilitate the handling and access to the animals, enabling advances in researches aimed at conserving of the endangered species such as the jaguar. This study aimed to analyze the answer of individuals of that species to conditioning, analyzing individual performance and its relationship with salivary cortisol concentration and the age of the animals. The experiment was conducted with eight animals (4 males and 4 females) who underwent an initial test for classification according to temper and then to 12 conditioning sessions in which basic commands were trained as touching the muzzle on target, stand still and follow the target. The animals were subjected to a sociability test that ranked the individuals as sociable (3), indifferent (3) and aggressive (2). As for the learning, all animals showed appropriate responses to initial commands, and five of them reached 5 assimilated commands. The two aggressive individuals had the lowest performance with increased delay for correct performance of the initial commands. The animals responded satisfactorily to training, so it is possible that the 
conditioning is used for captive jaguars as a strategy to facilitate the management, minimizing the stress involved in some routine procedures, improving the quality of human-animal relationship and contributing to the increase in welfare.

Palavras-chave: Bem-estar, condicionamento, Felinos sul-americanos, cortisol, cativeiro. 


\section{INTRODUÇÃO}

O treinamento de animais por meio de técnicas de condicionamento operante é chamado também de treinamento com reforço positivo, ou positive reinforcement training (PRT) e vem sendo utilizado, especialmente em primatas não humanos que, em laboratório, são treinados para executar comportamentos que auxiliam na rotina (Veeder, 2009) e em procedimentos veterinários (Lambeth et al., 2006). Além disso, o condicionamento facilita as pesquisas (Bassett et al., 2003), melhora a interação social (Schapiro, et al., 2001), promove bem-estar para os animais (Bloomsmith, et al. 1994) e torna mais positiva a experiência dos visitantes de zoológicos (Anderson et al., 2003).

O condicionamento operante, também conhecido como instrumental, é uma das categorias de aprendizagem estímulo-resposta, sendo descrito como a capacidade de aprender a executar um comportamento específico frente a um estímulo particular, assim como o condicionamento clássico. O ambiente está em constante mudança, por isso, a capacidade de aprender a desenvolver comportamentos adaptados às mudanças é crucial para a sobrevivência. As experiências vivenciadas pelos organismos modificam a forma como percebem e executam os comportamentos, por meio de alterações na estrutura física do sistema nervoso (Carlson, 2002).

O treino com reforço positivo consiste em recompensar os comportamentos desejáveis apresentados pelos animais, sendo possível reduzir o estresse e o medo associado a determinadas situações, uma vez que os animais passam a expressar escolha e cooperar com os procedimentos (Lambeth et al., 2006), o que pode otimizar a rotina de trabalho em laboratórios (Bassett et al., 2003). O reforço negativo é comumente utilizado com algumas espécies, como cavalos, por exemplo, no entanto, com o uso do reforço positivo os animais passaram a apresentar mais motivação para o treinamento e mais comportamentos exploratórios, indicadores de melhor bem-estar (Innes \& Mc Bride, 2008). 
Os estudos com PRT mostram que existem diferenças individuais, tanto quando se observou o efeito da técnica para redução de estereotipias (Coleman \& Maier, 2010) quanto para aprender os comandos (Bloomsmith et al. 1998, Bassett, et al. 2003). Existem ainda diferenças entre as espécies, principalmente no tempo de assimilação dos primeiros comandos (Rogge et al., 2014). A maioria dos estudos com PRT envolve primatas não humanos, especialmente em laboratórios, mas estudos recentes incluem espécies de aves (Heidereich , 2007, Guillette et al., 2015) e répteis (Emer, et al., 2015).

A qualidade da relação desses animais com as pessoas também é um fator que influencia o tempo utilizado para a aprendizagem, com o medo de pessoas sendo um fator determinante (Bassett, et al. 2003, Rooge et al., 2014). Nesse sentido, a relação homemanimal (HAR) tem sido assunto de muitos estudos relacionados à produtividade e ao bemestar animal de animais de produção, que mostram uma correlação negativa entre medo e produtividade, evidenciando que o medo de humanos é um fator limitante da produção e do bem-estar animal (Hemsworth, 2003).

Os animais domésticos tendem a apresentar medo do ser humano, especialmente quando a maior parte das interações é aversiva, como as vacinações, tratamentos veterinários e o manejo para o transporte, podendo aqui ser observada uma importante variável para determinar o medo nos animais, o comportamento do tratador, que é portanto o principal fator na qualidade da HAR. Quando há interações positivas desse profissional com os animais o estresse causado por procedimentos aversivos, como inspeções veterinárias de rotina, palpação retal e inseminação artificial, doma, dentre outros, parecem diminuir (Waiblinger, 2004).

Os estudos sobre HAR utilizam uma das três metodologias a seguir: testes que medem o quanto animais se aproximam ou evitam pessoas; testes sobre a resposta dos animais quando manipulados e escores subjetivos de classificação de temperamento frente a pessoas, tais como "calmo", "medroso", "dócil” (Passile et al., 2005). Os estudos sobre interações homem-animal geralmente associam dois ou mais testes e questionários, especialmente pela dificuldade de se avaliar de forma confiável parâmetros "emocionais", tanto dos animais quanto dos tratadores.

A relação entre homens e animais pode ser definida como "um histórico de interações que permite a cada um fazer predições sobre o comportamento do outro". A quantidade e a qualidade dessas interações determinam a natureza da relação e seus efeitos são recíprocos (Hemsworth, 2003).

A aplicação do conceito de HAR para animais em zoológicos e em centros de 
conservação de fauna e seus tratadores deve ser cautelosa, especialmente devido à influência exercida pela visitação. Assim, nesse caso as interações devem ser separadas em dois grupos, as que envolvem pessoas familiares aos animais, como os tratadores e as que envolvem pessoas não conhecidas, como os visitantes (Hosey, 2007). Embora a aplicação desse conceito aos animais em zoológicos ainda não seja corroborada para todas as espécies, para pequenos felinos a qualidade da interação com os tratadores foi um fator significante para o sucesso reprodutivo (Mellen, 1991). De acordo com Minier e colaboradores (2011), o uso do PRT levou à diminuição nos comportamentos agressivos de macacos rhesus direcionados aos seus tratadores, melhorando a relação homem-animal.

A qualidade da interação entre homem e animal pode ser também avaliada por meio de parâmetros fisiológicos, tendo sido encontrada correlação negativa entre o tempo de interação com os tratadores e os níveis de corticóides fecais para pantera nebulosa (Neofelis nebulosa) (Wielebnowski et al., 2002). O cortisol, um dos mais importantes representantes dos glicocorticóides, é um hormônio produzido pela glândula adrenal, cuja liberação está relacionada ao estresse físico ou psicológico (Guyton \& Hall, 2006), razão pela qual vem sendo utilizado como parâmetro a ser mensurado em estudos que buscam avaliar os níveis de bem-estar animal (Möstl \& Palme, 2002, Montanha, 2009, Vasconcelos, 2011).

Estudos recentes tem analisado os efeitos do treinamento por meio da mensuração do cortisol em diferentes espécies animais. Em cavalos o cortisol salivar foi utilizado para avaliar o estresse provocado por treinos físicos, como corridas (Keszieski et al., 2014) e para esses animais é comum o aumento na concentração desse hormônio, associado ao estresse provocado pelo início do treino de montaria (Schmidt et at., 2010). Já para macacos Rhesus, houve redução na concentracão de cortisol somente após 3 semanas de condicionamento, sugerindo que é necessário um tempo inicial de adaptação ao protocolo de manejo (Lee et al., 2013). Gatos domésticos treinados com condicionamento operante para coleta de sangue apresentaram cortisol mais baixo do que gatos não treinados (Lockhart, 2013).

Paralelo às observações até aqui mencionadas, o temperamento dos animais cativos deverá ser sempre considerado, pois pode ser afetado pelas ações do homem, e, ainda que essas ações sejam intencionais, os resultados podem ser diferentes a aquilo que foi projetado, com efeitos indesejados que podem afetar o sucesso das estratégias de conservação. Os traços de temperamento são suscetíveis às pressões de seleção e podem resultar em mudanças evolutivas, tanto em populações cativas quanto selvagens. Assim, estudos que considerem o temperamento dos animais são essenciais para elevar o sucesso dos programas de conservação (Dougall et al., 2006). 
A espécie escolhida, Panthera onca, sofre com a fragmentação de habitats (Sunquist \& Sunquist, 2002, Haag et al., 2010) e com a caça ilegal (Rosas-Rosas \& Valdez, 2010), que ocorre inclusive em áreas protegidas (Carvalho \& Morato, 2013), razões que estão provocando declínio populacional e ameaçam a espécie.

O presente estudo analisou o desempenho de onças-pintadas cativas submetidas a sessões de condicionamento, utilizando o cortisol salivar como parâmetro fisiológico para avaliação dos efeitos da técnica sobre os animais, especialmente quanto ao desempenho apresentado por cada indivíduo. Os animais integrantes do estudo foram categorizados previamente quanto à reação apresentada diante da presença humana, com objetivo de verificar se esse tipo de temperamento estaria relacionado ao desempenho individual. Foram trabalhados comandos básicos para facilitação do manejo e de procedimentos veterinários, que podem futuramente auxiliar na obtenção de informações sobre a espécie, uma vez que a partir do condicionamento é possível acessar mais facilmente o animal para realização de coletas que permitem conhecer melhor os parâmetros fisiológicos da espécie, contribuindo para os programas de conservação. 


\section{MATERIAL E MÉTODO}

\subsection{Local do experimento}

O estudo foi conduzido no Criadouro Conservacionista No Extinction "NEX", nos meses de agosto a outubro de 2013 e 2014. O Criadouro esta localizado no Município de Corumbá de Goiás a $80 \mathrm{~km}$ de Brasília. O local no momento do estudo contava com 12 onças pintadas (Panthera onca) e 08 suçuaranas (Puma concolor), além de outros felídeos silvestres. O NEX tem como finalidade a preservação dos felídeos da fauna silvestre ameaçados de extinção, proteção contra a caça e atua integrando as populações rurais mais carentes ao trabalho de defesa e preservação, por meio da conscientização, treinamento e educação ambiental (NEX, 2013).

\subsection{Animais e instalações}

O estudo foi realizado com 8 onças pintadas (Panthera onca) que faziam parte do Criadouro Conservacionista NEX e cuja caracterização (sexo, idade e origem) está descrita na tabela 3.1 . 
Tabela 3.1 - Descrição dos indivíduos que participaram do experimento

\begin{tabular}{lccc}
\hline Nome & Sexo & Idade & Origem (local provável) \\
\hline Sansão & Macho & 12 & Nascido em cativeiro \\
\hline Dalila & Fêmea & 12 & Nascido em cativeiro \\
\hline Carlota & Fêmea & 12 & Nascido em cativeiro \\
\hline Xingu & Macho & 5 & Possivelmente nascido em cativeiro \\
\hline Gaya & Fêmea & 1 & Nascido em cativeiro \\
\hline Brutus & Macho & 5 & Mato Grosso (capturado filhote) \\
\hline Xamã & Macho & 3 & Nascido em cativeiro \\
\hline Yamí & Fêmea & 5 & Possivelmente nascido em cativeiro \\
\hline
\end{tabular}

Os animais estavam alojados em casais, em recintos que possuem entre $100 \mathrm{~m}^{2} \mathrm{e}$ $400 \mathrm{~m}^{2}$. Todos os recintos apresentavam uma área verde, lago artificial, cambiamentos, plataformas para exploração vertical e vegetação. Os animais eram alimentados diariamente, no fim da tarde, com aproximadamente $3 \mathrm{~kg}$ de carne suína por indivíduo, oferecida no interior do cambiamento, área destinada ao manejo desses animais, considerando que a entrada de tratadores no recinto só ocorre com os animais nos cambiamentos, devidamente travados.

O indivíduo Brutus apresentava deficiência visual, possivelmente relacionada a deficiência nutricional durante o desenvolvimento do animal.

\subsection{Teste de sociabilidade}

Para realização do teste de sociabilidade (Tabela 3.2), uma pessoa aproximou-se do recinto e, durante 5 minutos, o comportamento do animal foi registrado utilizando-se uma filmadora. O teste foi realizado sempre com a mesma pessoa, com trajes escuros, e que não havia feito uso de perfumes. De acordo com a resposta à aproximação humana o animal foi enquadrado em uma das três categorias: sociável, indiferente ou agressivo, representados nas figuras $3.1,3.2$ e 3.3 . 
Tabela 3.2 - Graus de socialização das onças com humanos

\begin{tabular}{lc}
\hline Categorias & Descrição da resposta do animal ao teste de aproximação \\
\hline Sociável & Animal que se aproxima da tela, podendo encostar o corpo e permitir o toque \\
(Figura 3.01)
\end{tabular}

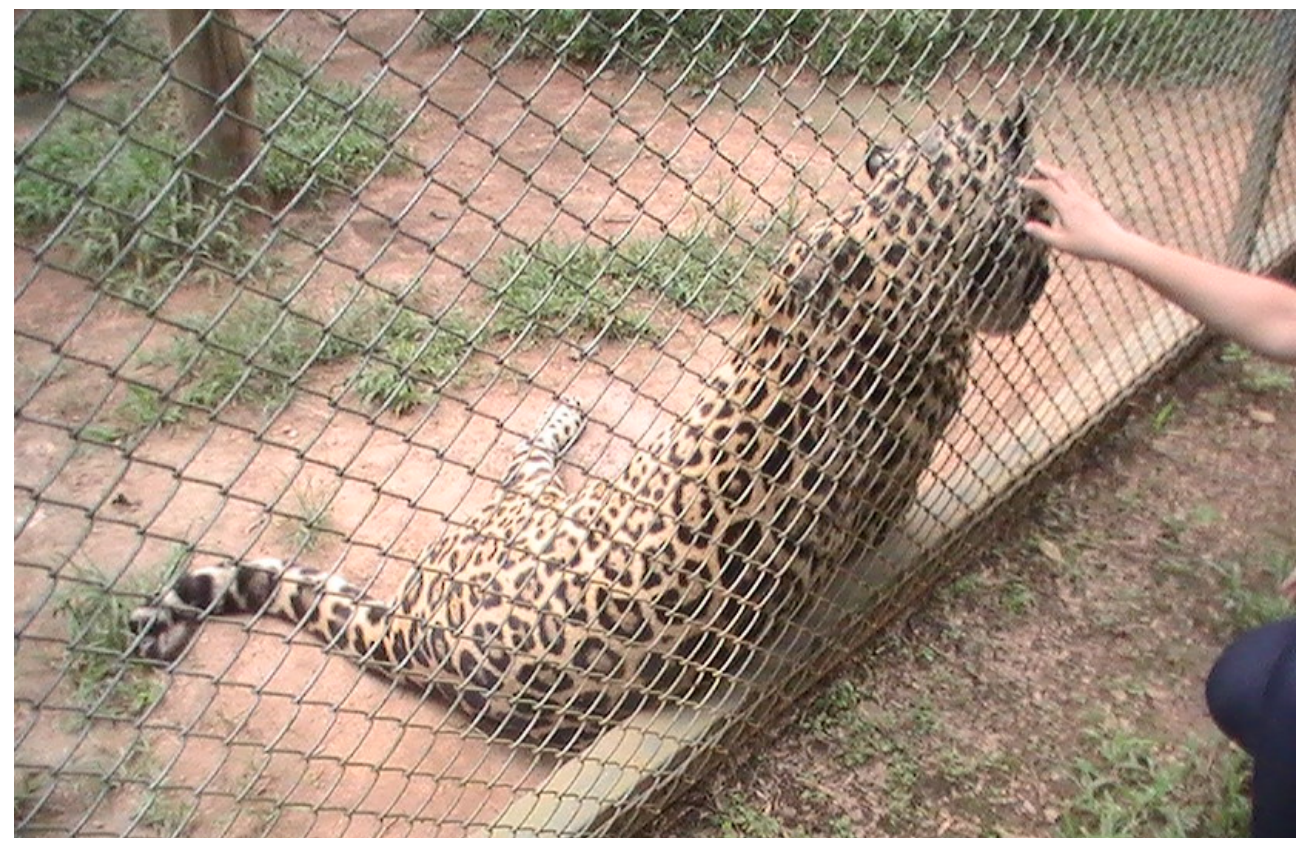

Figura 3.1 O comportamento típico dos animais classificados como sociáveis.

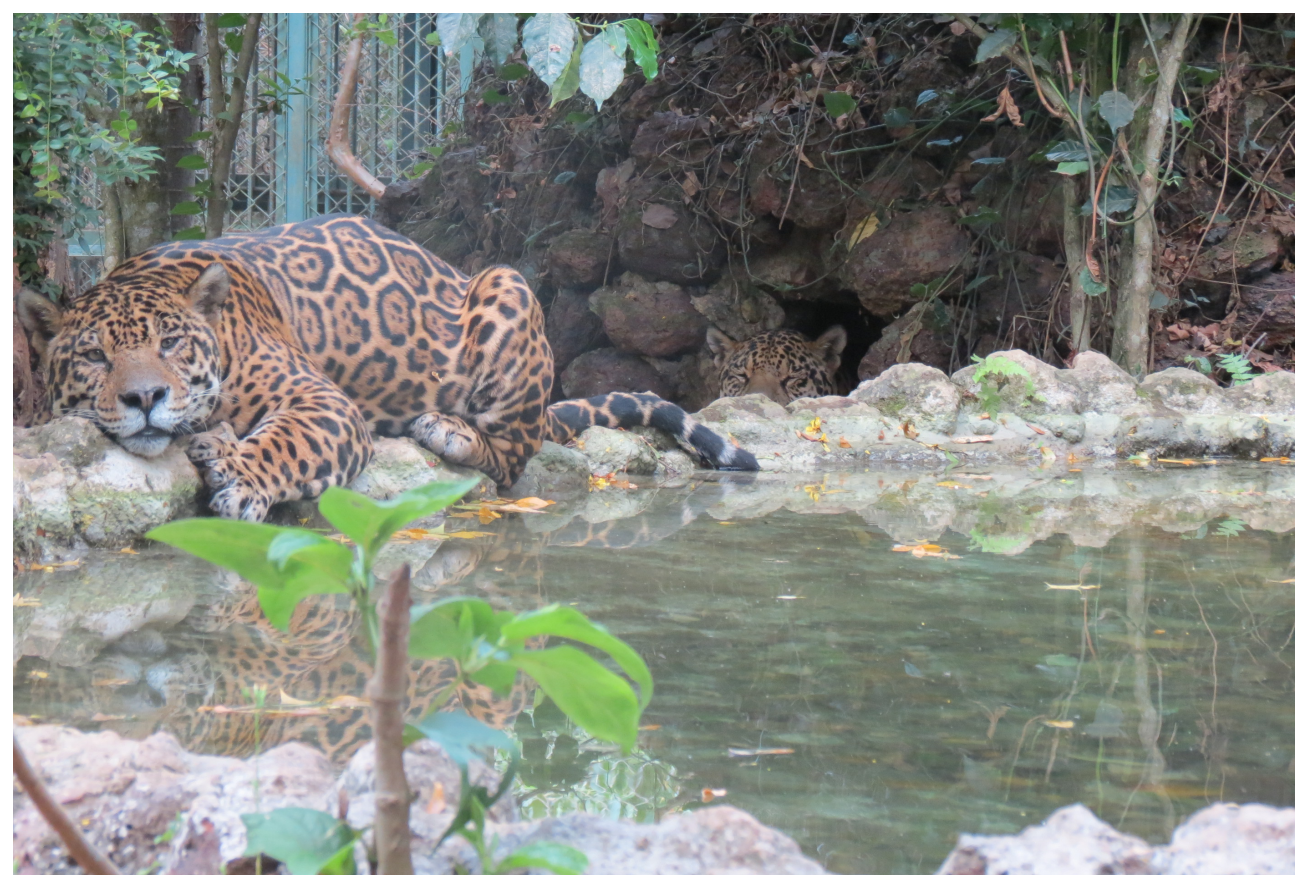

Figura 3.2. Um dos comportamentos dos animais classificados como indiferentes, que não alteram a expressão de seus comportamentos no sentido de interagir com o ser humano que se aproxima. 


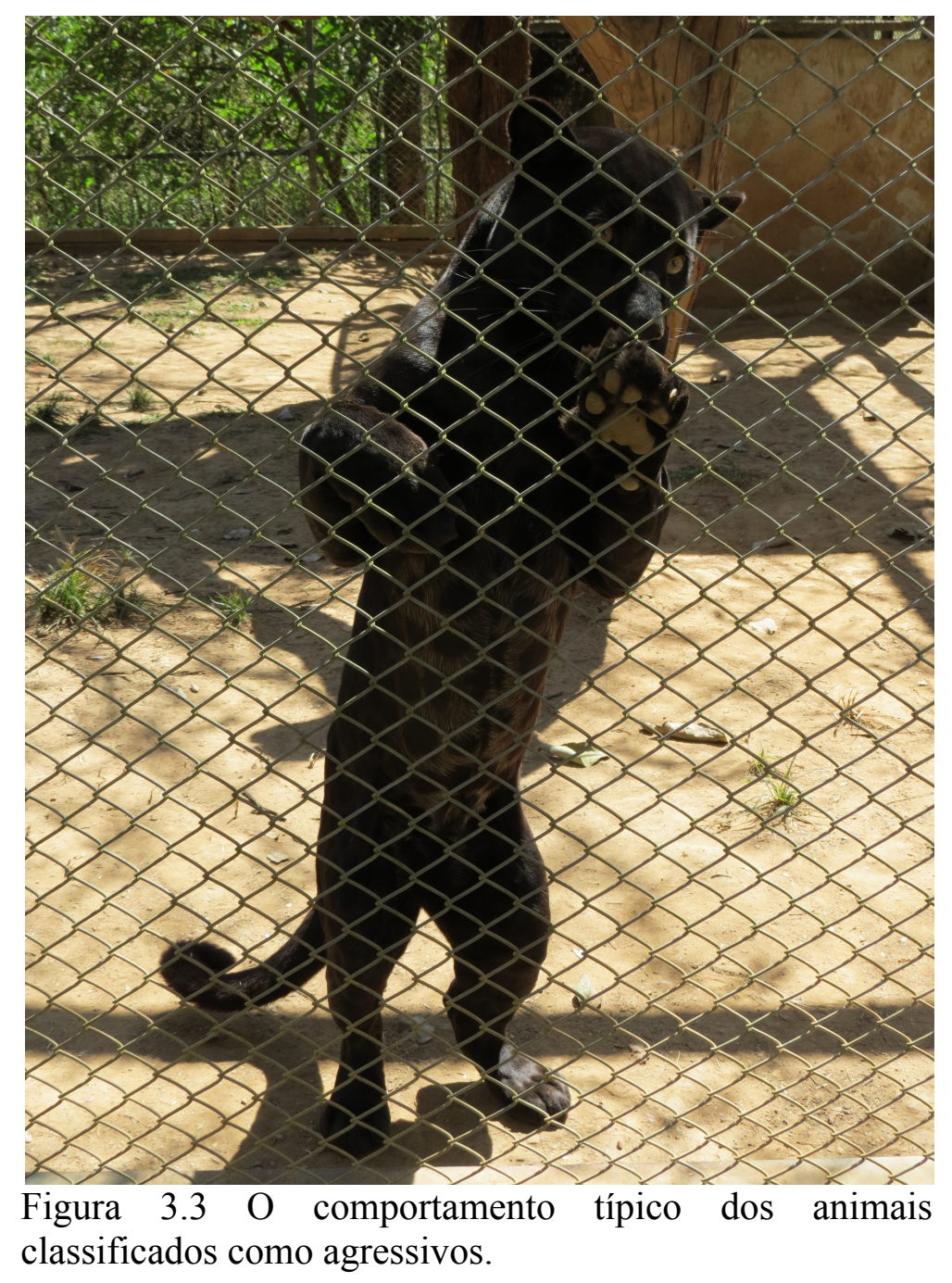

Também com a finalidade de caracterizar individualmente o perfil dos animais, foi aplicado um breve questionário aos tratadores e demais profissionais que trabalham com as onças e que consistia em solicitar que categorizassem o comportamento dos animais em relação à presença de seres humanos, utilizando-se as categorias: agressivo, sociável e indiferente (Apêndice 1).

\subsection{Condicionamento}

As atividades de condicionamento foram realizadas em 2 sessões diárias com cada um dos animais, durante três dias intercalados, cada uma com duração aproximada de 10 minutos, 
distribuídas entre 13:30 e 15:30 horas, respeitando o intervalo de uma hora entre as duas sessões e de pelo menos 15 minutos entre a segunda sessão e a coleta de saliva.

Foram realizados três dias de experimento na Fase I (2013) e três dias na Fase II (2014), dessa forma, entre as sessões 1 a 6 e 7 a 12 houve um intervalo de um ano, período no qual os animais não receberam nenhum tipo de treinamento, possibilitando analisar se os comandos assimilados na Fase I seriam mantidos pelos indivíduos.

A técnica utilizada para o treinamento foi baseada nos princípios do condicionamento operante, descrito por Skinner (1974) e adaptado para diversos animais por Pryor (2002). Como reforço primário, foram utilizados 20 pequenos pedaços de carne por sessão, oferecidos ao animal com utilização de uma pinça metálica longa $(20 \mathrm{~cm})$, totalizando 200 gramas de carne bovina por sessão. Foi utilizado o clicker, um aparelho que emite um estalo ao ser pressionado, como reforço secundário e um bastão com ponta arredondada foi utilizado como "target", ou seja, o alvo no qual o animal deveria encostar o focinho para realizar os comportamentos. O comando "bastão" pode ser utilizado para modelar diversos comportamentos posteriormente, o que o torna um comando versátil e geralmente utilizado no início dos treinamentos (Rogge, 2014). Em virtude de um dos animais apresentar deficiência visual, a extremidade do bastão recebeu uma sinalização olfativa, com aplicação de essência artificial de mel. Os comandos trabalhados estão descritos na tabela 3.3.

Tabela 3.3 - Descrição dos comandos trabalhados e das respostas consideradas corretas

\begin{tabular}{l|l}
\hline Comando & \multicolumn{1}{c}{ Descrição da resposta considerada acerto } \\
\hline Aproximação & $\begin{array}{l}\text { O animal deve sair de onde estiver posicionado no recinto e se aproximar do } \\
\text { local de treinamento, onde está a treinadora está posicionada. }\end{array}$ \\
\hline Bastão & $\begin{array}{l}\text { O animal deve tocar o bastão com o focinho. Esse comando serve como base } \\
\text { para os outros comportamentos e apresenta variaçoses, aumentando-se a } \\
\text { distância em que o bastão é oferecido, bem como seu posicionamento. Não } \\
\text { são considerados como acertos os comportamentos de atacar o bastão ou de } \\
\text { tocá-lo com as patas. }\end{array}$ \\
\hline Fica & $\begin{array}{l}\text { O animal deve encostar e permanecer com o focinho encostado no bastão, } \\
\text { sendo o tempo de permanência do animal aumentado gradativamente. }\end{array}$ \\
\hline Segue & $\begin{array}{l}\text { O animal deve encostar o focinho no bastão e segui-lo, acompanhando sua } \\
\text { movimentação, que deve variar na direção, entre horizontal, vertical, bem } \\
\text { como na velocidade com a qual é movimentado. }\end{array}$ \\
\hline Em pé & $\begin{array}{l}\text { O animal deve levantar-se sobre os dois membros posteriores, apoiando os } \\
\text { membros anteriores na tela do recinto. Para esse comando o bastão é } \\
\text { posicionado no alto, no local onde se espera que o animal toque com o } \\
\text { focinho. (Figura 3.4a) }\end{array}$ \\
\hline Senta & $\begin{array}{l}\text { O animal deve assumir a posição sentado, ou seja, com os membros } \\
\text { posteriores encostados sobre o solo e os membros anteriores estendidos, } \\
\text { apenas apoiados no chão. (Figura 3.4b) }\end{array}$ \\
\hline
\end{tabular}



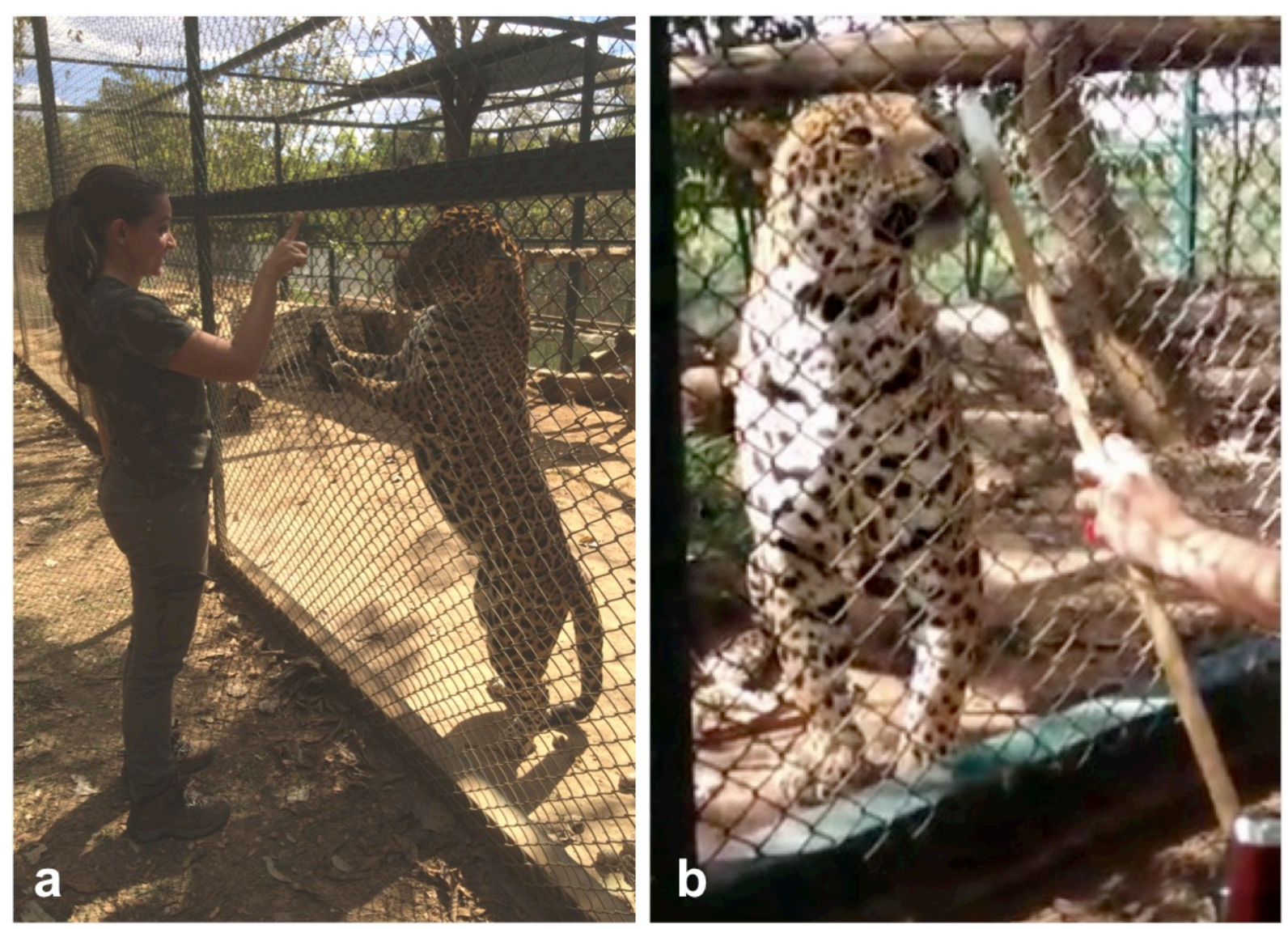

Figura 3.4 a) Animal (Xamã) durante realização do comando "em pé". Nesse caso, para demonstração do comando, o comportamento estava sendo solicitado sem a utilização do bastão, utilizando o gesto e o comando verbal, uma vez que o animal já o desempenhava corretamente. b) o mesmo indivíduo durante realização do comando "senta". A imagem foi capturada da gravação do treino.

O desempenho de cada animal foi acompanhado com registro do número de comandos aprendidos e de acertos ao final de cada uma das 12 sessões.

Cada comando foi considerado correto mediante resposta imediata do animal, sendo sucedido, após algumas repetições, pelo próximo comando a ser trabalhado, de acordo com a escala acima. Ao fim da última sessão de cada dia de trabalho, todos os comandos foram repetidos, para que pudessem ser fixados pelo animal. Da mesma forma, a primeira sessão do dia sempre era iniciada pelos comandos já aprendidos. Todas as sessões foram filmadas e as imagens transferidas para um HD externo ao fim de cada dia de trabalho.

A progressão dos treinos respeitou o desempenho de cada indivíduo, assim, nem todos os animais chegaram a ser submetidos a todos os comandos. 


\subsection{Coleta de saliva}

As coletas de saliva foram realizadas utilizando-se mordedores confeccionados com material absortivo, no fim da tarde (16:30), de forma similar ao que foi realizado por Montanha (2009) e Silva (2011). Após o animal ter mastigado o material, foram coletados fragmentos de $2 \mathrm{~cm} \mathrm{x} 4 \mathrm{~cm}$, armazenados em frascos para centrifugação, em caixa térmica para posterior processamento em laboratório, qual seja, centrifugação a $3000 \mathrm{rpm}$ durante 5 minutos. A saliva era então transferida para um microtubo devidamente identificado e congelada até a realização das análises.

A dosagem de cortisol foi realizada no Laboratório de Bem-estar animal da Universidade de Brasília, utilizando-se os kits The EIAsy Way-CORTISOL ${ }^{\circledR}$ (Diagnostics Biochem Canadá Inc.) na fase 1 e Cortisol Test System-EIA ${ }^{\circledR}$ 3625-300 (Monobind Inc.), ambos importados pela USA Diagnóstica na fase 2, específicos para quantificação de cortisol pelo método de ensaio imunoenzimático (ELISA).

\subsection{Análises Estatísticas}

As análises estatísticas foram realizadas utilizando-se o software SAS $^{\circledR}$ (Cary, North Carolina). A fim de conhecer o comportamento das variáveis em questão foi realizada uma análise de correlação por meio do teste de Spearman, em razão da existência dos dados não paramétricos. Foram correlacionados os dados de aprendizado, concentração de cortisol e idade. 


\section{RESULTADOS E DISCUSSÃO}

\subsection{Teste de sociabilidade}

Em relação ao teste de sociabilidade, os resultados encontrados, tanto em razão do teste quanto da classificação realizada pela equipe da instituição (Tabela 3.4), enquadram três animais como sociáveis, aproximando-se da grade, encostando-se e permitindo o toque (Gaya, Brutus, Xamã), três animais como indiferentes, não saindo dos locais onde já estavam ou, movendo-se, mas não apresentando nenhum tipo de interação com o observador (Sansão, Dalila, Carlota) e dois animais como agressivos, que demoravam para se aproximar mas ao fazer, investiam contra as grades do recinto (Xingu e Yamí).

Tabela 3.4 - Resultado do grau de socialização das onças com humanos

\begin{tabular}{lc}
\hline Categorias & Animais \\
\hline Sociável & Gaya, Brutus, Xamã. \\
\hline Indiferente & Sansão, Dalila, Carlota \\
\hline Agressivo & Xingu, Yamí \\
\hline
\end{tabular}

\subsection{Condicionamento}

O desempenho dos animais nas doze sessões de condicionamento, realizadas durante três dias intercalados de atividade em cada uma das fases, é apresentado na tabela 3.5. São apresentados então os resultados com as considerações pertinentes a cada indivíduo de acordo com a taxa percentual de acertos nas sessões. Para ser considerado acerto o animal deveria desempenhar o comportamento solicitado por meio do comando, de maneira quase imediata, 
o que significa uma demora de até 5 segundos. Foram consideradas as diferenças individuais para progredir com o treinamento de cada animal, dessa forma, alguns indivíduos desenvolveram um numero maior de comandos que outros. No entanto, podem ter atingido valores semelhantes de acertos, uma vez que os comandos que puderam assimilar foram bem executados.

Tabela 3.5 - Comandos desenvolvidos corretamente após o condicionamento

\begin{tabular}{lc}
\hline Animal & Comandos desenvolvidos corretamente ao fim do processo \\
\hline Gaya & Aproximação, tocar, seguir bastão, ficar e em pé. \\
\hline Brutus & Aproximação, tocar, seguir bastão, ficar e em pé. \\
\hline Xamã & Aproximação, tocar, seguir bastão, ficar, em pé e sentar. \\
\hline Carlota & Aproximação, tocar, seguir bastão, ficar e em pé. \\
\hline Dalila & Aproximação, tocar e seguir bastão. \\
\hline Sansão & Aproximação, tocar, seguir bastão, ficar e em pé. \\
\hline Xingu & Aproximação e tocar bastão. \\
\hline
\end{tabular}

Não foi possível analisar estatisticamente os dados de aprendizado (taxa de acerto por sessão) com a finalidade de comparar os três graus de sociabilidade, uma vez que o número de animais em cada grupo não permitiu tais análises, no entanto, ao apresentar o desempenho de cada indivíduo, são feitas considerações a cerca de seu temperamento, razão pela qual o enquadramento nas categorias propostas é mantido ao apresentar os resultados (Figura 3.5).

As análises realizadas mostraram não haver correlação entre o desempenho dos animais e a concentração de cortisol, cujos dados são apresentados na tabela 3.6. As faixas etárias também não apresentaram correlação com desempenho, assim como encontrado em estudo realizado com pequenos primatas (Rogge et al., 2014).

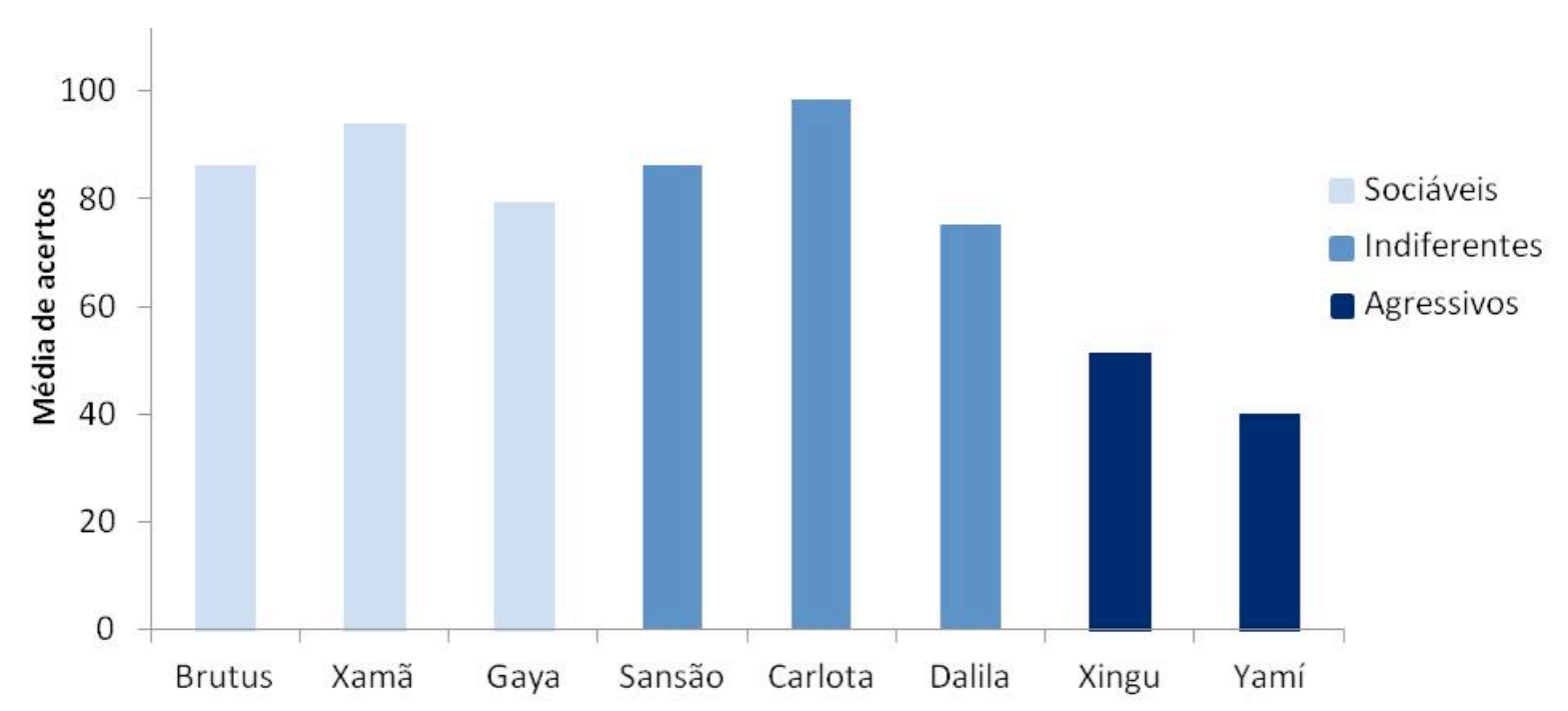

Figura 3.5 Gráfico do desempenho das onças dos três grupos nas sessões de condicionamento, de acordo com a média da taxa de acertos nas seis sessões realizadas. 
Tabela 3.6 - Taxa de acertos e concentração de cortisol $(\mu / \mathrm{dL})$ apresentados pelos animais durante o experimento

\begin{tabular}{|c|c|c|}
\hline Animal & $\begin{array}{c}\text { Taxa de acertos } \\
\text { média } \pm \text { erro padrão }\end{array}$ & $\begin{array}{l}\text { Concentração de cortisol } \\
(\mu / \mathrm{dL}) \text { média } \pm \text { erro padrão }\end{array}$ \\
\hline Sansão & $86,22 \pm 8,02$ & $7,67 \pm 3,23$ \\
\hline Dalila & $75,11 \pm 9,59$ & $4,31 \pm 1,60$ \\
\hline Carlota & $98,33 \pm 1,05$ & $6,46 \pm 2,33$ \\
\hline Xingu & $51,34 \pm 17,57$ & $5,84 \pm 1,57$ \\
\hline Gaya & $79,32 \pm 7,23$ & $10,90 \pm 4,19$ \\
\hline Brutus & $86,13 \pm 6,95$ & $6,73 \pm 2,79$ \\
\hline Xamã & $94,22 \pm 1,60$ & $5,14 \pm 2,16$ \\
\hline Yamí & $40 \pm 19,09$ & $10,99 \pm 4,16$ \\
\hline
\end{tabular}

Conforme o esperado, considerando que é possível modelar o comportamento de qualquer animal por meio do condicionamento operante (Skinner, 1974), todos os animais apresentaram algum nível de aprendizado, com o menor desempenho alcançado pelos dois únicos indivíduos enquadrados como agressivos: Xingu e Yamí, que são também, os únicos indivíduos melânicos (Figura 3.6). Esses animais apresentavam o comportamento de investir contra as grades do recinto quando ocorria a aproximação e a permanência de pessoas, razão pela qual o processo teve que ser cauteloso. No entanto, esse comportamento não foi apresentado nenhuma vez durante o desenvolvimento das sessões de condicionamento. É possível que a característica melânica esteja relacionada a um padrão comportamental de maior agressividade, mas não existem ainda dados na literatura que corroborem essa hipótese.

A agressividade parece estar relacionada ao baixo desempenho no condicionamento, especialmente nas primeiras sessões, uma vez que é nesse período que ocorre a adaptação do animal à aproximação humana, resultado semelhante ao encontrado por outros autores, em estudo que comparou o desempenho de saimiris e de macacos da noite (primatas do novo mundo) para a assimilação de comandos básicos, os saimiris foram mais rápidos para aprender os primeiros comportamentos, mas nos comportamentos subsequentes essa diferença não se manteve (Rogge et al., 2014).

A fêmea Yamí precisou de uma sessão apenas para aproximação, apresentando baixo desempenho na segunda sessão, com melhora nas duas sessões seguintes, no entanto, conforme foram sendo inseridos novos comandos o número de acertos voltou a cair. Essa fêmea foi transferida para um recinto afastado, razão pela qual não pôde participar da Fase II do estudo.

No caso do Xingu, somente no segundo dia de atividades, na quarta sessão de condicionamento, foi possível apresentar o bastão, quando o animal passou a aproximar-se e 
receber o reforço oferecido pela treinadora por meio de uma pinça, uma vez que foram necessárias três sessões apenas para que ele se aproximasse. No caso desse indivíduo, apesar de seu comportamento agressivo, foi possível observar demonstrações comportamentais de medo, como sobressaltos devido ao pequeno ruído provocado pelo clicker, bem como o comportamento de se esconder ou desempenhar pacing na presença de situações provavelmente consideradas pelo animal como aversivas, como a passagem de um trator perto do recinto, por exemplo, de forma mais acentuada do que observado nos outros animais. É possível que o medo tenha sido um fator determinante para o baixo desempenho desse indivíduo, uma vez que o fator medo, influencia no tempo de aprendizagem (Bassett, et al. 2003, Rooge et al., 2014).

Dois dos animais classificados como indiferentes, Sansão e Dalila, apresentaram o comportamento de avançar sobre o target, razão pela qual foi necessário dessensibilizá-los (Pryor, 2004), ou seja, minimizar as reações agressivas quanto ao bastão, reforçando o ato de permanecerem tranqüilos na presença da treinadora e posteriormente aproximando o target do focinho ao mesmo tempo em que o reforço era entregue. Esse procedimento foi suficiente para que os animais deixassem de atacar o bastão. Nos dois casos foi observado um menor desempenho na terceira sessão, mais evidente na Dalila, fato que pode estar relacionado ao início da apresentação de novos comandos ou ao comportamento de atacar o bastão, uma vez que a dessensibilização implica em baixa taxa de acertos, já que o animal está sendo conduzido a aceitar o bastão e, portanto, mesmo recebendo a recompensa não é computado como acerto. Porém, após esse processo o desempenho desses animais voltou a melhorar e não regrediu mais. A fêmea Carlota, também classificada como indiferente, foi o indivíduo que mais rapidamente assimilou que deveria encostar o focinho no bastão para receber o reforço, com taxa de acertos acima de 90\% em todas as sessões. (Figura 3.7).

Havia uma predição de que os animais sociáveis apresentariam maior facilidade para responder ao condicionamento, pelo fato de naturalmente se aproximarem de forma amistosa. No entanto, apesar da impossibilidade de uma análise estatística, foi possível observar que o padrão encontrado para esses animais (Figura 3.8) se assemelha ao encontrado para os animais classificados como indiferentes, sugerindo que as variações encontradas possam estar mais relacionadas a fatores individuais, como encontrado em outros estudos (Bloomsmith et al. 1998, Bassett, et al. 2003, Coleman \& Maier, 2010).

A fêmea Gaya inicialmente tentava pegar o target com a pata, sugerindo um comportamento lúdico direcionado ao objeto. Possivelmente esse comportamento esteja relacionado à idade do animal, que ao início do experimento tinha aproximadamente 11 
meses. Apesar desse comportamento, o indivíduo apresentou uma melhora gradativa no desempenho ao longo das sessões, sugerindo que essa dificuldade inicial não tenha prejudicado o desenvolvimento do aprendizado e que foi possível modelar a conduta do animal, minimizando a expressão do comportamento não adequado de tocar o bastão com a pata.

O macho Brutus, apesar de sua deficiência visual, assimilou ainda na primeira sessão que deveria encostar no bastão, sinalizado olfatoriamente, por meio da aplicação de essência de mel e apresentou evolução gradativa. É importante observar que quanto ao número de comandos aprendidos o resultado foi semelhante ao dos indivíduos de maior desempenho, embora seja possível observar que o processo foi mais gradual, com aumento de acertos sessão a sessão. Assim, a deficiência visual não parece ser um fator impeditivo ao treinamento do animal e à sua aprendizagem.

O animal com melhor desempenho em termos de número de comandos desempenhados foi o indivíduo Xamã, com desenvolvimento correto de 6 comandos ao final das doze sessões, sendo o único indivíduo com o qual foi trabalhado o comando sentar.

A fase II foi realizada após um ano de intervalo e o desempenho dos animais se manteve, sugerindo que os comandos assimilados não foram esquecidos pelos animais, ainda que durante esse período não tenha havido nenhum trabalho de condicionamento (Figura 3.9). Esse dado é importante para as instituições que abrigam um elevado número de animais, não sendo possível manter sessões de condicionamento diariamente com todos devido principalmente à limitação no número de profissionais. Uma alternativa seria desenvolver um programa de condicionamento para os animais e após assimilados os comandos básicos, as sessões podem ser realizadas de forma esporádica, mensalmente, por exemplo. Dessa forma, é possível que essa prática seja incorporada à rotina das instituições e seus benefícios possam ser efetivos, tanto na facilitação do manejo quanto no bem-estar de um número maior de animais cativos.

Na Fase II, com a aproximação da treinadora, os animais já se direcionavam aos locais próximos as grades do recinto onde eram realizadas as sessões, sugerindo estarem motivados para a atividade. 


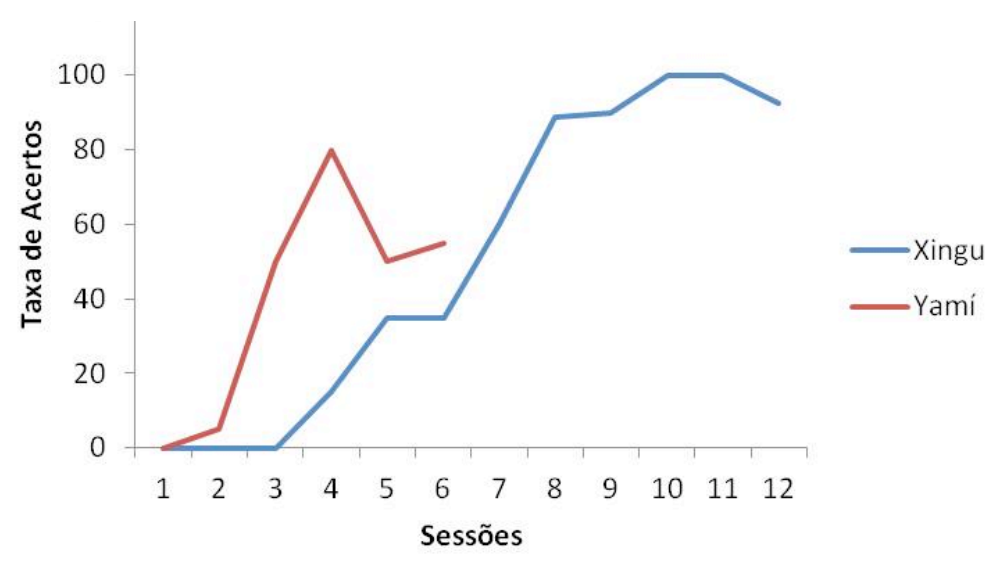

Figura 3.6 Desempenho dos animais classificados como agressivos.

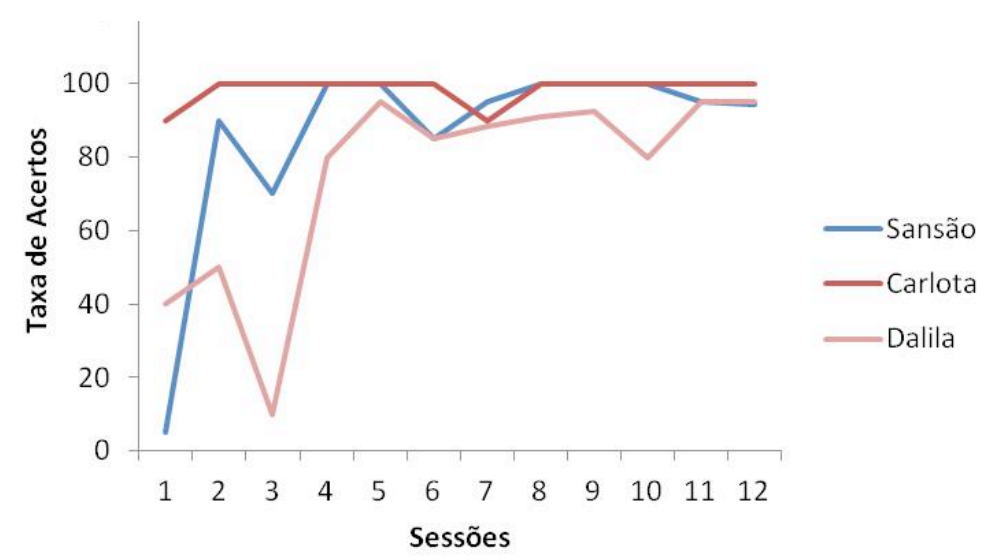

Figura 3.7 Desempenho dos animais classificados como indiferentes.

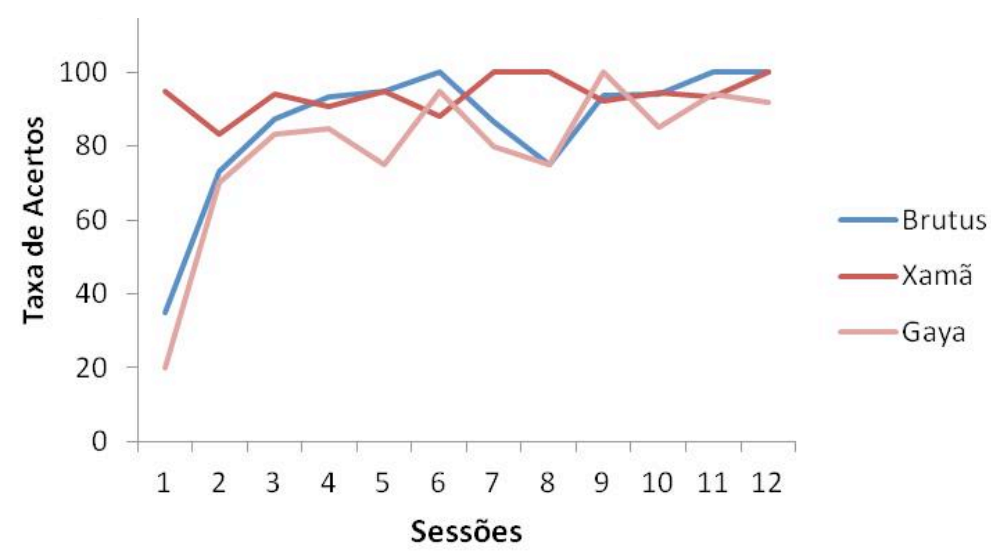

Figura 3.8 Desempenho dos animais classificados como sociáveis. 


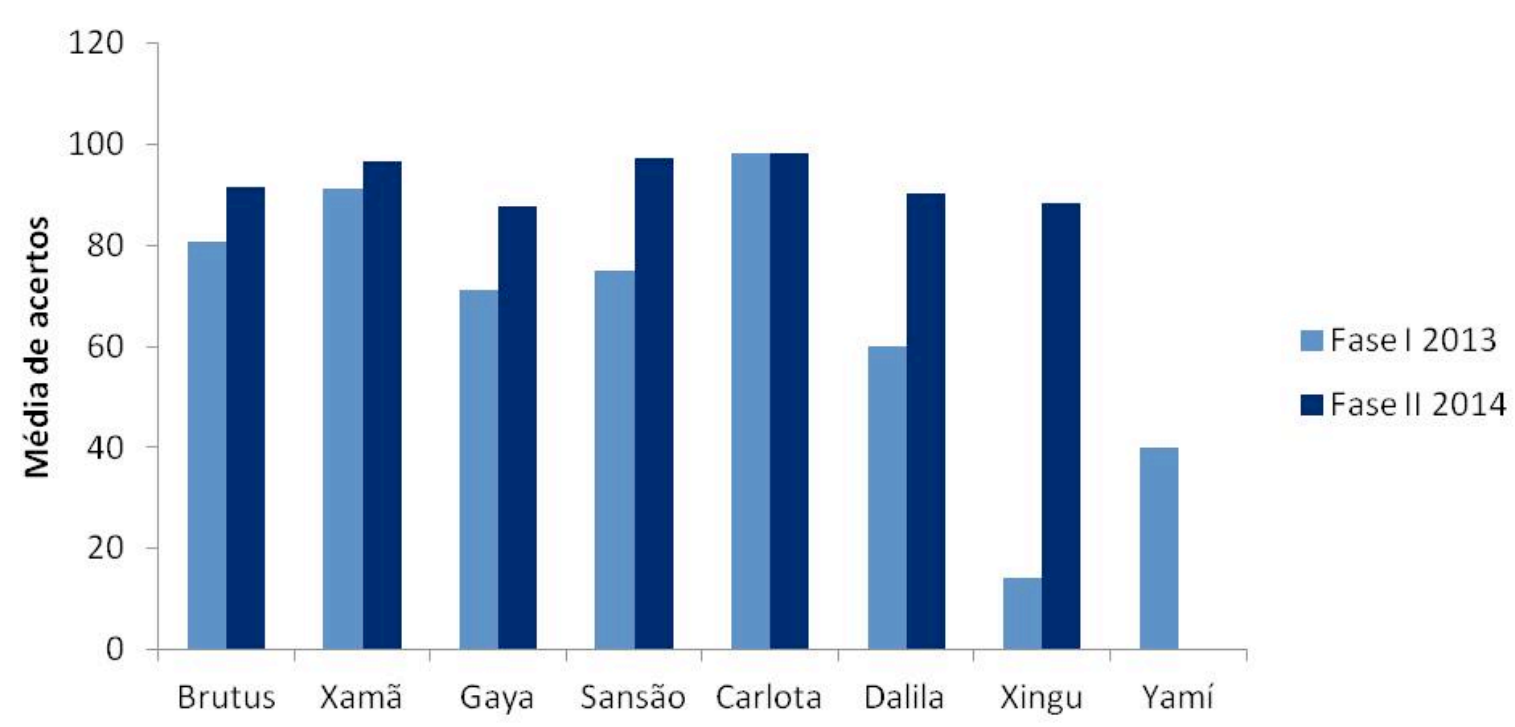

Figura 3.9 Gráfico da média de acertos apresentados pelas onças nas sessões de condicionamento nas duas fases do estudo.

Embora sejam comandos simples e iniciais de um trabalho de treinamento, ao fim das 12 sessões, cinco animais realizavam de forma correta cinco comandos. Um resultado que pode ser considerado satisfatório uma vez que estudos com primatas, por exemplo, registram entre 5 e 22 sessões para a assimilação do comando inicial de tocar no bastão (Rogge, et al., 2014). Dessa forma, é possível constatar que a espécie em questão responde rapidamente ao condicionamento. Portanto, é fortemente indicado que as instituições que mantenham esses animais passem a integrar essa prática às suas atividades, incluindo mudanças nos métodos empregados, especialmente no que diz respeito à uma maior observação da linguagem corporal do animal (Brando, 2012), com adoção de uma postura que vise evitar as respostas de medo e os comportamentos agressivos. 


\section{CONCLUSÃO}

O condicionamento se mostrou um método efetivo para as onças-pintadas, não havendo relação entre o desempenho dos animais e fatores como faixa etária, sexo e o cortisol salivar. A agressividade é um fator que torna o processo mais lento, no entanto, o condicionamento também deve ser utilizado com esses animais, possibilitando a diminuição dos comportamentos agressivos e melhor adaptação desses animais ao cativeiro.

Com base na receptividade dos animais, sugere-se que o condicionamento seja utilizado para onças pintadas cativas como estratégia para facilitar o manejo, minimizando o estresse envolvido em alguns procedimentos de rotina, melhorando a qualidade da relação homem-animal e contribuindo na elevação dos níveis de bem-estar. 


\section{REFERÊNCIAS}

ANDERSON, U.S.; KELLING, A.S.; PRESSLEY-KEOUGH, R.; BLOOMSMITH, M.A.; MAPLE, T.L. Enhancing the Zoo Visitor's Experience by Public Animal Training and Oral Interpretation at an Otter Exhibit, Environment and Behavior, v. 35, n. 6, p. 826-841, 2003.

BASSETT, L.; BUCHANAN-SMITH, H.M.; MCKINLEY, J.; SMITH T.E.. Effects of training on stress-related behavior of the common marmoset (Callithrix jacchus) in relation to coping with routine husbandry procedures. Journal of Applied Animal Welfare Science, v.6, n.3, p. 209-220, 2003.

BLOOMSMITH M.A.; LAULE G.E.; ALFORD P.L.; THURSTON R.H.. Using training to moderate chimpanzee aggression during feeding. Zoo Biology, v. 13, n.6, p. 557-566, 1994.

BLOOMSMITH, M.A.; STONE, A.M.; LAUlE, G.E.. Positive Reinforcement Training to Enhance the Voluntary Movement of Group-housed Chimpanzees Within Their Enclosures Zoo Biology, v. 17, n. 4, p. 333-341, 1998.

BRANDO, A.I.C.A. Animal learning and training: implications for animal welfare. The Veterinary Clinics of North America Exotic Practice, v.15, n.3, p. 387-398, 2012.

CARLSON, N. R. A aprendizagem e a memoria: mecanismos básicos. In: CARLSON, N. R. Fisiologia do Comportamento. ed. 7. Barueri: Manole, 2002 p. 424-465.

CARVALHO JR, E. A. R C.; MORATO, R. G.. Factors affecting big cat hunting in Brazilian protected areas. Tropical Conservation Science, v. 6, n. 2, p. 303-310, 2013.

COLEMAN, K.; MAIER, A.. The use of positive reinforcement training to reduce stereotypic behavior in rhesus macaques. Applied Animal Behaviour Science, v. 124, n.3-4, p. 142-148, 2010 .

DE PASSILLÉ, A.M.; RUSHEN, J. 2005. Can we measure human-animal interactions in onfarm animal welfare assessment? Some unresolved issues. Applied Animal Behaviour Science, v. 92, n.3, p. 193-209, 2005.

DOUGALL, P.T.; RÉALE, D.; SOL, D.; READER, S.M.. Wildlife conservation and animal temperament: causes and consequences of evolutionary change for captive, reintroduced, and wild populations. Animal Conservation. v.9, n.1, p. 39-48, 2006. 
EMER, S.A.; MORA, C.V.; HARVEY, M.T.; GRACE, M.S.. Predators in training: operant conditioning of novel behavior in wild Burmese pythons (Python molurus bivitattus). Animal Cognition, v. 18, n.1, p. 269-278, 2015.

GUILLETTE, L.M.; HAHN, A.H.; HOESCHELE, M.; PRZYSLUPSKI, A; STURDY, C.B; Individual differences in learning speed, performance accuracy and exploratory behaviour in black-capped chickadees. Animal Cognition, v.18, p.165-178, 2015.

GUYTON, A.C.; HALL, J.E.. Introdução à endocrinologia. In: Tratado de fisiologia médica: Rio de Janeiro: Elsevier. 2006. p.905-917.

HAAG T.; SANTOS A.S.; SANA D.A.; MORATO R.G.; CULLEN L.JR.; CRAWSHAW P.G. JR.; DE ANGELO C, DI BITETTI M.S.; SALZANO F.M.; EIZIRIK E.. The effect of habitat fragmentation on the genetic structure of a top predator: loss of diversity and high differentiation among remnant populations of Atlantic Forest jaguars (Panthera onca). Molecular Ecology, v.19, n.22, p. 4906-4921, 2010.

HEIDENREICH, B.. An Introduction to Positive Reinforcement Training and Its Benefits. Journal of Exotic Pet Medicine, v. 16, n.1, p. 19-23, 2007.

HEMSWORK, P.H.. Human-animal interactions in livestock production. Applied Animal Behaviour Science, v.81, n.3, p.185-198, 2003.

INNES, L.; McBRIDE, S.. Negative versus positive reinforcement: An evaluation of training strategies for rehabilitated horses. Applied Animal Behaviour Science, v. 112, n.3-4, p.357$368,2008$.

KĘDZIERSKI, W.; CYWIŃSKA, A.; STRZELEC, K.; KOWALIK, S.. Changes in salivary and plasma cortisol levels in Purebred Arabian horses during race training session, Animal Science Journal, v 85, n. 3, p. 313-317, 2014.

LAMBETH, S.P.; HAU, J., PERLMAN, J.E.; MARTINO, M.; SCHAPIRO, S.J.. Positive reinforcement training affects hematologic and serum chemistry values in captive chimpanzees (Pan troglodytes). American Journal of Primatology, v. 68, n.3, p. 245-256, 2006.

LEE, J.J.; SHIN, J.S.; LEE, J.E.; JUNG, W.Y.; LEE, G.; KIM, M.S.; PARK, C.G.; KIM, S.G.. Changes oh N/L ratio and cortisol levels associated with experimental training in untrained rhesus macaques, Journal of Medical Primatology, v. 42, n.1, p. 10-14, 2013.

LOCKHART, J.; WILSON, K.; LANMAN, C.. The effects of operant training on blood collection for domestic cats, Applied Animal Behaviour Science, v. 143, n.2-4, p. 128-134, 2013.

MELLEN, J.. Factors influencing reproductive success in small captive exotic felids (Felis spp.): a multiple regression analysis. Zoo Biology, 10, n.2, p. 95-110, 1991.

MINIER, D. E.; TATUM, L.; GOTTLIEB, D.H.; CAMERON, A.; SNARR J.; ELLIOT, R.; COOK, A.; ELLIOT, K.; BANTA, K.; HEAGERTY, A.; MCCOWAN, B.. Human-directed contra-aggression training using positive reinforcement with single and multiple trainers for 
indoor-housed rhesus macaques. Applied Animal Behaviour Science, v.132, n. p. 178-186, 2002.

MONTANHA, J. C.; SILVA, S. L.; BOERE, V.. Comparison of salivary cortisol concentrations in Jaguars kept in captivity with differences in exposure to the public. Ciência Rural, v. 39, n. 6, p. 1745-7451, 2009.

MÖSTL, E.; PALME, R.. Hormones as indicators of stress. Domestic Animal Endocrinology, v.23, n.1-2, p. 67-74, 2002.

NEX (2013) Quem somos. Disponível em < http://www.nex.org.br> Acesso em 18/07/2013.

PRYOR, K. Don't shoot the dog!: The New Art of Teaching and training. Gloucestershire, Ringpress Books Ltd, 2002, 202p.

ROGGE, J.; SHERENCO, K.; MALLING, R.; THIELE, E.; LAMBETH, S.; SCHAPIRO, S.; WILLIAMS, L.. A Comparison of Positive Reinforcement Training Techniques in Owl and Squirrel Monkeys: Time Required to Train to Reliability. Journal of Applied Animal Welfare Science, v.16, p. 211-220, 2014.

ROSAS-ROSAS, O.C.; VALDEZ R.. The role of landowners in jaguar conservation in Sonora, México. Conservation Biology v. 24, n. p. 366-371, 2010.

SCHAPIRO, S.; PERLMAN, J.E.; BOUDREAU, B.A.. Manipulating the Affiliative Interactions of Group-Housed Rhesus Macaques Using Positive Reinforcement Training Techniques. American Journal of Primatology, v.55, n. 3, p. 137-149, 2001.

SCHMIDT, A.; AURICH, J.; MOSTL, E.; MULLER, J.; AURICH, C.. Changes in cortisol release and heart rate and heart rate variability during the initial training of 3-year-old sport horses, Hormones and Behavior, v. 58, n. p. 628-636, 2010.

SILVA, R.O. (2011). Enriquecimento ambiental cognitivo e sensorial para onçaspintadas (Panthera onca) sedentárias em cativeiro induzindo redução de níveis de cortisol promovendo bem-estar. Brasília, Instituto de Psicologia da Universidade de Brasília, 2011. 58p. Dissertação (Mestrado em Ciências do Comportamento) - Departamento de Processos Psicológicos Básicos, Instituto de psicologia da Universidade de Brasília, 2011.

SKINNER, B. F. Sobre o Behaviorismo. São Paulo: Editora Cultrix, 1974, 209p.

SUNQUIST, M.E.; SUNQUIST, F. Wild cats of the world. Chicago: University of Chicago Press, 2002. 462p.

VASCONCELLOS, A.S.; VIRÁNYIL, Z.; RANGE, F.; MOSTL, E.; ADES, C.; KOTRSCHAL, K.. Social interactions and non-invasive stress monitoring in captive timber wolves (Canis lupus). Journal of Veterinary Behavior; Clinical Applications and Research, v. 6, n. 1, p. 71-72, 2011.

VEEDER, C.L.; BLOOMSMITH, M.A.; MCMILLAN, J.L.; PERLMAN, J.E.; MARTIN, A.L.. Positive Reinforcement Training to Enhance the Voluntary Movement of GroupHoused Sooty Mangabeys (Cercocebus atys atys). Journal of the American Association for 
Laboratory Animal Science, v. 48, n. 2, p.192-195, 2009.

WAIBLINGER, S. ,MENKE, C., BUCHER., 2004. Previous handling and gentle interactions affect behaviour and heart rate of dairy cows during a veterinary procedure. Appl. Anim. Behav. Sci., 85, 31-42.

WIELEBNOWSKI, N.C.; FLETCHALL, N.; CARLSTEAD, K.; BUSSO, J.M.; BROWN, J.L.. Noninvasive assessment of adrenal activity associated with husbandry and behavioral factors in the North American clouded leopard population, Zoo Biology, n. 21, v.1, p. 77-98, 2002. 
95

CAPÍtUlO 4

CONSIDERAÇÕES FINAIS 


\section{CONSIDERAÇÕES FINAIS}

O condicionamento operante aplicado a onças pintadas em cativeiro provocou modificações positivas no comportamento dos animais, com aumento da expressão de comportamentos indicadores de bem-estar. Do ponto de vista fisiológico, a técnica provocou aumento na concentração cortisol salivar, dado que, ao ser analisado conjuntamente com os parâmetros comportamentais, e considerando estudos semelhantes, sugere que o condicionamento tenha estimulado os animais de forma positiva.

As onças-pintadas apresentaram bom desempenho nas sessões de condicionamento e mantiveram o mesmo desempenho após um ano dos treinos iniciais. Não houve relação entre o desempenho dos animais e fatores como faixa etária, sexo e o cortisol salivar, mas aparentemente, a agressividade e o medo estiveram relacionados ao baixo desempenho.

Com base na receptividade dos animais, sugere-se que o condicionamento seja utilizado para onças pintadas cativas como estratégia para facilitar o manejo, a fim de minimizar o estresse envolvido em alguns procedimentos de rotina, melhorar a qualidade da relação homem-animal e contribuir na elevação dos níveis de bem-estar. 
ANEXOS 


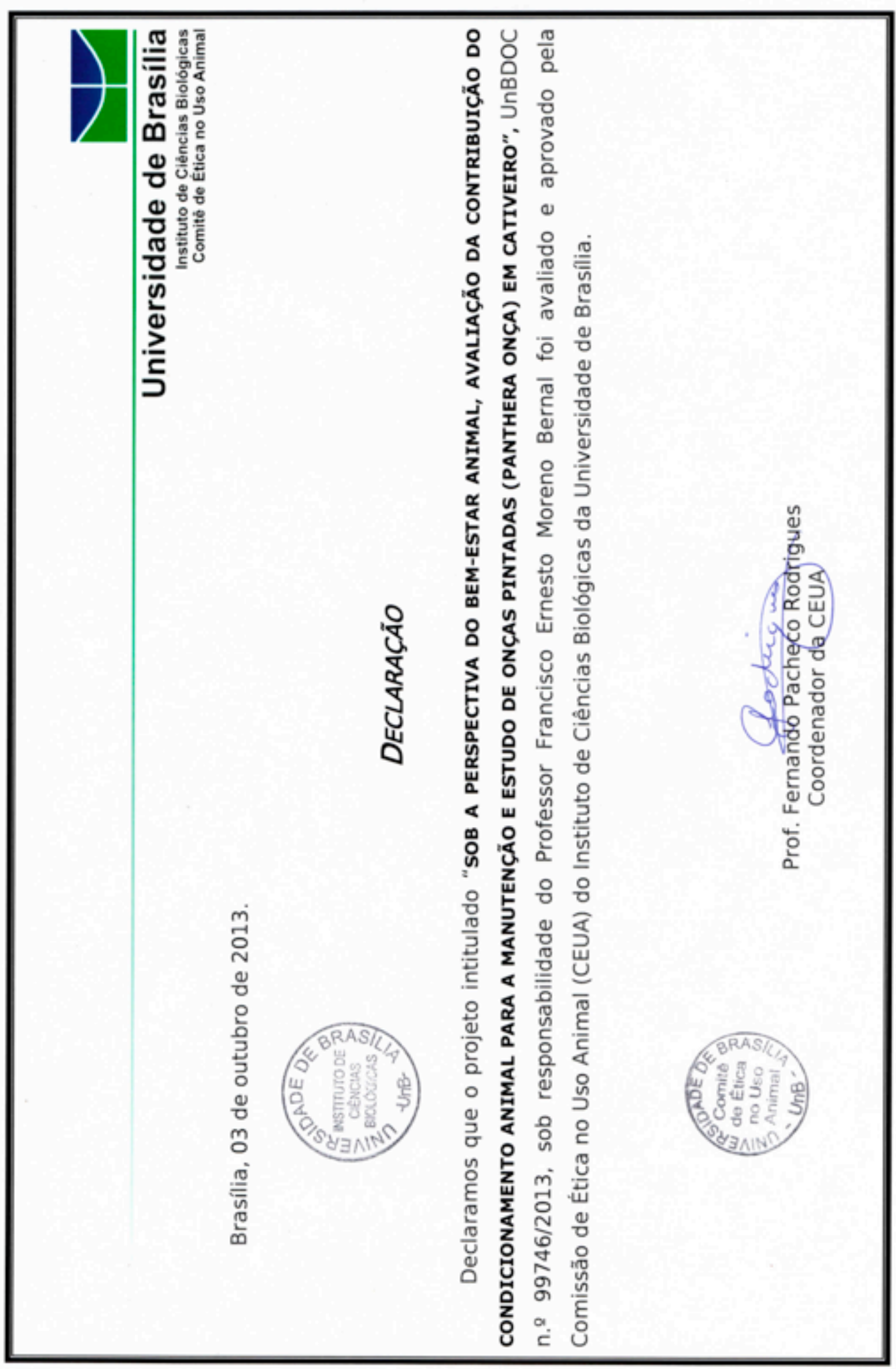




\section{Autorização para atividades com finalidade científica}

\section{Número: 40346-1 \\ Data da Emissão: 15/08/2013 14:58 \\ Data para Revalidação*: 14/09/2014}

* De acordo com o art. 33 da IN 154/2009, esta autorização tem prazo de validade equivalente ao previsto no cronograma de atividades do projeto, mas deverá ser revalidada anualmente mediante a apresentação do relatório de atividades a ser enviado por meio do Sisbio no prazo de até 30 dias a contar da data do aniversário de sua emissão.

\section{Dados do titular}

Nome: Liane Cristina Ferez Garcia CPF: $304.699 .878-39$

Título do Projeto: Sob a perspectiva do Bem-Estar Animal, avaliação da contribuição do condicionamento animal para a manutenção e estudo de felideos brasileiros em cativeiro.

Nome da Instituição : FUNDAÇÃO UNIVERSIDADE DE BRASÍLIA

CNPJ: 00.038.174/0001-43

Cronograma de atividades

\begin{tabular}{|c|c|c|c|}
\hline$\#$ & Descrição da atividade & Início (mês/ano) & Fim (mês/ano) \\
\hline 1 & Realização de observações comportamentais, coletas de saliva e análise de cortisol e condicionamento & $07 / 2013$ & $07 / 2014$ \\
\hline
\end{tabular}

\section{Observações e ressalvas}

As atividades de campo exercidas por pessoa natural ou jurídica estrangeira, em todo o território nacional, que impliquem o deslocamento de recursos humanos e

1 materiais, tendo por objeto coletar dados, materiais, espécimes biológicos e minerais, peças integrantes da cultura nativa e cultura popular, presente e passada,

obtidos por meio de recursos e técnicas que se destinem ao estudo, à difusão ou à pesquisa, estão sujeitas a autorização do Ministério de Ciência e Tecnologia.

Esta autorização NÄO exime o pesquisador titular e os membros de sua equipe da necessidade de obter as anuências previstas em outros instrumentos legais, bem

2 como do consentimento do responsável pela área, pública ou privada, onde será realizada a atividade, inclusive do órgão gestor de terra indígena (FUNAI), da

2 unidade de conservação estadual, distrital ou municipal, ou do proprietário, arrendatário, posseiro ou morador de área dentro dos limites de unidade de conservação federal cujo processo de regularização fundiária encontra-se em curso.

Este documento somente poderá ser utilizado para os fins previstos na Instrução Normativa IBAMA ${ }^{\circ}$ 154/2007 ou na Instrução Normativa ICMBio $n^{\circ}$ 10/2010, no que

3 especifica esta Autorização, não podendo ser utilizado para fins comerciais, industriais ou esportivos. O material biológico coletado deverá ser utilizado para atividades científicas ou didáticas no âmbito do ensino superior.

A autorização para envio ao exterior de material biológico não consignado deverá ser requerida por meio do endereço eletrônico www.ibama.gov.br (Serviços on-line -

4 Licença para importação ou exportação de flora e fauna - CITES e não CITES).

O titular de licença ou autorização e os membros da sua equipe deverão optar por métodos de coleta e instrumentos de captura direcionados, sempre que possível,

5 ao grupo taxonômico de interesse, evitando a morte ou dano significativo a outros grupos; e empregar esforço de coleta ou captura que não comprometa a viabilidade de populações do grupo taxonômico de interesse em condição in situ.

O titular de autorização ou de licença permanente, assim como os membros de sua equipe, quando da violação da legislação vigente, ou quando da inadequação,

6 omissão ou falsa descrição de informações relevantes que subsidiaram a expedição do ato, poderá, mediante decisão motivada, ter a autorização ou licença suspensa ou revogada pelo ICMBio e o material biológico coletado apreendido nos termos da legislação brasileira em vigor.

Este documento não dispensa o cumprimento da legislação que dispõe sobre acesso a componente do patrimônio genético existente no território nacional, na

7 plataforma continental e na zona econômica exclusiva, ou ao conhecimento tradicional associado ao patrimônio genético, para fins de pesquisa científica,

bioprospecção e desenvolvimento tecnológico. Veja maiores informaç̃es em www.mma.gov.br/cgen.

8 Em caso de pesquisa em UNIDADE DE CONSERVAÇÃO, o pesquisador titular desta autorização deverá contactar a administração da unidade a fim de CONFIRMAR

8 AS DATAS das expedições, as condições para realização das coletas e de uso da infra-estrutura da unidade.

Locais onde as atividades de campo serão executadas

\begin{tabular}{|c|c|c|l|l|}
\hline$\#$ & Município & UF & Descrição do local & Tipo \\
\hline 1 & CORUMBA DE GOIAS & GO & NEX No Extinction - Criadouro Conservacionista & Fora de UC Federal \\
\hline
\end{tabular}

\section{Atividades X Táxons}

\begin{tabular}{|c|l|l|}
\hline$\#$ & Atividade & Táxons \\
\hline 1 & Coleta/transporte de amostras biológicas ex situ & Oncifelis colocolo, Panthera onca, Leopardus pardalis, Puma concolor \\
\hline
\end{tabular}

Material e métodos 


\section{Autorização para atividades com finalidade científica}

\section{Número: 40346-1}

Data da Emissão: 15/08/2013 14:58

Data para Revalidação*: 14/09/2014

* De acordo com o art. 33 da IN 154/2009, esta autorização tem prazo de validade equivalente ao previsto no cronograma de atividades do projeto, mas deverá ser revalidada anualmente mediante a apresentação do relatório de atividades a ser enviado por meio do Sisbio no prazo de até 30 dias a contar da data do aniversário de sua emissão.

Dados do titular

Nome: Liane Cristina Ferez Garcia

CPF: 304.699.878-39

Título do Projeto: Sob a perspectiva do Bem-Estar Animal, avaliação da contribuição do condicionamento animal para a manutenção e estudo de felideos brasileiros em cativeiro.

Nome da Instituição : FUNDAÇÃO UNIVERSIDADE DE BRASíLIA

CNPJ: 00.038.174/0001-43

Destino do material biológico coletado

\begin{tabular}{|c|l|l|}
\hline$\#$ & \multicolumn{1}{|c|}{ Nome local destino } & Tipo Destino \\
\hline 1 & FUNDAÇÃO UNIVERSIDADE DE BRASILIA & \\
\hline
\end{tabular}

Este documento (Autorização para atividades com finalidade científica) foi expedido com base na Instrução Normativa n¹54/2007. Através do código de autenticação abaixo, qualquer cidadão poderá verificar a autenticidade ou regularidade deste documento, por meio da página do Sisbio/ICMBio na Internet (www.icmbio.gov.br/sisbio). 


\section{Autorização para atividades com finalidade científica}

\section{\begin{tabular}{|l|l|l} 
Número: 40346-1 & Data da Emissão: 15/08/2013 14:58 & Data para Revalidação*: 14/09/2014
\end{tabular}}

* De acordo com o art. 33 da IN 154/2009, esta autorização tem prazo de validade equivalente ao previsto no cronograma de atividades do projeto, mas deverá ser revalidada anualmente mediante a apresentação do relatório de atividades a ser enviado por meio do Sisbio no prazo de até 30 dias a contar da data do aniversário de sua emissão.

Dados do titular

Nome: Liane Cristina Ferez Garcia

CPF: 304.699.878-39

Título do Projeto: Sob a perspectiva do Bem-Estar Animal, avaliação da contribuição do condicionamento animal para a manutenção e estudo de felideos brasileiros em cativeiro.

Nome da Instituição : FUNDAÇÃO UNIVERSIDADE DE BRASÍLIA

CNPJ: 00.038.174/0001-43

\section{Registro de coleta imprevista de material biológico}

De acordo com a Instrução Normativa $n^{\circ} 154 / 2007$, a coleta imprevista de material biológico ou de substrato não contemplado na autorização ou na licença permanente deverá ser anotada na mesma, em campo específico, por ocasião da coleta, devendo esta coleta imprevista ser comunicada por meio do relatório de atividades. O transporte do material biológico ou do substrato deverá ser acompanhado da autorização ou da licença permanente com a devida anotação. O material biológico coletado de forma imprevista, deverá ser destinado à instituição científica e, depositado, preferencialmente, em coleção biológica científica registrada no Cadastro Nacional de Coleções Biológicas (CCBIO).

\begin{tabular}{|c|c|c|c|c|}
\hline Táxon* & Qtde. & Tipo de amostra & Qtde. & Data \\
\hline & & & & \\
\hline & & & & \\
\hline & & & & \\
\hline & & & & \\
\hline & & & & \\
\hline & & & & \\
\hline & & & & \\
\hline & & & & \\
\hline & & & & \\
\hline & & & & \\
\hline
\end{tabular}

Este documento (Autorização para atividades com finalidade científica) foi expedido com base na Instrução Normativa $n^{\circ} 154 / 2007$. Através do código de autenticação abaixo, qualquer cidadão poderá verificar a autenticidade ou regularidade deste documento, por meio da página do Sisbio/ICMBio na Internet (www.icmbio.gov.br/sisbio). 


\section{Autorização para atividades com finalidade científica}

Número: 40346-1

Data da Emissão: 15/08/2013 14:58

Data para Revalidação*: 14/09/2014

* De acordo com o art. 33 da IN 154/2009, esta autorização tem prazo de validade equivalente ao previsto no cronograma de atividades do projeto, mas deverá ser revalidada anualmente mediante a apresentação do relatório de atividades a ser enviado por meio do Sisbio no prazo de até 30 dias a contar da data do aniversário de sua emissão.

Dados do titular

Nome: Liane Cristina Ferez Garcia

CPF: $304.699 .878-39$

Título do Projeto: Sob a perspectiva do Bem-Estar Animal, avaliação da contribuição do condicionamento animal para a manutenção e estudo de felideos brasileiros em cativeiro.

Nome da Instituição : FUNDAÇÃO UNIVERSIDADE DE BRASíLIA

CNPJ: $00.038 .174 / 0001-43$

* Identificar o espécime no nível taxonômico possível.

Este documento (Autorização para atividades com finalidade científica) foi expedido com base na Instrução Normativa $n^{\circ} 154 / 2007$. Através do código de autenticação abaixo, qualquer cidadão poderá verificar a autenticidade ou regularidade deste documento, por meio da página do Sisbio/ICMBio na Internet (www.icmbio.gov.br/sisbio). 
APÊNDICES 
QUESTIONÁRIO PARA AVALIAÇÃO DO TEMPERAMENTO DAS ONÇAS

Identificação do participante

Trabalha com os animais a quanto tempo:

Função:

Frequência com que lida com cada animal (vezes por semana):

Avaliação do temperamento das onças

\begin{tabular}{|c|c|c|c|}
\hline Animal & \multicolumn{3}{|c|}{ Temperamento em relação a pessoas } \\
\hline Sansão & ( ) Sociável & ( ) Indiferente & ( ) Agressivo \\
\hline Dalila & ( ) Sociável & ( ) Indiferente & ( ) Agressivo \\
\hline Xingu & ( ) Sociável & ( ) Indiferente & ( ) Agressivo \\
\hline Carlota & ( ) Sociável & ( ) Indiferente & ( ) Agressivo \\
\hline Brutus & ( ) Sociável & ( ) Indiferente & ( ) Agressivo \\
\hline Gaya & ( ) Sociável & ( ) Indiferente & ( ) Agressivo \\
\hline Xamã & ( ) Sociável & ( ) Indiferente & ( ) Agressivo \\
\hline Iamí & ( ) Sociável & ( ) Indiferente & ( ) Agressivo \\
\hline
\end{tabular}

